\title{
An Information \\ Visualisation Tool for \\ Emergency Management
}

by

Neil Ramsay

\author{
A thesis \\ submitted to Victoria University of Wellington \\ in fulfilment of the \\ requirements for the degree of \\ Master of Science \\ in Computer Science.
}

Victoria University of Wellington

2012 



\begin{abstract}
The development of computerised information systems for large scale emergency management is lacking. These systems could present information and support information transfer across shifts. This is important as providing timely information is critical for efficient search and rescue operations in an emergency environment. This thesis contributes the design and prototype implementation for an interactive visualisation, called RescueTime, which is then evaluated. The evaluation showed that RescueTime is as effective as a traditional tool used by emergency managers. This demonstrates the feasibility of designing and developing larger information systems, for the purpose of emergency management.
\end{abstract}

ACM Classification Keyword: H.5.2 User Interfaces

General Keywords: Emergency Management; Graphical User Interfaces; Interactive Information Visualisation (Visualization); Prefuse 


\section{Acknowledgements}

There are many people I would like to thank for their support throughout my Masters thesis. I do this in no particular order and I apologise to anyone whom I miss out.

Stuart Marshall, my supervisor, for his support throughout, especially during the arduous writing process.

Mum and Dad, I thank you for your encouragement and continued interest in my studies at university. I could not have achieved this without your continued love and support. I hope I have made you proud.

Friends and family. Those close to me have kept me sane (mostly) for the last few years. I thank you for tolerating my moments of insanity and especially my very bad puns.

Interview and Evaluation Participants, for giving up some of their free time, voluntarily, to take part in interviews and evaluations. Without these, this thesis would not be possible. 


\section{Contents}

$\begin{array}{ll}\text { Contents } & \text { iii }\end{array}$

List of Figures ix

List of Tables $\quad$ xi

1 Introduction 1

1.1 Motivation . . . . . . . . . . . . . . . 1

1.2 Methodology .................... 2

1.3 Background ..................... 3

1.3.1 Emergency management . . . . . . . . . . . 3

1.3.2 My personal experience. . . . . . . . . . . 5

1.4 Contributions ..................... 5

1.5 Thesis structure . . . . . . . . . . . . 5

2 Analysis $\quad 7$

2.1 Interviews . . . . . . . . . . . . . . 7

2.1.1 Methodology ............... 8

2.1 .2 Results . . . . . . . . . . . . . . . 9

2.2 Requirements . . . . . . . . . . . . . . . . 13

2.3 Related work . . . . . . . . . . . . . . . 15

2.3.1 Information visualisation . . . . . . . . . . 15

2.3.2 Emergency management . . . . . . . . . . . . 17

2.3.3 Shift handovers . . . . . . . . . . . . . . . . 17 
2.3.4 Traditional timeline. . . . . . . . . . . . 19

2.3.5 BBC History timeline . . . . . . . . . . . . 20

2.4 Discussion . . . . . . . . . . . . . . . . . . . . . 20

2.4 .1 Interviews . . . . . . . . . . . . . 20

2.4.2 Planned observations . . . . . . . . . . . . . 25

2.4.3 Extended requirements . . . . . . . . . . . 25

3 Design $\quad 27$

3.1 Visualisation Design . . . . . . . . . . . . . . 27

3.1.1 Timeline . . . . . . . . . . . . . . . 27

3.1.2 Phases . . . . . . . . . . . . . . . . 28

3.1 .3 Colours . . . . . . . . . . . . . . . 28

$3.1 .4 \mathrm{Y}$ dimension use . . . . . . . . . . . . . 30

3.1 .5 Event shape . . . . . . . . . . . . . . 30

3.1.6 Event collision avoidance . . . . . . . . . . . 31

3.1.7 Popup information boxes . . . . . . . . . . . 31

3.1.8 Event root . . . . . . . . . . . . . . . . . . . 32

3.1 .9 Navigation control . . . . . . . . . . . . . . . . . 32

3.1 .10 Related events . . . . . . . . . . . . . . . . . 32

3.1.11 Variable time scale . . . . . . . . . . . . . . 32

3.2 Alternative Designs . . . . . . . . . . . . . . . . . 33

3.2.1 Multiseries timeline . . . . . . . . . . . . . . 34

3.2 .2 Towards scatter plot . . . . . . . . . . . . 34

3.2.3 Timeline augmentation . . . . . . . . . . . . 35

3.2.4 Eras and milestones . . . . . . . . . . . . . . 36

3.2.5 Active time movement . . . . . . . . . . . . . 38

3.2.6 Related events . . . . . . . . . . . . . . 38

3.3 Whiteboard design . . . . . . . . . . . . . . . . 38

3.4 Discussion . . . . . . . . . . . . . . . . . . . . . 40

3.4 .1 Priority .................... 40

3.4 .2 Colour selection . . . . . . . . . . . . . . . 41

3.4 .3 Time labelling . . . . . . . . . . . . . . . . . 42 
4 Implementation $\quad 43$

4.1 Language selection . . . . . . . . . . . . . . . . . . . . 43

4.2 Prefuse . . . . . . . . . . . . . . . . . . . . 44

$4.2 .1 \quad$ Prefuse pipeline . . . . . . . . . . . . . . . 44

4.2 .2 Source data . . . . . . . . . . . . . . . 46

4.2 .3 Visual abstraction . . . . . . . . . . . . . . 46

4.2.4 View transformations . . . . . . . . . . . . . . . . 47

4.3 Implementing features . . . . . . . . . . . . . . . . . . . . . 48

4.3.1 Timeline . . . . . . . . . . . . . . . . 48

4.3 .2 Phases . . . . . . . . . . . . . . . . 50

4.3 .3 Colours . . . . . . . . . . . . . . 50

4.3.4 Layering . . . . . . . . . . . . . . . . . . . . 51

4.3.5 Y dimension use . . . . . . . . . . . . . 51

4.3.6 Event shape . . . . . . . . . . . . . . . . . . 52

4.3.7 Event collision avoidance . . . . . . . . . . . . . 52

4.3.8 Popup information boxes . . . . . . . . . . . . . 53

4.3 .9 Event root . . . . . . . . . . . . . . 53

4.3.10 Navigation control . . . . . . . . . . . . . 54

4.3.11 Related events . . . . . . . . . . . . . . 54

4.3.12 Experimental branches . . . . . . . . . . . 55

4.4 Discussion . . . . . . . . . . . . . . . . . . 56

4.4.1 Time calculations . . . . . . . . . . . 56

4.4.2 Extensibility. . . . . . . . . . . . . . 57

4.4.3 CPU cost . . . . . . . . . . . . . . 58

4.4.4 Popup boxes . . . . . . . . . . . . . . . . . 58

4.4.5 Sticky popup boxes . . . . . . . . . . . . . 59

4.4.6 Event roots . . . . . . . . . . . . . . . 59

4.4.7 Exception handling . . . . . . . . . . . . . . 60

5 Evaluation $\quad 61$

5.1 Experimental overview . . . . . . . . . . . . . . 61

5.2 Hypothesis . . . . . . . . . . . . . . . . . . . . 62 
5.3 Population . . . . . . . . . . . . . . . . . . 62

5.4 Experimental artifacts . . . . . . . . . . . . . . 63

5.4.1 Scenarios ................. 63

5.4 .2 RescueTime . . . . . . . . . . . . 67

5.4 .3 Whiteboard ................. 67

5.5 Testing procedure . . . . . . . . . . . . . . . . 69

5.5.1 Intended data collection . . . . . . . . . . . 70

5.5 .2 Controls . . . . . . . . . . . . . . . . . 73

5.6 Results . . . . . . . . . . . . . . . . . 73

5.6.1 Graded questions . . . . . . . . . . . . . 74

5.6 .2 Open questions . . . . . . . . . . . . . . . 75

5.6 .3 Situation reports . . . . . . . . . . . . . . 90

5.6.4 RescueTime observations . . . . . . . . . . . . 91

5.7 Experimental issues . . . . . . . . . . . . . . . . . . . . . 94

5.7.1 Screen colour management . . . . . . . . . . . 94

5.7.2 Inconsistent questioning . . . . . . . . . . . 96

5.7.3 Uncontrolled bias . . . . . . . . . . . . . . . . 96

$\begin{array}{llr}6 & \text { Conclusion } & 97\end{array}$

6.1 Future work . . . . . . . . . . . . . . . . . . . 98

$\begin{array}{ll}\text { A Glossaries } & 101\end{array}$

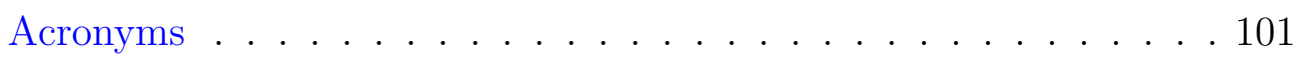

Rescue concepts . . . . . . . . . . . . . . . . . . . 101

Technical concepts . . . . . . . . . . . . . . . . 103

$\begin{array}{ll}\text { B Bibliography } & 107\end{array}$

$\begin{array}{lr}\text { C Evaluation protocol } & 111\end{array}$

C.1 Room setup . . . . . . . . . . . . . . . . . . . 111

C.2 Greeting participant . . . . . . . . . . . . . 111

C.3 Thanking participant . . . . . . . . . . . . . . . . . . 112

C.4 First round of questions . . . . . . . . . . . . . . . . . . . 113 
C.5 Scenario specific questions . . . . . . . . . . . . . . 113

C.6 Second round of questions . . . . . . . . . . . . . . . . . . . . 114

C.7 Comparison of tools . . . . . . . . . . . . . . . . . . . 114

C.8 Instructions . . . . . . . . . . . . . . . . . . . . . . . 115

C.9 Acronyms . . . . . . . . . . . . . . . . . . 116

C.10 Checklist . . . . . . . . . . . . . . . . . . 117

C.11 Introduction to the visualisation . . . . . . . . . . . . . . . 118

$\begin{array}{ll}\text { D Evaluation data } & 121\end{array}$

D.1 Scenario One: Electricity service disruption . . . . . . . . . . . 121

D.2 Scenario Two: Earthquake . . . . . . . . . . . . . . . . . 127

E Evaluation results 135

F Human Ethics Committee forms - 1st round 141

G Human Ethics Committee forms - 2nd round 149 


\section{List of Figures}

2.1 Traditional timeline . . . . . . . . . . . . . . . . . . . . . . 19

2.2 BBC history timeline overview . . . . . . . . . . . . . . 21

2.3 BBC history timeline zoomed view . . . . . . . . . . . . 22

2.4 BBC history timeline zoomed detail . . . . . . . . . . . . . 23

2.5 BBC history timeline features . . . . . . . . . . . . . . 24

3.1 RescueTime timeline view . . . . . . . . . . . . . . . 28

3.2 RescueTime phases view . . . . . . . . . . . . . . . . . 29

3.3 RescueTime design annotated . . . . . . . . . . . . . . 33

3.4 Traditional timeline with multiple series . . . . . . . . . . 34

3.5 Multiple traditional timelines to show multiple series . . . . . 34

3.6 Timeline with multiple series using a common scale . . . . . . 35

3.7 Timeline augmented with priority . . . . . . . . . . . 36

3.8 Timelines with priority background . . . . . . . . . . . . 37

3.9 Timelines with phases background . . . . . . . . . . . . . 39

3.10 Whiteboard companion paper sheet template . . . . . . . . . 40

4.1 Prefuse pipeline . . . . . . . . . . . . . . . . . . . . . . 45

4.2 Prefuse package outline . . . . . . . . . . . . . . . 45

4.3 Implementation class diagram . . . . . . . . . . . . . . . . 49

5.1 Scenario one as seen on the whiteboard . . . . . . . . . . . 65

5.2 Scenario two as seen on the whiteboard . . . . . . . . . . 66

5.3 View of usability laboratory computer screens . . . . . . . . . 67 
5.4 Usability laboratory view . . . . . . . . . . . . . . . 68

5.5 Scenario one as seen on RescueTime . . . . . . . . . . . . 68

5.6 Scenario two as seen on RescueTime . . . . . . . . . . . . . . 69

5.7 ISPAARE sheet . . . . . . . . . . . . . . . . . 71

5.8 Graphs of graded tool questions . . . . . . . . . . . . . . . 79

5.9 Side-by-side graphs of graded tool questions . . . . . . . . . . 80

5.10 Graph of graded comparison questions . . . . . . . . . . . . . 82

5.11 Participant believed performance vs relative performance graph 93 


\section{List of Tables}

3.1 RescueTime event colour scheme . . . . . . . . . . . . . 29

3.2 RescueTime phases colour scheme . . . . . . . . . . . . . 29

5.1 Graded questions for RescueTime . . . . . . . . . . . . 76

5.2 Graded questions for whiteboard . . . . . . . . . . . 77

5.3 Graded questions grouped by scenario . . . . . . . . . . . 78

5.4 Graded questions for comparing tools . . . . . . . . . . . . . . 81

5.5 Information extraction open questions . . . . . . . . . . 89

5.6 Evaluation of situation reports . . . . . . . . . . . . . 92

5.7 RescueTime information search techniques . . . . . . . . . 95

D.1 Scenario One: Electricity Service Disruption . . . . . . . . . . 127

D.2 Scenario Two: Earthquake . . . . . . . . . . . . . . . 133

E.1 Graded questions complete table . . . . . . . . . . . . 136

E.2 Graded questions grouped by scenario . . . . . . . . . . . . 137

E.3 Situation report gradings for scenario one (S1) . . . . . . . . . 138

E.4 Situation report gradings for scenario two (S2) . . . . . . . . 139 


\section{Chapter 1}

\section{Introduction}

The development of computerised information systems for large scale emergency management is lacking. This is despite computers infiltrating almost every other aspect of our lives.

This Master of Science (MSc) thesis examines whether information visualisations are able deliver information to emergency managers as effectively as traditional tools used, such as a whiteboard.

\subsection{Motivation}

New Zealand is a tectonically active country; we have active volcanoes and experience numerous earthquakes every year. Also as a coastal nation we are vulnerable to tsunamis. With recent natural disasters throughout the world, such as the Boxing Day tsunami, Sichuan province China earthquake, Haiti earthquake, and closer to home the Christchurch earthquakes, there has never been a better time to investigate how we can improve the response to such disastrous events.

Efficient decision making is key to maximising the effectiveness of the limited rescue resources available and ultimately protect lives and property. There is potential for computers to provide a platform to assist those who are trying to manage scarce rescue resources. 
Computer and battery technology has developed a lot in the last ten to fifteen years. We now all carry a cellphone on us at all times, which can last up to a week without needing its battery charged and access sophisticated wireless networks. Even modern portable laptop computers can last up to eight hours a day, while accessing wireless computer networks. This versatility makes computers reliable enough - physically at least - to operate in an environment where there is limited electricity access, where in the past computers would have stopped operating. Combined with modern computer wireless networks, smart phone technology (iPhones, Android) that is becoming ubiquitous, powerful solutions can be developed that provide support to rescuers from workers through to managers.

Additionally computers are very effective at mining large data sets. This can be used to retrieve specific information or create aggregates. Both cases can be visualised to allow emergency workers to retrieve information on demand and maintain an overview of an incident, which may become very large and complex to manage over time.

\subsection{Methodology}

Analysis was performed by interviewing members of an emergency management team and then reviewing existing literature. This resulted in the creation of a set of requirements. These requirements were then used to develop a visualisation design, derived from a traditional timeline. This design was then implemented using Java and the Prefuse visualisation library. Upon completion, the implementation was evaluated to determine its effectiveness against a traditional tool employed by emergency management teams. 


\subsection{Background}

\subsubsection{Emergency management}

New Zealand's emergency management protocols are based on internationally agreed search and rescue practises. These protocols can be divided into a number of components, which we will introduce in the next subsections.

\section{CIMS}

Coordinated Incident Management System (CIMS) is a New Zealand system for the coordination of emergency services at the scene of an emergency. The emergency can be any scale from a car crash though to a major disaster. It defines which agency has control, based on local legislation, and how other agencies should interact.

CIMS has various New Zealand Qualifications Authority (NZQA) levels. Level 2 is an awareness of CIMS and where individuals fit in to the whole system. Level 4, which we refer to as Coordinated Incident Management Team (CIMS4)[16], are the skills required to manage an emergency, with four emergency management roles. These four roles may be performed by a single person for small events or broken out into a full team.

The four roles are:

Incident Controller (IC) The person responsible for coordinating and directing rescue efforts for an incident.

Intelligence Manager The person who gathers situation information and investigates future possibilities.

Logistics Manager The person responsible for acquiring and handling assets as required.

Operations Manager The person responsible directing personnel to complete tasks. 
An important concept of CIMS is "Command and Control"; Control is cross agency, where the lead agency tasks what tasks to do, which must not be confused with command. Command is within each organisation based on their existing internal command structures, and can direct how a task can be completed.

\section{USAR}

Urban Search and Rescue (USAR) in New Zealand adopts Australian USAR and United Nations (UN) International Search And Rescue Advisory Group (INSARAG)[10] standards. These define rescue and common communication techniques (such as spay paint symbols and radio terminology). The New Zealand Fire Service sets the USAR training standards, which are then accredited by the NZQA.

There are two groups within USAR; the professional task forces and parttime or volunteer response teams. The task forces (TF1 in Palmerston North; TF2 in Christchurch; and TF3 in Auckland) are operated by the New Zealand Fire Service and train to the international USAR 'medium' level. To supplement the task forces there are USAR response teams throughout New Zealand, trained to the USAR 'light' level. Response teams are designed to provide initial response and then assist the task forces once they arrive and are set up.

All members of task forces and response teams are trained up to various levels within New Zealand USAR[13]:

CAT1A: Awareness Basic understanding of rescue techniques and terminology[14].

CAT1R: Responder CAT1A plus First Aid, CIMS (level 2)[15], and General Rescue[17].

CAT2: Technician CAT1R, plus specialist skills (Fire Service only). 
CAT3: Manager CAT2, plus Advanced CIMS, USAR Unit Management (Fire Service only).

USAR operations usually fall under the control of the Operations manager.

\subsubsection{My personal experience}

I have been a member of the Victoria Rescue search and rescue team for about seven years; four as a recruit and three as a senior member. I am qualified with USAR CAT1R, and CIMS level four, as well as other rescue related qualifications. The qualifications and training provides me with an insight in to the rescue process and how our rescue team processes information. I was also deployed after the Christchurch February 22nd earthquake with Victoria Rescue as a USAR responder.

\subsection{Contributions}

This thesis contributes the following:

1. development of a timeline based visualisation design for use by emergency managers during a disaster.

2. proof-of-concept prototype of the design using the Prefuse information visualisation library.

3. evaluation of the implementation against both rescue and non-rescue participants.

\subsection{Thesis structure}

This thesis is broken into the following chapters: 
Analysis sets out the problem definition which was established by interviewing emergency managers and existing literature, and resulted in a set of requirements for the design.

Design takes the requirements from the analysis phase and develops a design for an information visualisation.

Implementation goes through the process of creating a prototype information visualisation based on the design.

Evaluation goes through the testing of the visualisation prototype and the results obtained.

Conclusion provides a conclusion of what has been presented in the former chapters.

Appendices provide glossaries, the bibliography, and all the parts required for the interviews and evaluation processes. These include the Human Ethics Committee (HEC) forms, raw data used for the scenarios, protocol used to perform evaluations, and some large tables of the resulting data from user evaluations. 


\section{Chapter 2}

\section{Analysis}

The aim of the thesis is to identify whether interactive computer systems are able to support and enhance emergency management processes. The goal is to develop a proof-of-concept prototype visualisation, and evaluate it's performance. The proof-of-concept prototype is designed to prove the concept that emergency management information can be visualised, and be comparable to existing data presentation.

This chapter presents the results of interviews with some emergency managers and discusses the existing literature, resulting in the specification of design requirements for our computer tool, implemented in later chapters.

\section{$2.1 \quad$ Interviews}

Victoria University of Wellington (VUW) has an Incident Management Team (IMT) of emergency managers that were able provide information on how interactive computer systems could support their roles.

The IMT is part of the VUW emergency management plan responsible for coordinating the response and recovery efforts to emergencies that effect the university. This is no small undertaking with potentially 10,000 people present on campus in the middle of a weekday.

Members of the IMT volunteer their time outside of their normal posi- 
tions of responsibility within the university, taking the time to run through scenarios. The IMT were a valuable source of information and experience. As large scale emergencies are very infrequent, and organising scenarios takes considerable preparation, the IMT may not practise often as they may like.

\subsubsection{Methodology}

We interviewed the IMT with open questions ranging from data handling to how they track information mentally or visually. The following questions were asked:

\section{IMT Role}

- What is your role in the IMT?

- What does this entail?

- What problems do you usually encounter?

\section{Data handling}

- What pieces of information do you handle?

- How do you categorise your data?

- Do you grade the quality of your data source?

- How do you prioritise your tasks?

- Can corrections be done or is data permanent (with appended corrections)?

- What standard forms do you use? 


\section{Data sharing}

- What information do you share with other roles (including what you need from other roles)?

- Do you need to track who is responsible for a task?

- Do you need access restrictions to your data?

- How do you brief those that replace you?

\section{Visual representation}

- What information is difficult to keep track of?

- What information would be useful if searchable?

- What 'perspectives' are of interest in your role?

- What reports/summaries do you create?

- What usual drawings do you use?

We were able to interview the people responsible for two of the four Coordinated Incident Management Team (CIMS4) roles from the VUW IMT; the Incident Controller (IC) and Intelligence Manager. They were interviewed in a place and time of their choosing. The Human Ethics Committee (HEC) submission (see Appendix F) and the questions were emailed to them beforehand. The interviews were recorded with paper notes plus audio recordings.

\subsubsection{Results}

Many of the answers to the questions, set out in subsection 2.1.1, revealed that many of the data handling and sharing practises were performed implicitly. In the following sections the shaded boxes are typical responses to specific questions. 


\section{Data handling}

Data categorisation, grading, and prioritisation were left to the judgement of the individual performing a role, allowing them to be flexible relative to the situation; information that may be important in one situation may not be in another. Data correction tended to be appended to the original information and data was openly shared between managers in the different roles.

\section{Data sharing}

Information appeared to be shared openly, but in an ad-hoc manner, which resulted in not all members of the IMT maintaining similar situational awareness.

\section{6}

"[Data sharing] is probably an area of weakness for us as well; making sure that everyone is working on the same page and has the same information coming in and up to speed where various things are tracking along at." -- IMT

Handovers involved an approximately 10 minute general briefing from the outgoing Incident Controller to the incoming team, then an individual briefing from the outgoing manager to the incoming manager in each roles.

\section{6}

"The hand over is an area, which has traditionally caused a few difficulties, with our exercises, in terms of the continuity."

-- IMT

\section{6}

"Hand overs come down a lot to the personalities of the people in the room, and what their presentation skills are." 
66

"[In one of our exercises] no one was leaving, it was just an extra person coming in to the team, and they could get up to speed okay, but it is a bit harder when there is someone leaving the room, and potentially taking information with them, because it hasn't been handed over."

-- IMT

From this it was concluded that a requirement of any tool should be to assist shift handovers.

\section{Visual representations}

We also received some feedback regarding some visual representations, which may be of some value.

"Some way of being aware of stuff that is still pending" -- IMT

\section{6}

"It would be good if we could have some popup alarm; saying you were expecting to get information back on this thing, and you haven't any confirmation of receiving data"

-- IMT

This next comment, regarded the use of maps, where the scale is not sufficient to portray lots of information from various floors of the same building. A computer tool which was able to 'drill down' from a campus (high level) to individual floor (low level) view very quickly, when needed would be useful.

"A map like [the campus maps], doesn't give you the different floor levels." -- IMT 
Another major problem mentioned was that of 'clumping events', where large numbers of events occurred within a close temporal proximity, therefore becoming difficult to read. This is another candidate for a requirement.

66

"[The timeline] does get very clogged, because our timelines are over a 24-hour period."

-- IMT

\begin{abstract}
66
"And we move in and at the start of the [exercise] we get a whole bunch of information; so say our situation started at nine o'clock in the morning, we tend to have a whole bunch of things come down - this information happening at 9:05, and then we have another one coming down at 9:10 so it all gets really bunched up. So if it was a computer based system, we would be able to expand that out, and give us more room to zoom in to the time scale."

-- IMT
\end{abstract}

\title{
Miscellaneous
}

The following are some miscellaneous, but valuable, comments.

"I like to know where and what our resources are doing; so staffing, vehicles, and emergency services - that is really critical"

-- IMT

\section{6}

"We often get into the situations of people not being familiar enough with their roles, so that the tasks are delegated well."

-- IMT 
This confusion of roles, creates a new requirement that tool should divide information in to the roles it is associated with.

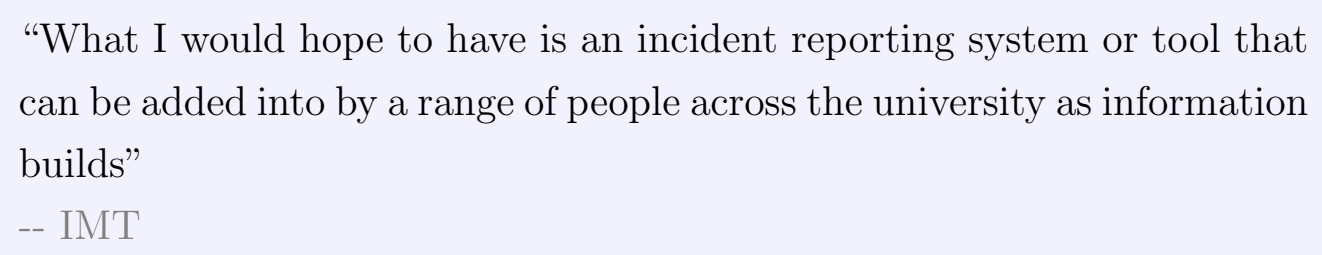

\section{$2.2 \quad$ Requirements}

Shift handovers are critical for maintaining effective response to emergencies that span multiple days, where members of an IMT begin to find it difficult to concentrate and make the right decisions after working for many hours. A new shift is needed with a fresh set of eyes able to continue making decisions that are well thought through and timely. For this reason we decided to focus on the development of a tool to assist in shift handovers as well as maintaining coherence of situational awareness within shifts, where members of the IMT are being bombarded with information.

Based on the interviews any tool developed to assist hand overs must satisfy the following requirements:

R1 Multiple shifts: we are focusing on shift handovers we obviously need to display two or more shifts. There should also be a clear delineation between two shifts.

R2 High event densities: as noted by the IMT there are periods of time when many events occur, which leads to difficulty in fitting events on a timeline. The number of events visible should be allowed to change. This should roughly be ten to twenty events in five minutes.

R3 Event categories: Events categorised by CIMS4 role to help with delegation of activities and events, events should be categorised in to the 
different CIMS4 roles; 'Intelligence', 'Logistics', and 'Operations'. The Incident Controller was left out as they make decisions, but are not delegated tasks or information coming in from the situation. Each role would have different specialised user goals, but all users should have an overview of all events. There should also be some visual separation between the different roles.

We also created some requirements based on existing knowledge of the rescue domain, or of the VUW IMT.

R4 Low learnability time: volunteers involved in emergency management, such as the VUW IMT, are not necessarily going to train with any tool developed enough to learn a complicated tool. Additionally those who are trained may not be available and therefore their role will be filled by someone without experience in such tools.

R5 Chronological based (chronology): events have a high temporal ordering in search and rescue; most are either cause and effect or effect and response. Events also have a duration from when the event occurred to the current time, or towards the future (for example personnel shifts). Any tool developed should order events based on their temporal location, and maintain a linear temporal progression.

R6 Large data: emergencies can have huge variability of scale; some, like student sports injuries, have relatively few events, as opposed to wider scale disasters, such as major earthquakes. Any tool developed should scale to handle emergencies with hundreds or thousands of events.

R7 Event information: the following fields are required as a minimum to describe abstract events.

- Date

- Time

- Title 
- Description; a field that can contain extended details of an event (i.e. number of casualties located, and their triage codes)

- Category; 'Intelligence', 'Logistics', 'Operations'

Note that data handled by emergency managers is multidimensional in nature. It can be organised by date and time, or by location of where an event occurred, or by who is responsible for responding to an event, or some definition of priority. We decided to minimise the dimensionality so we could focus on the basics of information processing.

Some important limitations need to be noted from our requirements. We are interested in testing shift handovers, so some features are not required. These features include the ability to enter data or completely separate views for each IMT user. It is also worth noting we are not attempting to develop a decision support or expert system. We are also ignoring the technical requirements around hardware or Operating System (OS) technology, for the purpose of focusing on a visualisation proof-of-concept.

\subsection{Related work}

The application of information visualisations to emergency management is a very recent development, and therefore there is not much existing related work. We will visit existing information visualisation, and emergency management literature, as well as some timeline techniques.

\subsubsection{Information visualisation}

Information visualisations are able to display complex information while decreasing the cognitive load on users. A popular definition of information visualisation is that "[an] information visualization deals with data that do[es] not have inherited geometry." [4]. This is true of visualising abstract data as opposed to visualising geographic data, which just scales from the geometry of the world. 
Time is an abstract concept and therefore does not have an inherit geometry - even though it has an ordering. We then have "the freedom of mapping the underlying data to any geometric forms so long as one asserts meanings, no matter how arbitrarily, to the end produce of such mapping." [4] We will discuss our mapping in chapter 3.

Information visualisations are essentially the modern day equivalents of graphs and charts. When information visualisations are combined with interactive techniques, they create interactive information visualisations, which transforms the person from passively viewing it to an active user of the visualisation. As a user they can explore a data set.

Yi et al. provide a taxonomy of interaction[23] in visualisation that groups existing interaction techniques into seven categories:

Select "mark something as interesting".

Explore "show [the user] something else".

Reconfigure "show [the user] a different arrangement".

Encode "show [the user] a different representation".

Abstract/Elaborate "show [the user] more or less detail".

Filter "show [the user] something conditionally".

Connect "show [the user] related items".

These categories describe the intention of the user using the visualisation. One or more actions may be used to perform a task by a user. In chapter 3 we will describe each interactive technique using these categories.

Symbols are commonly used on maps to signify a location of importance, and convey that to viewers. This requires viewers to be familiar with the symbols used, and their meaning. Dymon[6] identified a problem that in the United States there was no standardised map symbology used in emergency management. They noted "Emergency symbols should be easily perceived in terms of size, colour or background. The symbols should have a 
precise meaning without needing explanation." The suggested solution was standardisation by the Federal Geographic Data Committee or the Federal Emergency Management Agency. Standardisation should be done at an international level, and for rescue be specifically standardised by International Search And Rescue Advisory Group (INSARAG).

\subsubsection{Emergency management}

The application of information visualisations to emergency management has only recently emerged as a field of study. The majority of literature is based on the training of emergency managers or post-event analysis.

Andrienko and Andrienko[1] presented an approach for the use of intelligent visualisations to assist in emergency management (which they call civil crisis management). The paper provides a discussion of the knowledge they believe is required for the development of emergency management and visualisation expert systems, and the information flow between the two. The knowledge for emergency management used is based on a subset of emergency events, mainly flooding. The visualisation expert system is not well defined though, with no concrete examples of how the data from the emergency management expert is transformed into a visualisation. Both an emergency management expert system and visualisation expert system should be proven individually before combining the two. The aim of the thesis is to develop a simple visualisation, and prove it's value, so to lead to a more complex visualisation system.

\subsubsection{Shift handovers}

The medical discipline has performed analysis of shift handovers, as like the rescue domain failure to transfer information via shift handovers can result in mistakes occurring.

Tang and Carpendale present a paper titled "An Observational Study on Information Flow during Nurses' Shift Change"[21]. This paper contains 
many of the problems and goals that are faced by emergency managers. Primarily nurses need to maintain information between shifts, where failure to do can have catastrophic consequences. They perform this by acquiring and dispersing information from multiple sources at the beginning and end of their shifts. This information is focused on the history of the patients, the present states, and future treatments required. Rescue managers also require a complete view to make informed decisions. The sources nurses use are digital based, paper based, whiteboard based, and verbal. This is something that rescue managers should embrace. The paper also describes the roles of a head nurse, who all other nurses report to. The transfer between two shifts may not occur synchronously, with the outgoing shift not available for direct verbal interaction. Shift handovers were identified as typically taking 30 to 45 minutes, which is what would be reasonable for an emergency management handover.

Another paper by Patterson et al. "Handoff strategies in settings with high consequences for failure: lessons for health care operations" [18], discusses a large number of handover strategies employed by NASA, a few nuclear power plans, and a few logistics organisations. It discusses what strategies are used at what organisation, and what effects they have. A few of the strategies involve the use of information systems to gather information before a verbal handover is provided. This is where visualisations can assist.

Emergency managers have the same goals, but can perform synchronous handovers. The use of multiple sources should be encouraged, with each manager processing information in their preferred form. This echoes one of the issues identified by the IMT, where handovers are heavily affected by the personalities of the emergency managers incoming and outgoing. The mirroring of nurse shift handovers should be something to aspire to.

\section{TIPS sheet}

The TIPS sheet[7] is a chart designed to assist a CIMS4 team prioritise and assign rescue activities. It is a target board shape with each ring expanding 
from the centre; from centre to edge:

1. Situation Identifies what has occurred.

2. Factors What problems need to be dealt with.

3. Priority Priority of problem.

4. Options What options are available to resolve the problem.

5. Tasks What tasks are required to implement the option.

6. Responsibility Who is responsible for completing the task.

Each 'factor' is a segment of the circle extending from the centre to edge. There may be multiple items at a ring level, such as multiple options, which divides the initial segment.

The TIPS chart can be modelled with an existing visualisation, Docuburst[5], it may be useful to evaluate that in future studies.

\subsubsection{Traditional timeline}

The traditional timeline typically has a few simple features:

- Horizontal line with consistent short vertical division lines along a scale.

- Text below vertical division lines displaying data scale.

- Data items aligned along the straight line, usually represented as dots or another shape.

These features can be seen in Figure 2.1.

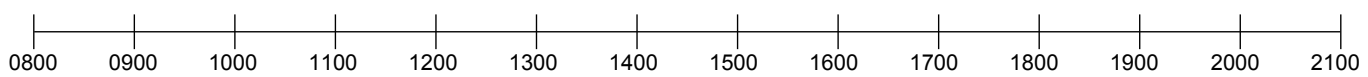

Figure 2.1: Traditional timeline, featuring a horizontal line with labelled vertical division lines.

The IMT currently have a timeline of this style at the top of their whiteboards in their Emergency Operations Center (EOC). 


\subsubsection{BBC History timeline}

The BBC History timeline[3] is an Adobe Flash (Flash) driven interactive visualisation. Its purpose is as an educational tool to show the rich history of the United Kingdom; England, Ireland, Scotland, and Wales.

It contained strong use of colours; clear divisions of time, 'eras', which gave general categorisation of events (Figure 2.2); clear overview and navigation visual items to provide constant context; 'drill down' to the detail of individual events in history (Figure 2.4); and filter and search functionality. These features are annotated in Figure 2.5.

On deeper inspection, there were quirks to the visualisation, that were confusing. When hovering over an event in history it showed two other events either side of the hovered one (Figure 2.3). These events appeared to be unrelated, and it was unclear why they were displayed at all. Another problem was with the search feature, which required perfect matching on words. For example, if "axes" is searched for, it would find a few events, but if you searched for the non-plural version, "axe", it would not find any events.

\subsection{Discussion}

In this sections we will discuss practical considerations that arose during data collection.

\subsubsection{Interviews}

The VUW IMT were primarily chosen due to ease of access, but other factors directed us too. At the time advice had been received that other emergency managers may be busy preparing for the expected arrival of swine influenza, which was a concern to many. 


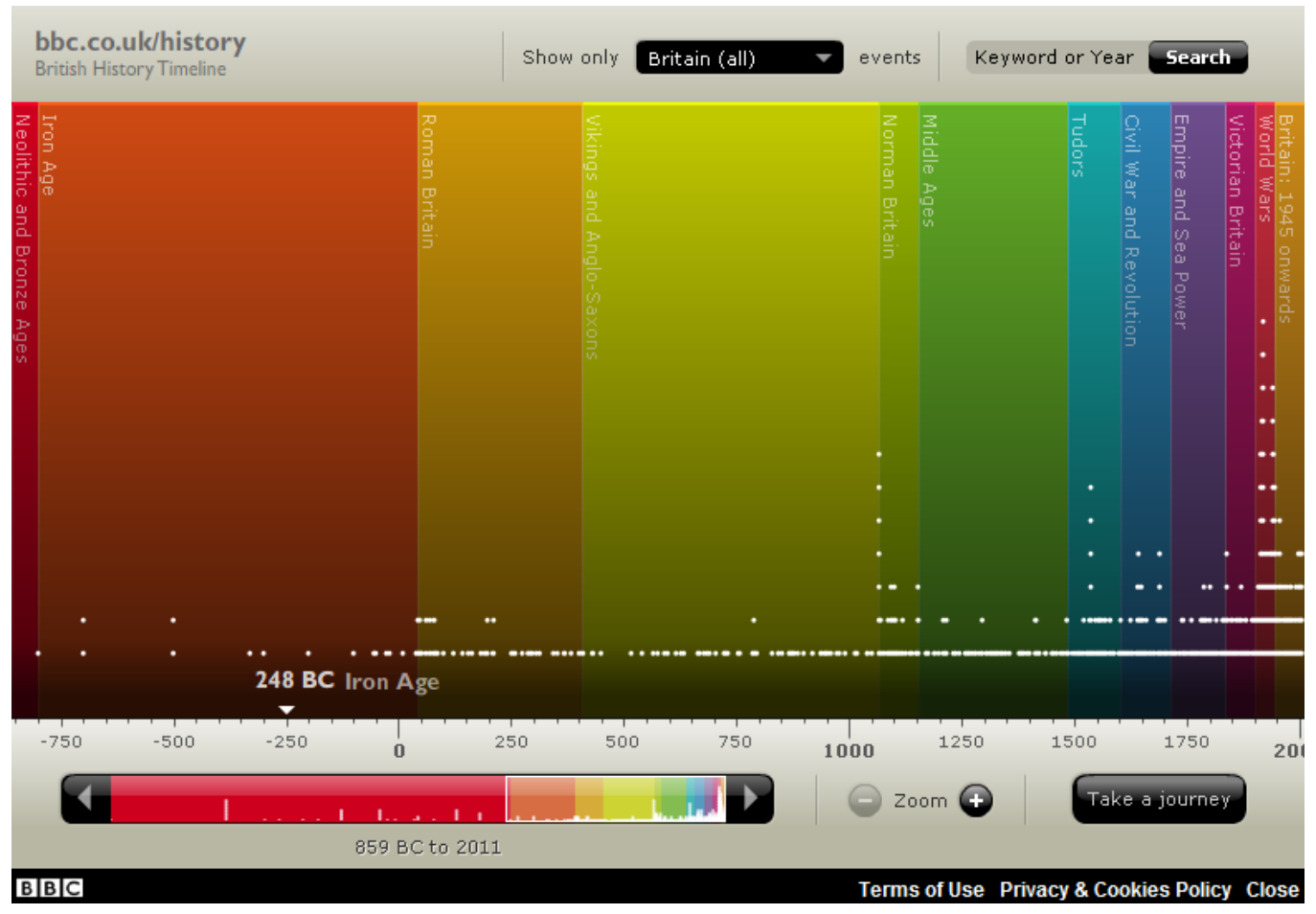

Figure 2.2: $\mathrm{BBC}$ history timeline showing an overview of British history events from roughly $859 \mathrm{BC}$ to $2011 \mathrm{AD}$. In the bottom left corner is a slider for whole history available. Each era is a different coloured background with a title at the top. Events are the white dots at the bottom of the view. Where multiple events occur in the same year they are stacked on top of each other. The pointer with " 248 BC Iron Age" is the horizontal position of where the mouse is. 


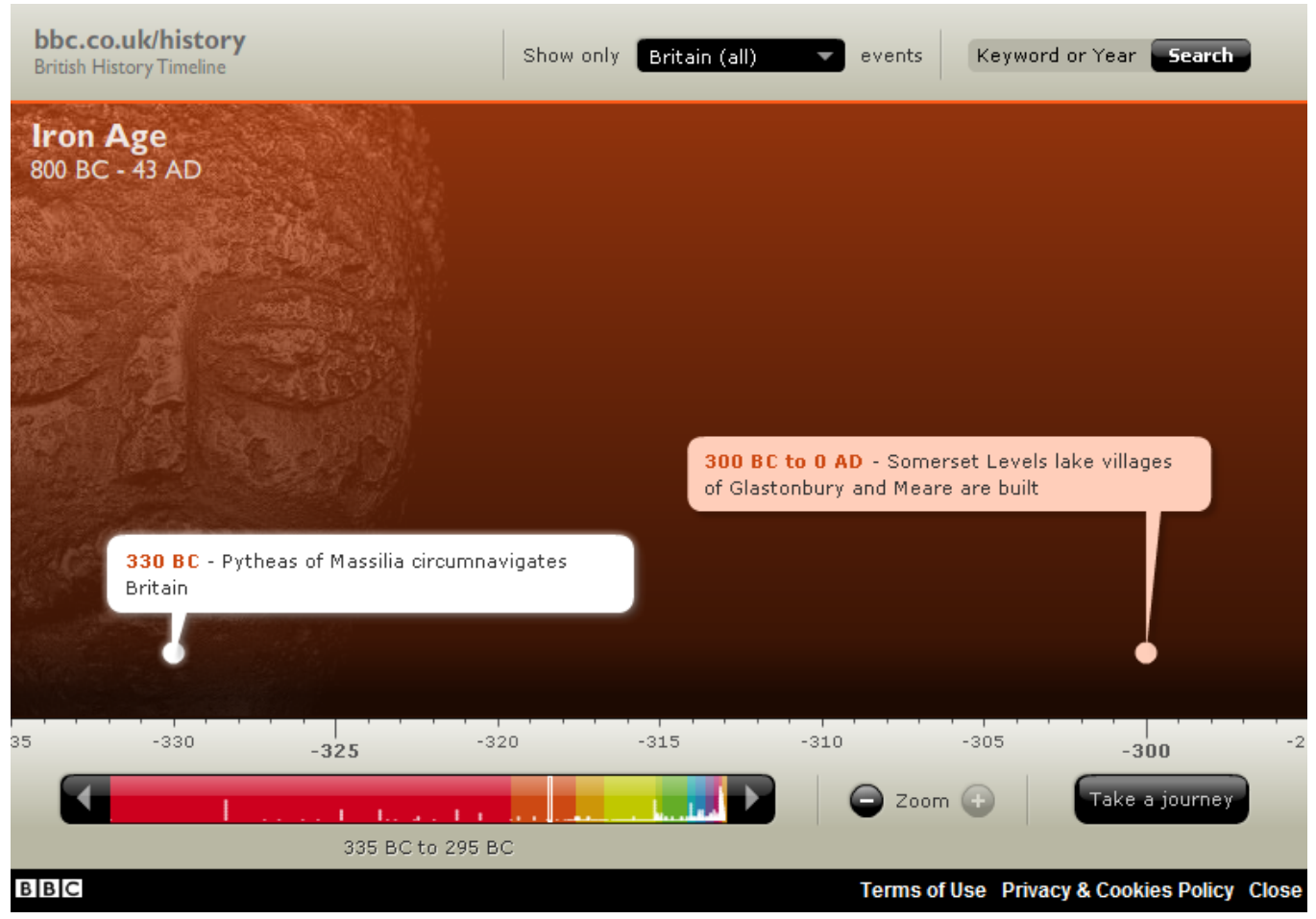

Figure 2.3: BBC history timeline showing a zoomed in view of part of the Iron Age (335BC to 295BC). It shows two events with a date and title displayed in popup boxes. The white box is the event currently being selected. Notice how the titles appear to be unrelated. 


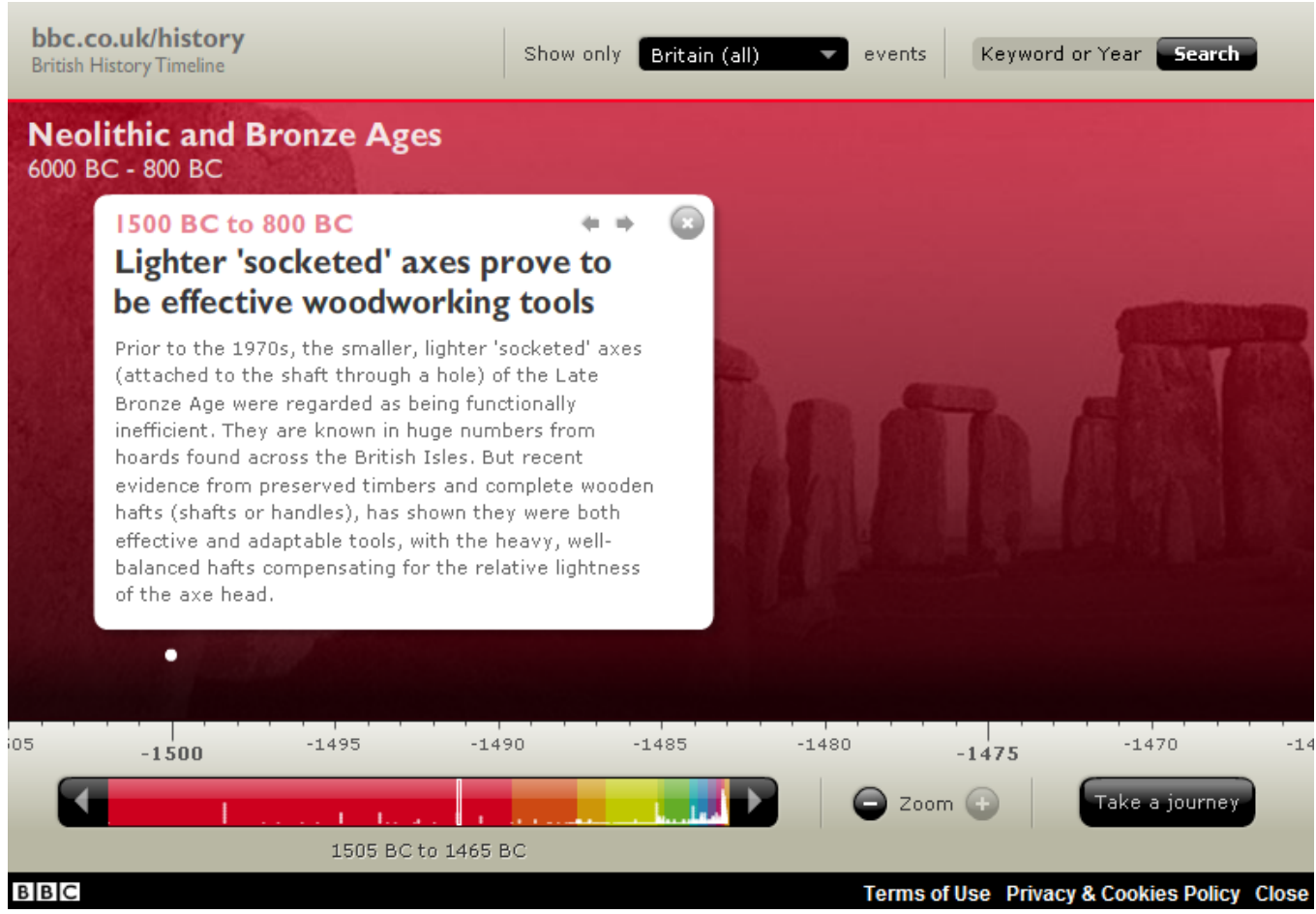

Figure 2.4: BBC history timeline showing zoomed detail of an event in the Neolithic and Bronze Ages. The event has been expanded to show the date, title, and a description of the event. The arrows in the top left corner of the popup box allow the user to navigate to the previous or next event. 


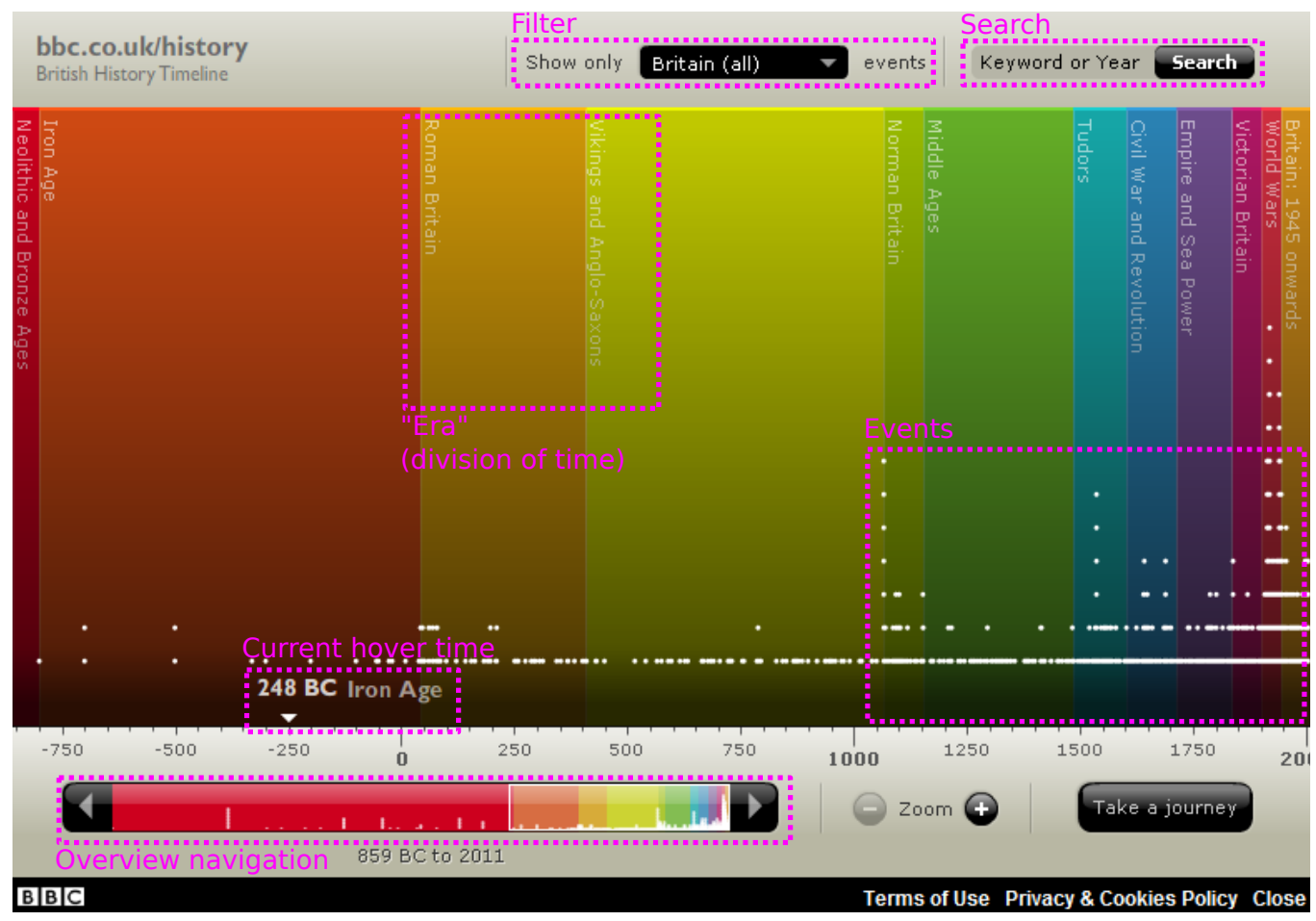

Figure 2.5: BBC history timeline with various functionality annotated. In the top right corner, filter and search allow a user to limit the number of events visible or locate events of interest. Events are divided into eras, and can be navigated using the overview navigation feature. 


\subsubsection{Planned observations}

The VUW IMT perform tabletop exercises to practise their skills. The original plan was to observe the IMT during one of these exercises, and use the observations to improve the visualisation designs. The intent was also to use later exercises to test any implementations.

Planning and organising these exercises requires a considerable effort, and therefore do not run often. It was not possible to develop a design or implementation to coincide with when these exercises were being run and therefore it was opted to perform interviews and user evaluations instead.

\subsubsection{Extended requirements}

Some problems identified in the interviews, were not added as requirements. It was decided that these requirements would introduce unnecessary complication, and therefore were not included. It may be useful for these requirements to be considered in future research projects.

These requirements were:

Pop-up alarms for reminding a manager that some feedback for an event was due, and it has not arrived.

Events pending list, so that managers can track what areas require their attention. 


\section{Chapter 3}

\section{Design}

\subsection{Visualisation Design}

It was decided to use the existing paradigm of a timeline, which is already used by the Victoria University of Wellington (VUW) Incident Management Team (IMT). However it has been extended to utilise features available to computers, such as interactive visualisation techniques.

The sections following will introduce features to our timeline design, followed by some alternative designs, finishing with a discussion of the design created. Throughout this chapter we will be referring to the taxonomy of interaction[23] presented in subsection 2.3.1. The next chapter will then go through the implementation of the timeline design.

\subsubsection{Timeline}

The timeline axis bar gives context to the entire view seen by the user. This helps assist with maintaining spatial and temporal awareness of where data points are and where they lie relative to everything else. Distinct units of time need to be contrasted to allow the user to quickly identify the time of a particular location and roughly how much space there to the next division in time. The traditional timeline can be seen in Figure 2.1. 


\section{$1400 \quad 1500$}

$19 / 05 / 2011$

Figure 3.1: RescueTime timeline view. Each alternating hour and day change between a black and $80 \%$ grey background. The full date is always visible and times are presented in 24-hour format.

Some events will be vertically far away from the timeline, which makes it easier to loose their timeline context. The y-dimension layout will be described in subsection 3.1.4. To maintain the user's awareness of the dimension of time, while using their peripheral vision, an alternating greyscale block for each hour was adapted. Black for one and $80 \%$ grey for the other. The hour of the day, in 24-hour format, is placed in each hour block. Below the hours is a block holding the full date, which also alternated colours. This timeline scheme can be seen in Figure 3.1.

\subsubsection{Phases}

To implement requirement R1 (handle multiple shifts), it was decided that the background of the visualisation could be broken up into shifts. This would clearly show user the which shift an event occurred in.

The phases were laid out with the starting and ending $\mathrm{x}$ coordinates aligned with the starting and ending times of the phase, and the full ydimension being used. In the top left corner of the phase, a text label was placed to identify the phase, which would always be visible as the view was panned.

\subsubsection{Colours}

Two colour palettes have been defined; one for events (see Table 3.1); and one for phases (see Table 3.2).

The Hue, Saturation, and Brightness (HSB) colour scheme was used. This is built from three components; hue, the colour with values between 0 and 


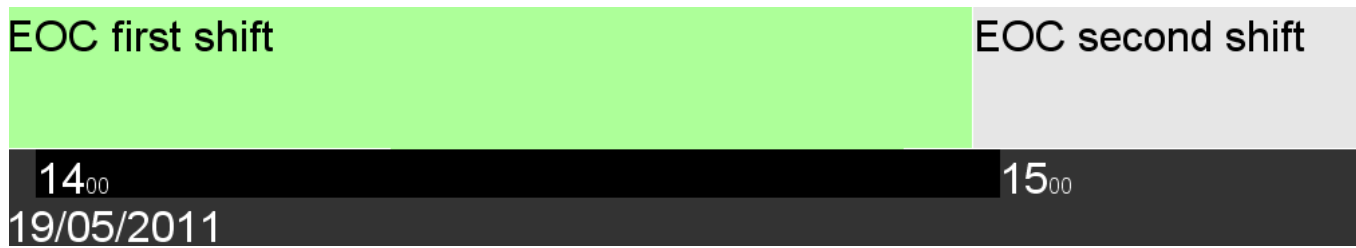

Figure 3.2: RescueTime phases view. This condensed view shows the timeline presented in Figure 3.1 and presents two phases above it. The phases are labelled with their phases title.

\begin{tabular}{|l|l|l|l|l|l|}
\hline Group & Colour & Hue & Saturation & Brightness & Sample \\
\hline Intelligence & Red & $0^{\circ}$ & $60 \%$ & $100 \%$ & \\
\hline Logistics & Blue & $240^{\circ}$ & $60 \%$ & $100 \%$ & \\
\hline Operations & Cyan & $180^{\circ}$ & $60 \%$ & $100 \%$ & \\
\hline Hovered & Orange & $30^{\circ}$ & $100 \%$ & $100 \%$ & \\
\hline Related & Black & $0^{\circ}$ & $0 \%$ & $0 \%$ & \\
\hline
\end{tabular}

Table 3.1: RescueTime event colour scheme. Each of the event categories is coloured with colours of different hues with $60 \%$ saturation and $100 \%$ brightness. Events that are hovered over or related to a hovered event are coloured orange and black respectively.

\begin{tabular}{|l|l|l|l|l|l|}
\hline Phase & Colour & Hue & Saturation & Brightness & Sample \\
\hline 1 & Green & $120^{\circ}$ & $40 \%$ & $100 \%$ & \\
\hline 2 & Grey & $0^{\circ}$ & $0 \%$ & $90 \%$ & \\
\hline
\end{tabular}

Table 3.2: RescueTime phases colour scheme. 
360; saturation, with values between 0 and 100; and brightness, with values between 0 and 100. The hue is a 360 degree colour wheel starting from red $\left(0^{\circ}\right)$, going through yellow $\left(\sim 60^{\circ}\right)$, green $\left(\sim 120^{\circ}\right)$, cyan $\left(\sim 180^{\circ}\right)$, blue $\left({ }^{\sim} 240^{\circ}\right)$, and magenta $\left(\sim 300^{\circ}\right)$ before returning to red at 360 degrees.

Events are coloured based on the category they are in; Intelligence, Logistics, and Operations. Events also dynamically changed their colours when hovered over or a related event was being hovered over. The hover action is an example of Encode for the hovered event and Encode and Connect for related events [23].

The colour generation process will be discussed in subsection 3.4.2.

\subsubsection{Y dimension use}

Based on the requirement R3 (events categorised by CIMS4 role), it was decided to use the y-dimension to group events by role. Each role would be laid out in thirds above the timeline, with Operations at the top, followed by Logistics, and then Intelligence in the bottom third. This also assists with dealing with requirement R2 (handle high event densities).

\subsubsection{Event shape}

The shape used for an event either needs to be domain specific or a simple geometric shape.

Domain specific shapes were found to be difficult to work with, because they do not necessarily scale well, need to be widely used and understood by those in the domain, and can be difficult to identify if partially obscured. Research from the medical area on symbols used on medical equipment across multiple countries showed that there were no standard symbols used by manufacturers and many doctors and nurses incorrectly inferred meaning from the symbols, which could ultimately lead to mistakes [11].

It is safer to use simple geometric shapes, which do not convey additional meanings, so a circle was adapted to represent events. 


\subsubsection{Event collision avoidance}

One of the key issues with having a timeline is that multiple events can occur at the same instant of time. This means that events can obscure other events.

Utilising the unused space between categories allows for 'stacking' of events. If two events collide, then the second event is pushed up so that it is just above the other. This helps deal with requirement R2 (handle high event densities).

\subsubsection{Popup information boxes}

Popup information boxes allow for hiding of information until the user wants to Elaborate[23] it. These boxes contain an event's title, category, and description.

The title of an event is significant as it should provide enough information for the user to decide whether the event is interesting enough to spend the time reading the description or should be deferred until later. Therefore it should be prominent, it's font was made larger (24pt) than the description text (16pt), sans-serif and placed above the description text, identical to a news paper layout. The description text was kept sans-serif to keep maximum readability, and at 16 point size. It wrapped the description text so that the box does not become too wide.

The overall background colour for the popup was yellow with a transparency value of $75 \%$. The description was put in a sub-box with a background colour of green again at $75 \%$ transparency.

The popup boxes appear to the bottom right of the mouse cursor and are not be allowed have any part of it out of view. This can be seen in Figure 3.3.

The popup information boxes implement part of the requirements for R2 (handle high event densities), R6 (scale to handle large data), and R7 (representing event information). R2 and $\mathrm{R} 6$ are achieved by hiding information until it is needed on demand. R7 is achieved by displaying event information when an event is hovered. 


\subsubsection{Event root}

Focusing on a event that is not within close proximity to the timeline can make it difficult to determine the exact time of that event. A visual aid was added, the time root, to Elaborate[23] an event's time.

The time root is a vertical dotted line going down from the event to the timeline. At the bottom of the line the exact time of the event is drawn. This gives the user both a precise time of the event and a straight line they can follow to prevent them from loosing the event they are interested in.

\subsubsection{Navigation control}

In an interactive visualisation, it is possible to hide information from a user's field-of-view until they need it. For long running situations, it is only necessary to see at most one phase (or shift) at one time, so we added horizontal panning. This implements requirement R1 (handle multiple shifts), by showing one or part of one shift. The ability to pan is an expression of the user wanting to Explore[23].

\subsubsection{Related events}

Rescue scenarios tend to have related events, whether they are cause-andeffect or effect-and-response. This is different from categorisation, which groups together events of a similar type (i.e. casualties). The aim was to create a visual indication that events Connected[23]. This would assist the user discover information and navigate.

The visualisation changes the colour of related events, as noted in subsection 3.1.3, when an event is hovered over by the mouse.

\subsubsection{Variable time scale}

As part of requirement R6 (scale to handle large data), a variable time scale was needed. This would allow for maximum utilisation of the view win- 
dow. The visualisation could be Reconfigured[23], on start up, to scale the $\mathrm{x}$-dimension to fit one day or one hour within the window depending on the situation. A variable timescale combined with panning implements requirement R6 (scale to handle large data).

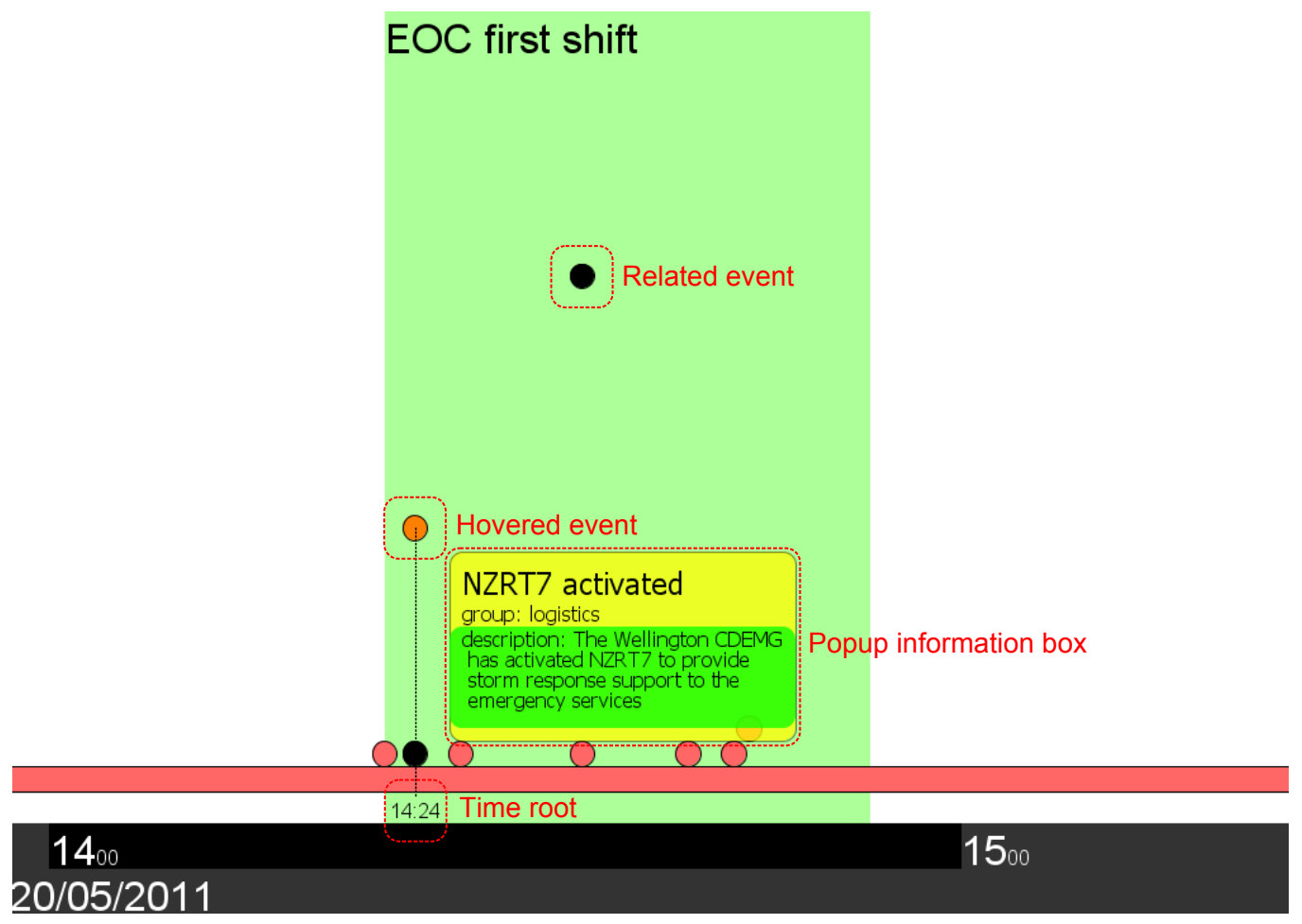

Figure 3.3: RescueTime design annotated. Hovered and related events, the popup information box and the time root are annotated.

\subsection{Alternative Designs}

Design is an evolution from initial concept to final design. In the process of developing the final design, alternative designs were created. 


\subsubsection{Multiseries timeline}

The first logical extension to the traditional timeline (presented in subsection 2.3.4) was to include multiple series of data on a single timeline. This required a mechanism to distinguish between the different series; it was decided to use either colour or shape. It was decided that colour was a much more effective for distinguishing between series than shape, especially when individual data elements may end up very close to each other and possibly cover part of a previous shape. This first extension can be seen in Figure 3.4.

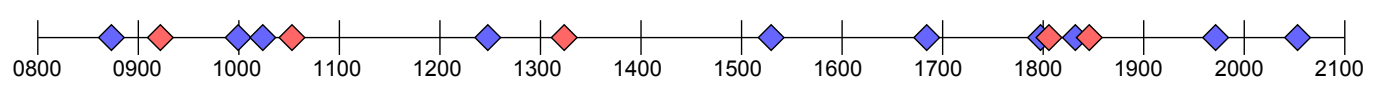

Figure 3.4: Traditional timeline with multiple series

The next logical extension was to include multiple timelines, therefore utilising the y-dimension. This duplicated the reference axis lines, allowing for multiple scales. This is shown in Figure 3.5

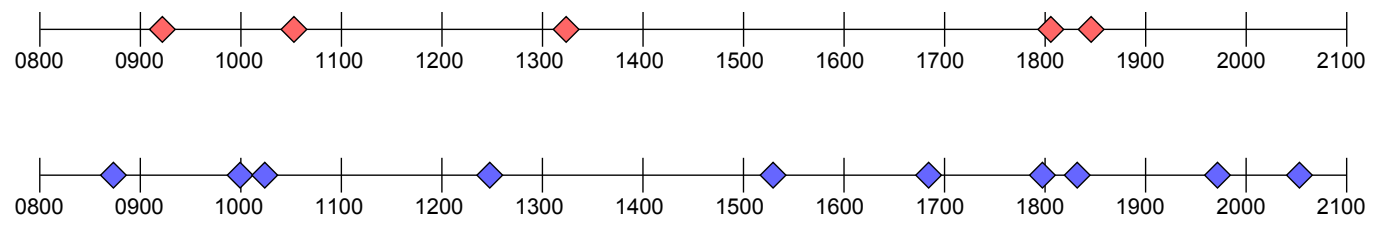

Figure 3.5: Multiple traditional timelines to show multiple series

\subsubsection{Towards scatter plot}

Having multiple axises showing the scale was redundant. It gave the user instant access to the context for data elements within the data series, but added visual distraction. Therefore a common timescale was used, which eliminated that visual distraction, while maintaining contextual awareness.

Grid lines could be extended from the common timeline axis to provide a visual reference to follow for confirmation of the context of a data element. 


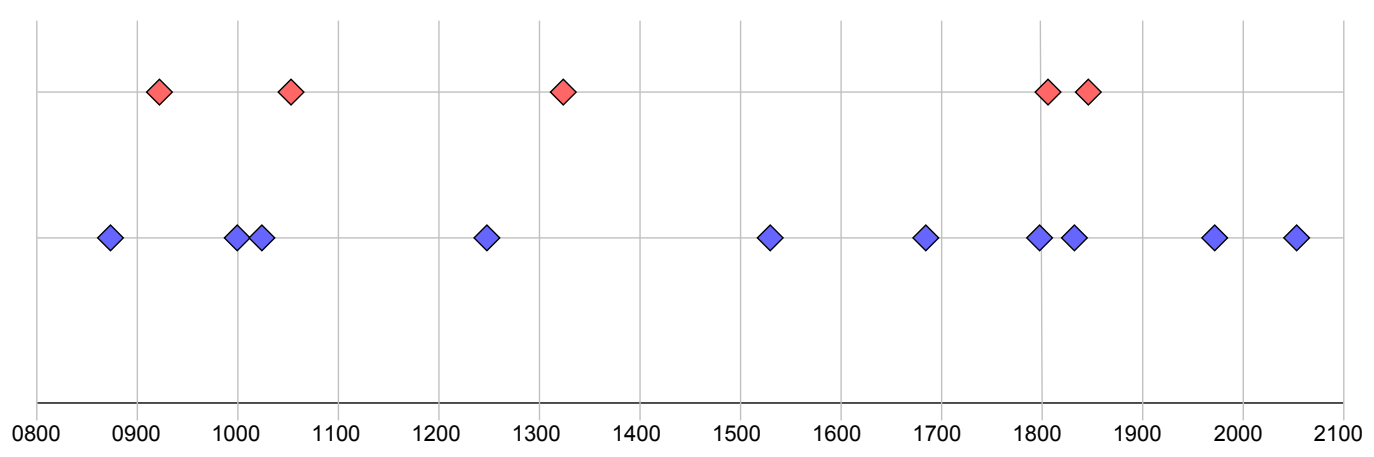

Figure 3.6: Timeline with multiple series using a common scale. Similar to a scatter plot graph, the y-axis is used to divide each series, and the x-axis used as the time scale.

The result looked similar to a scatter plot graph with an axis on the bottom and each series organised within the y-dimension. This is shown in Figure 3.6.

Introducing a new visual concept, priority, was investigated; changing the vertical position of each data element based on the elements priority. Using the words "high" and "low", which are quite often used in describing the priority of things, it was possible to position high priority elements literally near the top of the visualisation and low priority elements near the bottom. As an additional cue a traffic light scale was used along the y-axis was. The result of this augmentation is shown in Figure 3.7

An alternative to the previous augmentation was to include the colour gradient across the entire background. This continuously reminded the user of the priority scale. This however is rather distracting, and therefore it was later altered to be slightly transparent (see Figure 3.8a).

\subsubsection{Timeline augmentation}

As introduced in subsection 3.1.1, some experimentation was undertaken with the context timeline axis. For greater contrast the idea of blocks of time was extended to augment the context timeline on the x-axis. It involved applying 


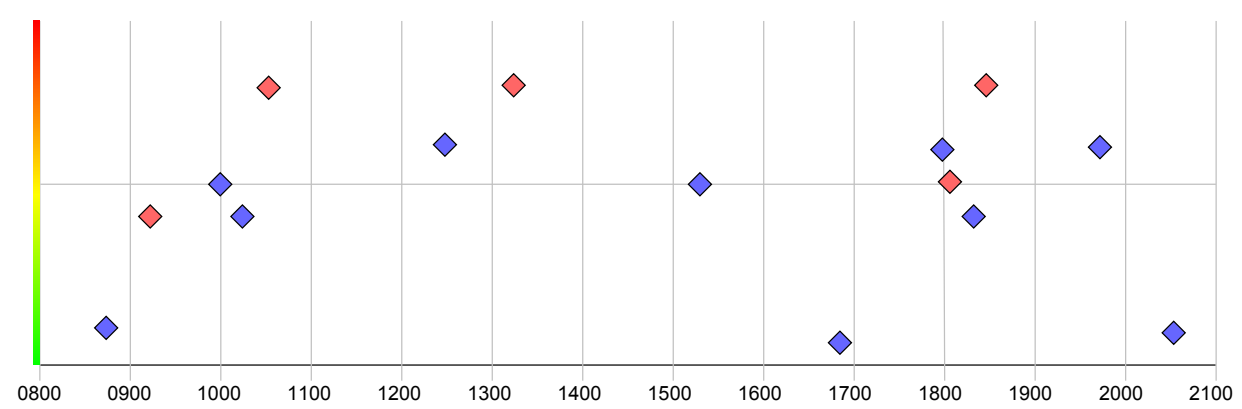

Figure 3.7: Timeline augmented with priority. Figure 3.6 with the y-axis augmented to show priority. The priority scale is from most important (red), neutral (yellow), to least important (green). Neutral priority has a grid line in the middle of the graphic.

reverse contrast, and having alternating background between black and grey. This was taken from the concept of alternating table row colours to help users distinguish the limits of each division of time.

The experimentation included moving the grid lines so that they were directly over the hour word, i.e. 1100, to indicate it was exactly that time and the blocks were indicating time that was closest to which hour. This was quickly abandoned, as it caused confusion; the block and lines seemed to contradict each other, with the block indicating the hour starting at the start of the block and the line indicating the start of the hour at the line (see Figure 3.8c).

There were discussions about having a duplicated timeline axis bar at top of the view, so that events near the top of the visualisation would not require as much effort to determine their time. This was not adopted, because it would use a considerable amount of space. Instead a visual aid, the time root, discussed in subsection 3.1.8, was developed.

\subsubsection{Eras and milestones}

One of the features of the BBC History timeline, mentioned in subsection 2.3.5, that appeared to be quite effective was that of 'eras' - for example 


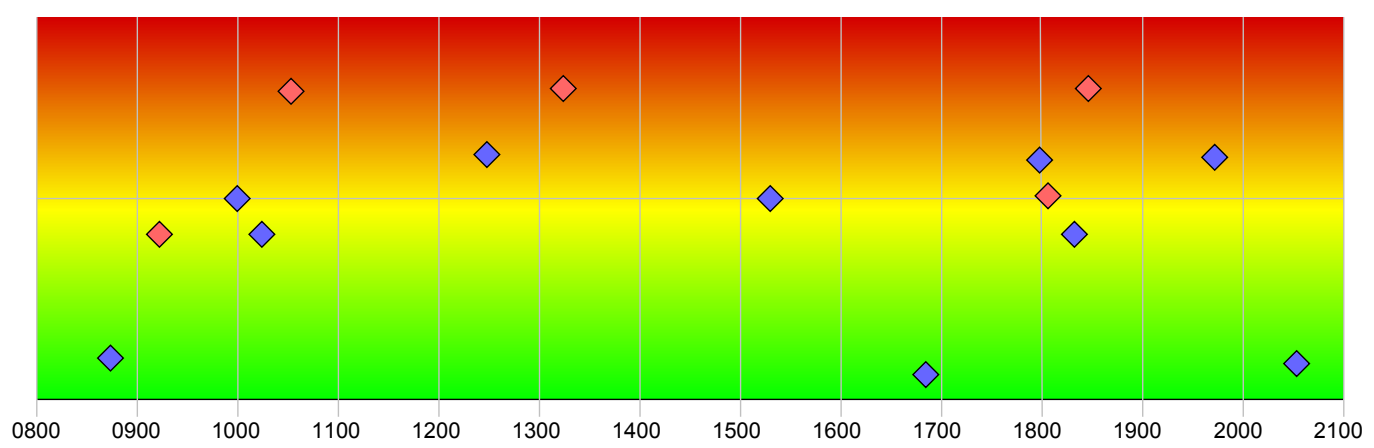

(a)

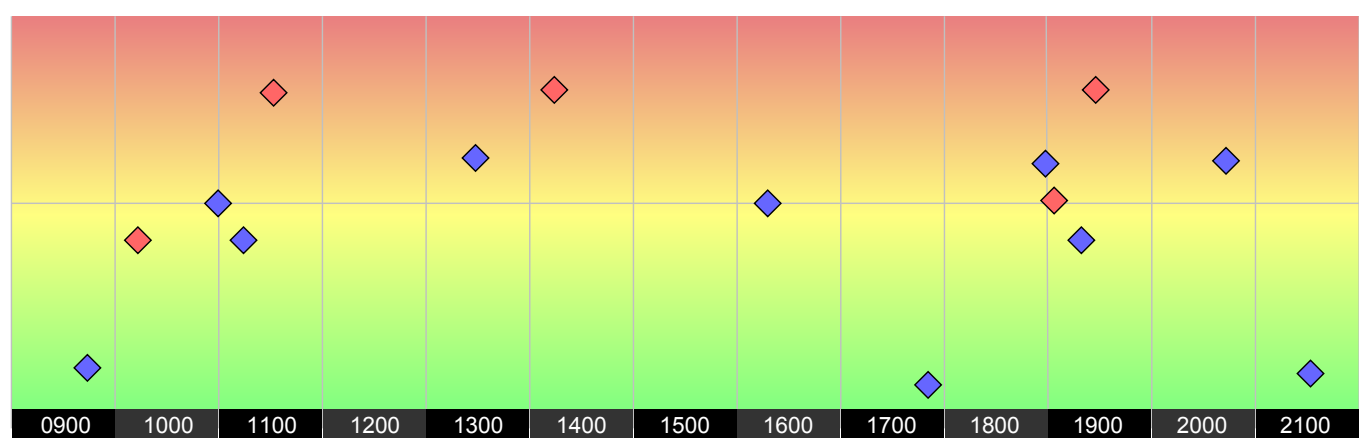

(b)

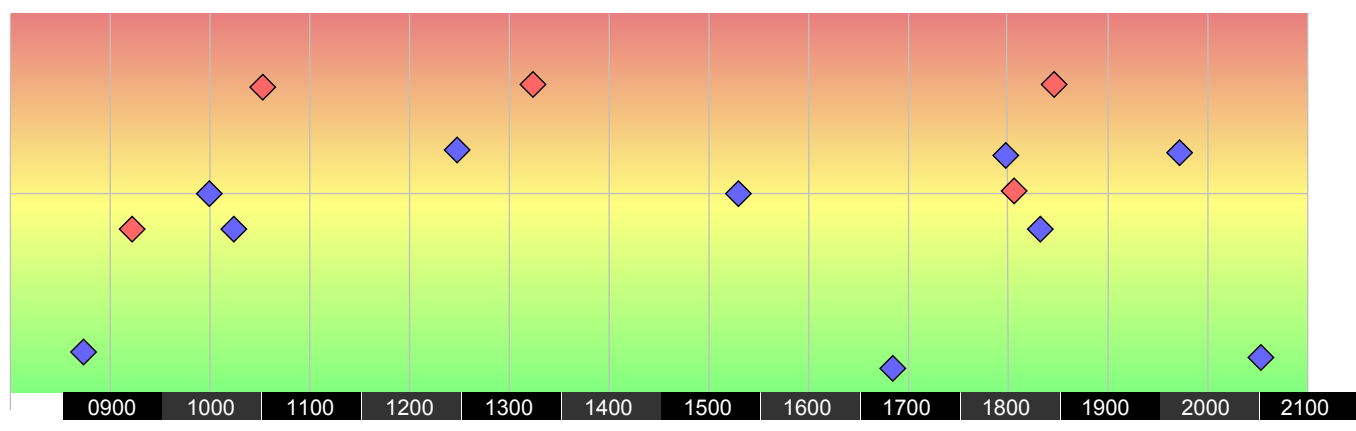

(c)

Figure 3.8: Timelines with priority background. Figure 3.7 extended as three variants. Figure 3.8a has the y-axis bar extended to the whole background. Figure $3.8 \mathrm{~b}$ uses the former background, lightened with transparency, and introduces blocks on the x-axis bar for hours. Finally Figure 3.8c offsets the $\mathrm{x}$-axis bar to see if it made sense to centre the hour transition around the middle of each hour block. 
the Stone Age. From a search and rescue perspective there are phases that are useful in generating a higher level of contextual reference than time alone. We introduced phases in Figure 3.9a.

In addition to phases, a management team may want to set future goals or place down markers for areas of interest, so we introduced milestone markers, seen in Figure 3.9b.

\subsubsection{Active time movement}

A scenario is rarely static, it moves over time. A possible design was to have the timeline pan over time, so that it gave the feeling of the passage of time. It would pan the view from left to right every minute.

\subsubsection{Related events}

The first concept of related events was to use the simple technique of lines connecting related events together. However it became a web of lines that tangled up the view and was hard to follow individual lines. The second concept was to only show lines related to an event when one of the related events was hovered over. This was an improvement, but was later abandoned in favour of colour change; whenever an event was hovered over, its related events would change colour.

\subsection{Whiteboard design}

In chapter 5 the visualisation design will be evaluated. The visualisation will be evaluated and compared against a whiteboard, as typically used by the IMT. It will contain the same information as displayed on the visualisation. Therefore, a whiteboard design was created to show such information.

Whiteboards are constrained on how much information they can show as everything is visible at all times and the size of a whiteboard is limited. The information on the whiteboard was laid out in to the groupings of Intelligence, 


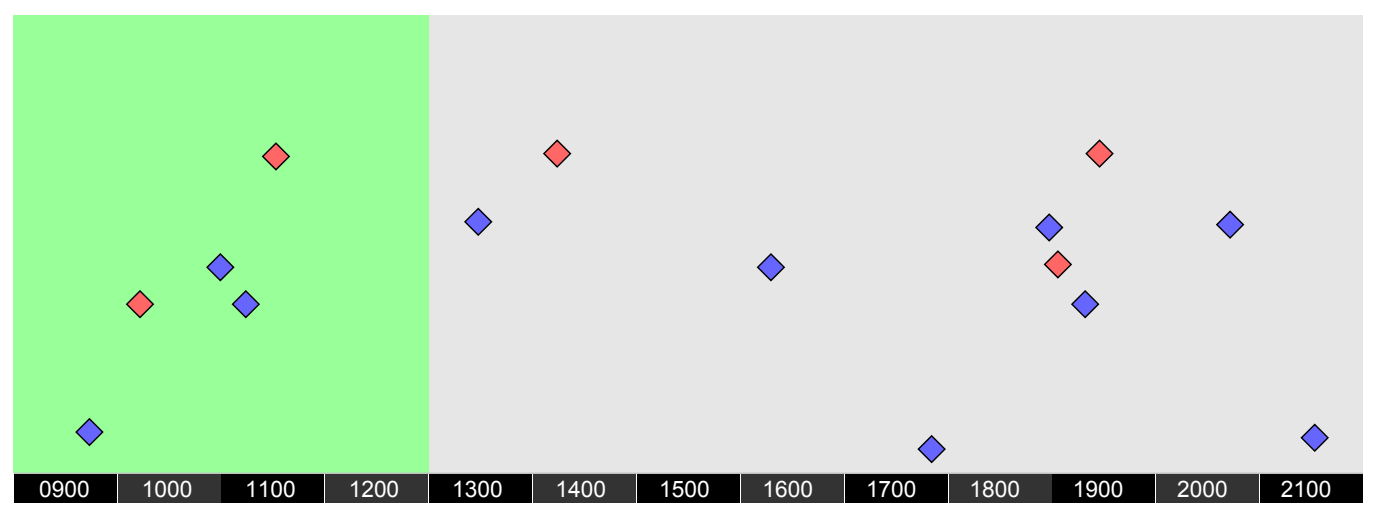

(a)

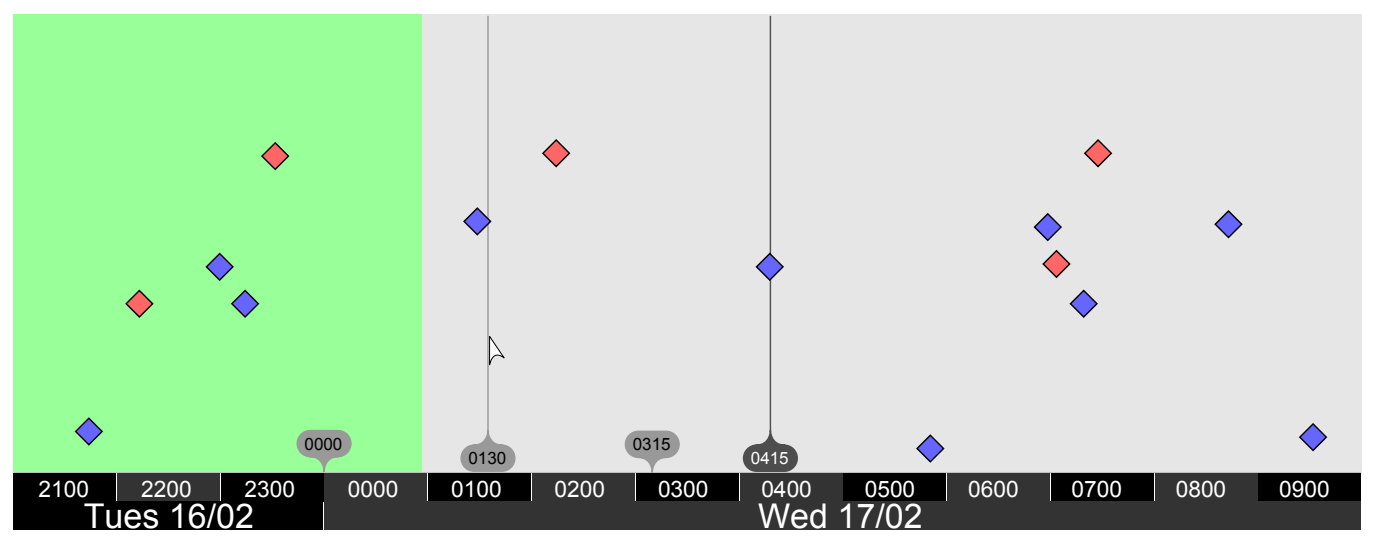

(b)

Figure 3.9: Timelines with phases background. Figure 3.8b is modified to show phases in the background rather than the priority. Figure $3.9 \mathrm{~b}$ additionally shows the date, milestones, the current mouse cursor location (0130), and the current time (0415). Milestones are where the user has placed a marker of interest, where they may investigate in the future. 


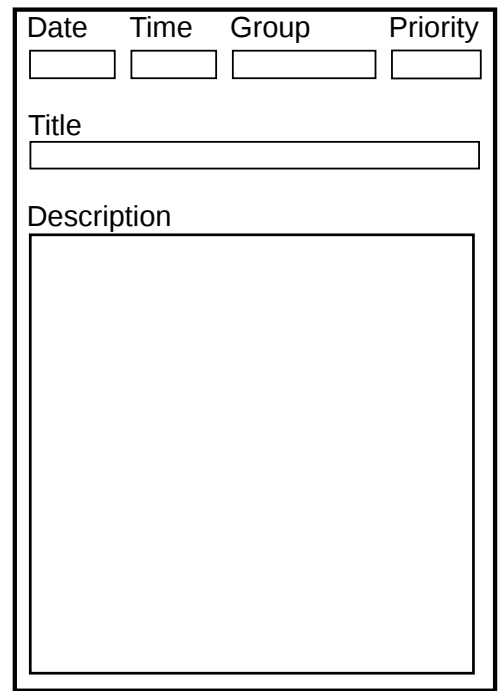

Figure 3.10: Whiteboard companion paper sheet template

Logistics, and Operations. Under each group's heading the events would be listed from top to bottom chronologically. For each event data fields were listed from left to right. The data was; an optional exclamation mark to denote high priority; a time; and the event's title.

To show equivalent information to the visualisation, except for the relationships, paper pages were created (see Figure 3.10), for each event, to hold descriptions of the events. Relationships were left out as it was not possible to find an effective way of representing them. Using lines to connect events would create a messy web that probably would confuse participants.

\subsection{Discussion}

\subsubsection{Priority}

In the initial designs it appeared to make sense to use the y-dimension for event priority, but this was later abandoned it in favour of group categorisa- 
tion of events. This in part due to a problem of defining the levels of priority. Most people coarsely define the priority of event as either low, normal, or high. Another problem is that of perception; each person has a different opinion of what important events are, and since the visualisation is being designed for shift changeovers priority should not heavily effect the display of information. Priority was then going to be applied to the title in the popup information boxes, but it was not clear whether bold or italic would be more noticeable. The decision was made to use italic and see if participants would notice it in the evaluation stage.

There was another experimental idea to have high priority events as another field in the popup information box with a red background. This was dropped due to black on red colour blindness issues.

\subsubsection{Colour selection}

Colour selection is complicated by many factors. Approximately one in ten males are colour blind in one form or another, and what may be seen as a danger colour in one culture may be seen as good luck in another. For example, red is seen as the colour of blood and danger (OSHA Coding) in most western cultures, but seen as a colour of good luck in China [12].

To accommodate colour blind individuals, who may not be able to distinguish two colours of the same shade (luminosity), but different hue, an attempt was made to develop a palette of colours of varying shades. Initially the aim was to create a reasonably sized palette of seven event categories, and seven phases. However it proved very difficult to create such a palette. In particular, based on our usage of a World Wide Web Consortium (W3C) tool [22], there are no other combinations available with the colour red. This is a major problem as red is a fundamental colour that invokes strong response in colour-able individuals. It eventually became apparent that there was no solution to choose colours that are accessible to all individuals and the approach instead focused on minimising the conflict, while maintaining the colour contrasts for colour-able individuals. 
The technique used to generate colours for events and phases was as follows. The hue values were stepped up in 60 degree increments, looking for distinct colours. Colours were softened by dropping their saturation to $60 \%$ for events and $40 \%$ for phases. For hovering and related events, where we were trying to grab attention, we used orange and black with $100 \%$ saturation. Only two phases were needed so a light green and light grey were adopted.

\subsubsection{Time labelling}

The decision was made in the design to develop the event root to provide time context to an event. Another possibility identified later in the whole process was that of having the time at both the top and the bottom of the event root. Both possibilities may assist a user with establishing the time of an event with minimal eye movement and distraction. 


\section{Chapter 4}

\section{Implementation}

This chapter presents the implementation of the interactive timeline visualisation design using the Java programming language and Prefuse visualisation library. It discusses how Prefuse works and how it was used to implement the features described in the Design Chapter, as well as the problems encountered with developing each feature. The resulting implementation will be evaluated in the next chapter.

\subsection{Language selection}

The development of the visualisation prototype, RescueTime, required the use of either a visualisation specific language; or a generic language (such as Java or Microsoft .net (.net)) with libraries to support visualisation development.

Visualisation libraries allow a developer to use a generic language, and provide interfaces and operations common to visualisations. This speeds up development and enhances reusability of visualisation components.

Some visualisation library alternatives were:

- Visualization Library; A lightweight $\mathrm{C}++$ OpenGL middleware for 2D/3D graphics. 
- Flare; A Adobe Flash (Flash) library.

- Prefuse; A Java library.

- Protovis; A web based library using Javascript and Scalable Vector Graphics.

- VTK - A C++ library.

It was decided to use Prefuse, as a precedent had been set for its usage within our department, and the original user of Prefuse was still present. Our department (School of Engineering and Computer Science (ECS)) also heavily teaches Java throughout our undergraduate programme, which would reduce the learning curve required.

\subsection{Prefuse}

Prefuse[9] is a Java visualisation library, originally developed by Jeffrey Heer and developed further as an open source project under the BSD Licence.

Prefuse allows a visualisation developer to define high level rules that define how a dataset should be rendered on the screen. Data within a dataset can have different colours, positions, be animated to show trends and made interactive. Prefuse provides Java Interfaces in its Application Programming Interface (API) to allow a developer to define and install custom components into the visualisation - which we will cover later in the discussion section (subsection 4.4.2).

\subsubsection{Prefuse pipeline}

Prefuse operates a pipeline for data flow from raw data imported into table or graph data structures through to the actual rendering. This pipeline, which can be seen in Figure 4.1, has a couple of stages where data is transformed by adding or altering abstract visual properties, such as position and colour. 


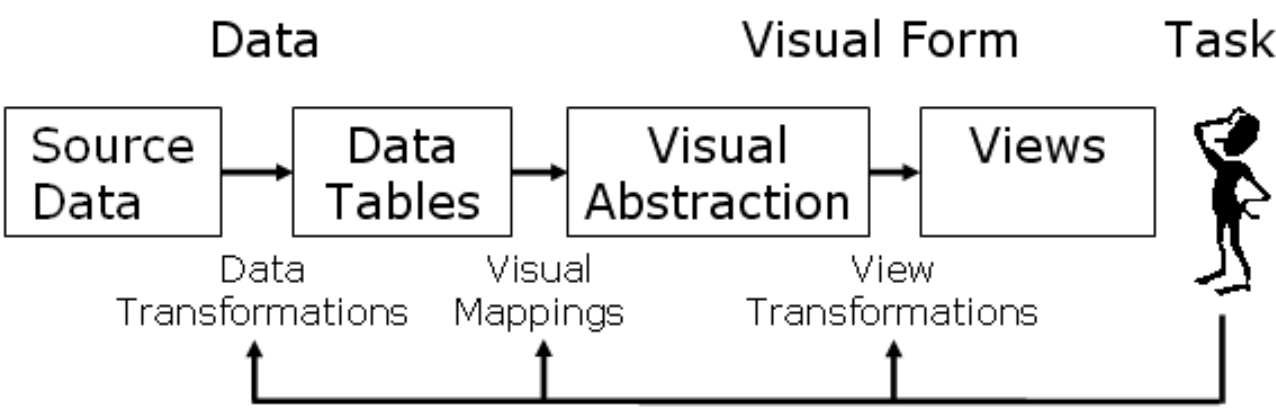

Figure 4.1: Prefuse pipeline[20]. Data is first loaded from a data source then transformed into a visual abstract form before being presented to the user.

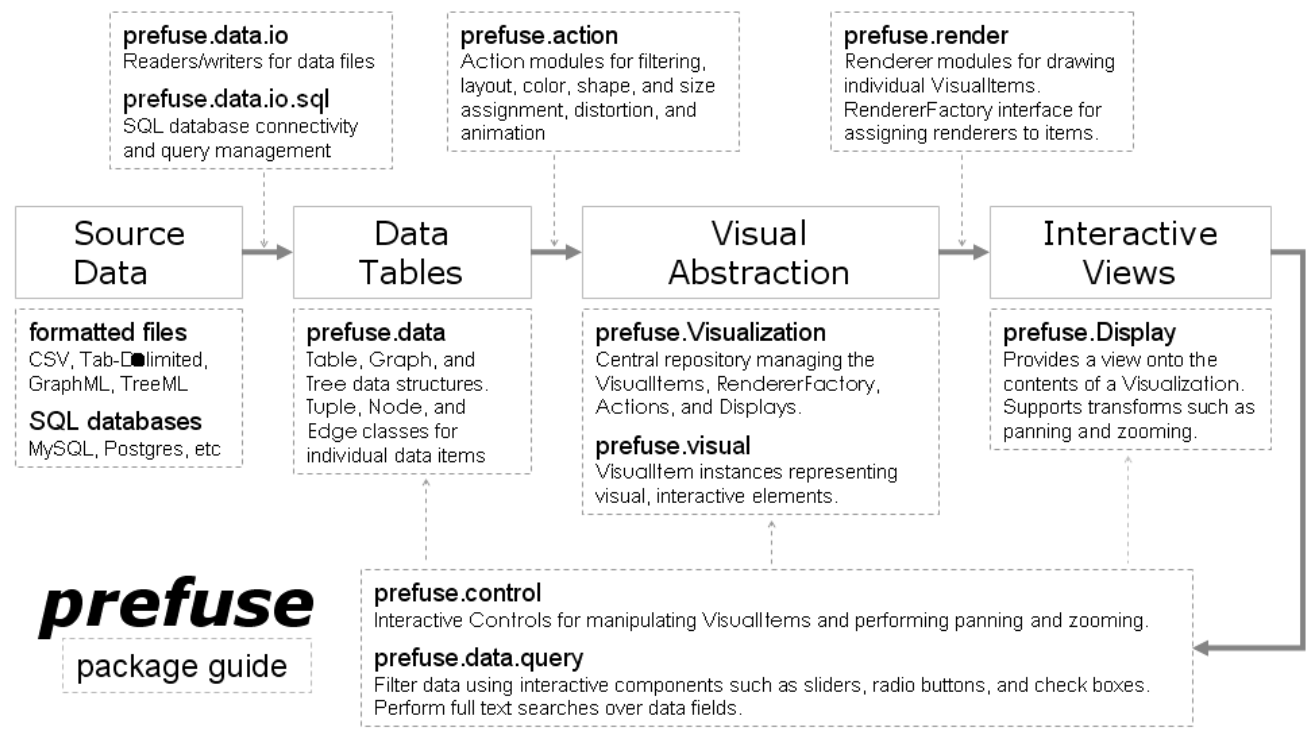

Figure 4.2: Prefuse package outline[19]. Prefuse classes involved in the Prefuse pipeline. 
The core component of Prefuse is the Visualization class. This class acts as the Controller in the Model, View, Controller (MVC) pattern, mediating between the data model and views. This is the first class that is instantiated by the developer of a visualisation, and usually accessible from almost every method context from that point forward. With the Visualization object, we load data, register Renderers, define layering, and Actions. Views, which are instances of the Display class, then take a Visualization instance and generate the final output to the user.

\subsubsection{Source data}

Raw data in Prefuse takes the forms of either Tables or Graphs. They both implement the TupleSet interface, which is the abstraction across all data structures in Prefuse. The Table class provides rows and columns like a regular table, and allows for typing of columns; either the Java primitive types or Java class types. The Graph class provides Nodes and Edges. The Nodes, just like the Table, can store values in each Node, with a common set of properties defined in the Graph. Nodes are connected together by Edges, which can be uni or bi directional.

Tables and Graphs can either be populated programatically, or loaded from an external source, such as Comma Separated Values (CSV) files, Graph Markup Language (GraphML) files, Tree Markup Language (TreeML) files, or Structured Query Language (SQL) databases. Prefuse provides pre-built classes to assist with loading data from the above sources. This loading of data is the "Data Transformations" stage of Figure 4.1.

\subsubsection{Visual abstraction}

Once a Table or Graph object has been instantiated, it is passed to the Visualization instance. The Visualization instance, creates corresponding VisualTables and VisualGraphs, and a symbolic group name for them. This is part of the "Visual Mappings" stage of Figure 4.1. The VisualTables 
and VisualGraphs contain VisualItems, which contain all the fields of data from the Table or Graph, and additionally include fields for defining visual abstractions. These additional fields include a VisualItems $\mathrm{x}$ and $\mathrm{y}$ coordinates, shape (if a ShapeRenderer is used), colour, and size. These are commonly set by running Actions.

Actions, or collections of actions, ActionLists, are used format groups of VisualItems to either have the same properties, or different properties depending on a data field within the Visualltem. Simple Actions; ColourAction; ShapeAction; and SizeAction; set the colours, shapes, and sizes, respectively, to all members of a Visualitem group. The more complicated DataColourAction, for example, can colour Visualltems into categories, or along a linear scale - like temperatures from 0 to 100 degrees Celsius.

VisualItems within the visualisation are also laid out with Actions. The extensions of abstract subtype Layout take in a group of VisualItems and change their $\mathrm{x}$ and $\mathrm{y}$ coordinates to fit within the layout scheme. Some examples of these layout managers are; CircleLayout, which lays items around a circle; and AxisLayout, which lays items along an axis depending on a value within a data field.

Actions can also handle dynamic events, such as a user hovering the mouse over an item. These Actions utilise Predicates, such as the HoverPredicate, which in conjunction can change the colour of a Visualitem when hovered over with the mouse. Actions or ActionLists are registered with Visualization, again with a symbolic name, and executed either as one off, when the visualisation starts, or on a regular basis. For Predicates to be evaluated, the Actions need to be run on a regular basis. Once the Actions have been run the "Visual Mappings", stage of Figure 4.1 is complete.

\subsubsection{View transformations}

The next stage, "View Transformations", is where the VisualItems are rendered on to the various Displays. A Display is an implementation of a 
Java Java Swing (Swing) Component, which allows Prefuse to render a visualisation using the standard Java Graphical User Interface (GUI) system - Abstract Windowing Toolkit (AWT) or Swing. For each VisualTable or VisualGraph group, a Renderer needs to be specified. These Renderers take VisualItems and generate Java AWT or Swing commands to draw the item on the Display. For example, the ShapeRenderer, reads the VisualItem's position, shape, colour, and size fields and then tells Swing to draw that shape of a specific size at the position specified with a specific colour.

Finally, there is feedback from the user. The user can control the visualisation by providing specific inputs. These inputs are defined by Controls being added to the Display. For example, the PanControl allows a user to click in the background and pan the visualisation up or down, left or right.

Prefuse has many other features, including animation, view distortions, item filters, full-text search, pull-push elastic force layout managers, and item sorting, but they will not be covered here.

\subsection{Implementing features}

\subsubsection{Timeline}

VisualItems for days were generated dynamically in the data loading stage of the visualisation, and given a static layout using the TimeLineLayout Action. The TimeLineRenderer created two rectangles; one for the hours and one for the date. The top rectangle, for hours, used the two colours, black and $80 \%$ grey, for the background in an alternating pattern over the 24-hour period, with white text used for the hours of the day. The second rectangle, below, that covered the whole day displayed the date, formatted for the local systems locale settings; "dd/MM/YYYY" format on my development machine, and "MMM dd, YYYY" on the evaluation system. This date scrolls so is always visible when the user pans the view. 


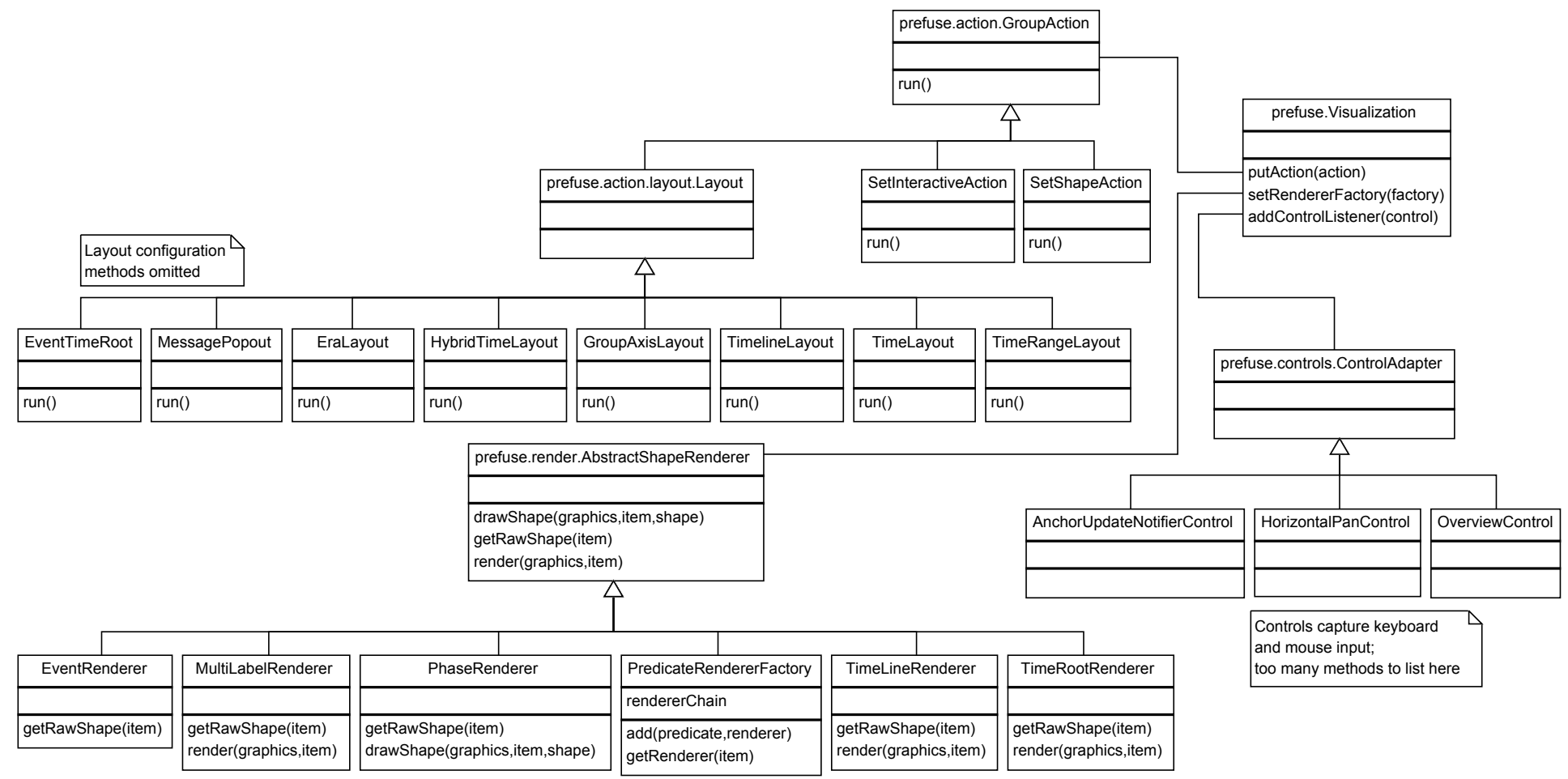

Figure 4.3: Implementation class diagram. Basic class diagram presenting relationships between Prefuse classes and classes developed for the implementation of the design. 
The timeline is conceptually continuous from the past to the future. In Prefuse this is impractical as it is necessary to define the dimensions of VisualItems. The solution was to develop a VisualItem per day, with the number of days dependent on the events within the dataset. In our case, since evaluations were being performed with static data, it was decided to identify the earliest and latest events in our loaded dataset and create the timeline VisualItems to encompass the data.

\subsubsection{Phases}

Phases are simple shapes. They are rectangular, have a constant height - from the top of the view, to the timeline - and constant colour. Phases are loaded from file and then laid out by taking the height of the view minus the timeline at the bottom. Initially a ShapeRenderer was used to draw the phases, but later a custom Renderer, called PhaseRenderer, was developed to draw the title of the phase in the top-left corner of the phase. Unfortunately, the title does not always stay in view, which was not discovered until evaluations had already begun.

\subsubsection{Colours}

Colours in Prefuse can be assigned two ways using Actions; either homogeneously across a group, using the ColorAction; or heterogeneously across the group, using the DataColorAction, which assigns colours to VisualItems based on a data field. The DataColorAction uses a palette, either autogenerated or provided by the visualisation developer, and a specification of what kind of data the data field is; linear, on a scale similar to the Celsius temperature scale; categorical, where the number represents categories that should be coloured the same; or a sequence of data. Additionally you can specify colours when certain Predicates evaluate true.

The events had DataColorActions applied to them, using the category mode based on an events group. They also had some Predicates, which 
changed the colour of events when hovered over with a mouse or a related event was hovered over.

Phases were coloured using DataColorActions, using the sequence mode.

These ColorActions were fed straight into Visualization when RescueTime was initialised.

\subsubsection{Layering}

Prefuse has an internal layering system that defines how VisualItems should be rendered in the view. The default layering manager groups all VisualItems together, as it doesn't know how to sort them implicitly, and raises Visualitems that are hovered or selected. This introduced a few problems because whenever the mouse hovered over a phase, or the timeline, the events would disappear under it and become non-visible.

The solution was to define a custom layout manager to instruct Prefuse to ignore hover events over the timeline and phases when calculating the VisualItem layering. An implementation of ItemSorter was created with the score method overridden to lower the scores of phases and the timeline. This ItemSorter was then passed to the Display. In doing this the events would always be visible, and the phases could still have hover events if needed.

\subsubsection{Y dimension use}

The use of the y-dimension was developed in three stages; the first stage involved making events layout above the timeline, the second stage was grouping the events into their category groups, and the third stage was developing an event collision avoidance system.

The first stage involved creating a Layout to place all event VisualItems above the timeline. The height of the timeline bar was known, and the layout would statically set the $\mathrm{x}$ coordinates of all events to be above the timeline bar.

The second stage was to group the events by their categorisation. To 
start off a one to ten number was used to specify where the event should be placed in the y-dimension; one for down above the timeline and ten for being at the top of the screen. When this was confirmed to work the Layout was modified to split the y-dimension up into the number of categories and place each event at the determined y-coordinate for that group.

A major problem was that events were overlapping each other, making it difficult to hover over events of interest. So for the third stage a crude collision avoidance system was developed, which is discussed in subsection 4.3.7.

\subsubsection{Event shape}

Implementing shapes in Prefuse was made very easy with a predefined class, ShapeRenderer, which already had a good range of simple shapes. The circle shape was available and required only its size to be specified.

Later the decision was made to opt for circles for events which were pointsin-time, and rectangles for events that occurred over a duration. ShapeRenderer was not suitable, as the geometry between the two types of events were different. The circle was specified as being located at a point, with a size associated with it. Whereas, the rectangle did not have a point, but rather had starting and ending $\mathrm{x}$ coordinates. The solution was to develop a specific Renderer, EventRenderer, which would check an event to see what type it was and render it accordingly.

\subsubsection{Event collision avoidance}

As noted in subsection 4.3.5, it was possible for one event to obscure another, either partially, making it difficult to select, or completely. A collision avoidance algorithm was needed when laying out events. Since events had a fixed $\mathrm{x}$ dimension location, relative to time, only the y dimension could be used.

First, the events were divided into their category groups and their $\mathrm{y}$ coordinate set to that of the group. Then, for each event the shape was determined, depending on whether it was a point in time or duration event. 
Future events within the current event's size were then compared to see if they collided. If they did, the future event was pushed up enough to avoid the current event, otherwise we moved on.

Once complete, there were stacks of events where there was a lot of activity, and all events were visible and navigable.

\subsubsection{Popup information boxes}

The popup information boxes are Decorators for event Nodes. They are created by calling a method on Visualization, which generates a VisualItem subgroup based on a Predicate. In this case the Predicate is a HoverPredicate. A Renderer was then defined to handle the Decorators when they are visible.

Two iterations of the popup boxes were developed.

The first was using the built-in LabelRenderer, which would create a box and render a single field of data.

The second iteration was to adapt the LabelRenderer into a new class, called MultiLabelRenderer, to handle multiple fields and apply different backgrounds to each field. We borrowed the text wrapping algorithm from LabelRenderer, and modified it slightly. There would always be a title, and then any additional fields would be displayed with their field name prefixing the data. The title field was always displayed at the top of the popup box. All fields including the title field, defined their display behaviour using the Schema class.

The Schema class is used by Prefuse to define the default value of visual fields in VisualTables and VisualGraphs, when the developer does not explicitly define a value.

\subsubsection{Event root}

The event 'root' is a Decorator for event Nodes, just like the popup information boxes. 
TimeRootRenderer first read the time from the event Node, and formatted it into 24-hour format with a colon between the hours and minutes (HH:mm). It then would work out the width and height of the generated text string, and vertical distance from the event to the timeline. A dotted line was then drawn from the event down to the timeline, minus the text height. The time string was then drawn with the middle of the string under the dotted line. If the event was a duration type, it would perform the same actions at both ends of the event.

\subsubsection{Navigation control}

Prefuse provides a class, called PanControl, to allow for panning the view in all directions. In our tool it was preferable to limit the panning to the horizontal dimension only. Unfortunately, PanControl could not be configured to change its behaviour.

It was therefore decided to implement a new Control, HorizontalPanControl, which was restricted to horizontal panning. Whenever it received mouse movement events, it calculated the $\mathrm{x}$ delta only, and instructed the Display to pan by the $\mathrm{x}$ delta.

\subsubsection{Related events}

In order for related events to work a Graph structure was required, which defined the Edges between the various Nodes. This structure was specified in GraphML files and loaded into the Visualization using the GraphMLReader class.

A NeighborHighlightControl was added, which sets the 'highlighted' field for neighbouring Nodes to the one currently being hovered over. The ColorAction for the event Nodes was configured to handle the Predicates for hover and the 'highlighted' fields. This Action had to respond to user input so was set to run on a regular basis. 


\subsubsection{Experimental branches}

\section{Filters}

Prefuse contains two Java packages to perform filtering of data; prefuse.data.query, and prefuse.data.search.

The query subpackage contains classes, allowing a visualisation developer create GUI controls, which can manipulate a Predicate.

The search subpackage, allows for complex searching of text within data using the Lucene search engine. It has predefined classes to search for prefixes, keywords, and regular expressions. The developer can create their own classes based off the SearchTupleSet.

Exploration of the query subpackage was performed, with the ListQueryBinding class being used. The instance of the ListQueryBinding was configured to use a Predicate, which effected category colour assignment Actions. A checkbox group was created, and unselected categories were made to go grey. The ListQueryBinding is capable of generating radio button groups, check boxes, and combo boxes.

\section{Active time movement}

The physical change of view as time progressed was envisioned as a useful feature. The view would move from right to left, as each minute passed.

This was approached in two ways: The first was to recalculate the position of all VisualItems in RescueTime, by shifting their x coordinate to the left by one minute. Unfortunately this was very computationally expensive, and was prone to errors with recalculating the time to $\mathrm{x}$ coordinate mapping. The solution was to instead pan the view window by one minute to the right. This was achieved by creating an Action that was scheduled to run forever, and activate every minute. It would move the Display every minute from the time RescueTime was started. It was desirable to make it move on the minute, but it was not possible to do that. 


\section{Overview}

Prefuse has the capability to have multiple views. It was decided to utilise this to generate an overview window, similar to the one in Figure 2.5.

It was possible to implement this feature fairly quickly, but it required tweaking. The aim was to show the overview without the interactive features visible; the popup information boxes, or events changing colours as they were hovered over. Hiding the popup information boxes was possible, but preventing the events changing colours was not possible.

The navigation of the two views were tied together so that the overview showed the current view as a box in the overview. The navigation of the main view remained as desired, horizontal panning only, but when clicking in the overview it was possible to pan vertically, which was not desirable.

This feature was not integrated into the main stream development branch, as it was decided to zoom RescueTime to fit all the available events.

\subsection{Discussion}

\subsubsection{Time calculations}

The $\mathrm{x}$ dimension of RescueTime laid everything out relative to time. This required both a translation from time to $\mathrm{x}$ coordinates, and a scale of pixels relative to time.

There is no direct mapping of time to coordinate space - they are both abstract concepts. Two dimensional coordinate space has the idea of a 'zero point' $(\mathrm{x}=0, \mathrm{y}=0)$, but time has no zero point. Therefore a 'zero time', known as an epoch, needs to be invented. 'Zero time' will be used to describe both the 'zero point' and epoch for RescueTime. Some existing epochs are the Gregorian calendar epoch, at 0AD, and Unix epoch, at the first of January 1970. Neither were feasible as using their epoch as zero for $\mathrm{x}$ meant all the $\mathrm{x}$ coordinates for items within RescueTime would be very large and possibly overflow integer or long data types. The solution was to use an epoch closer 
to the real time; either a specific time for a scenario, or the time RescueTime was started for a realtime situation.

For any time in the past or future relative to the 'zero time', a x coordinate needs to be determined. It is possible to work out the time difference between 'zero time' and the point in time one is interested in, but this does not translate in to a x coordinate. What is needed is a scale of time; how many units of time are there to each unit in coordinate space. The aim was to have at least a granularity of minutes, so a scale of 60 minutes to 60 pixels was used. This was later augmented with a variable scale allowing for time to be compressed or expanded when RescueTime was started.

\subsubsection{Extensibility}

Prefuse operates in a MVC fashion, and the Controller acts as a mediator between the Prefuse library, the intentions of the visualisation developer, and user input (via Controllers). The library is a mix of highly extensible components, using Object Oriented (OO) inheritance, and non-extensible components. It is very easy to extend visual components, such as Visualitems, Actions, Renderers, and Controls; the core components of RescueTime.

VisualItems (derived from Tables or Graphs before being transformed into VisualTables and VisualGraphs) contain fields of data that can be of any Java type. Due to the field nature, developers can add custom fields as data flows through the pipeline and use it later in layout or rendering.

Some of the fringe classes and features were not as extensible. For example, ISO 8601 time representation was used in the data files, which were loaded using the Prefuse GraphMLReader. But these could not be automatically translated from the text string into a Java GregorianCalendar class instance. GraphMLReader used an interface called DataParser to parse text into various types, such as integers or floats. The problem was that it is not possible to register your own implementations of DataParser, so transformations had to be done at a later processing stage, after Prefuse had loaded the data from the file into Tables or Graphs. 


\subsubsection{CPU cost}

Prefuse has a gallery of example visualisations with their source code available. All the examples and guides found for Prefuse created monolithic classes, which are hard to understand, and tended to rerender the visualisation - even though no changes may have occurred. The university NetBSD systems, which had Intel Core 2 Duos, could barely keep up and the interaction delay was very noticeable (sometimes up to 2-3 seconds delay). When run on Windows 7 , with an Intel Core i7, the visualisations appeared to run well.

In inspecting the code for the examples, it was noticed that various Actions were continuously running, which by default is every $100 \mathrm{~ms}$. They also used force directed layouts, which have a heavy cost. The aim was to develop a more modular, and reusable approach, which was more event driven.

The various phases of the Prefuse pipeline (seen in Figure 4.1) were split into separate methods, so that it was clear what that phase was being performed. The advantage is that unnecessary computation is avoided, but the caveat is that sometimes visual elements do not show up initially until an event triggers them.

Creating this event driven system was achieved by registering a listener to handle GUI and Prefuse events. Listeners, implementing the Control interface, were registered with the Display instance for the visualisation. Therefore, only if something had changed, would a graphics redraw be performed.

\subsubsection{Popup boxes}

Development of the popup information boxes was quite difficult. Although LabelRenderer was available to model the text wrapping and VisualItem dimension calculations off, when they were transferred over they didn't quite work as hoped and continued to cause minor layout errors. These were errors 
such as text spilling out of the box or excess space for text.

\subsubsection{Sticky popup boxes}

As mentioned in subsection 4.3.8, Decorators were used to produce the popup information boxes. The possibility of having popup boxes that could be held in place by the user clicking on the event they wanted to keep a box up for was investigated. However there was limited success with this. An attempt was made to create a new Decorator, which created the same box, but with a different coloured background and Predicate. The Predicate was linked to the Prefuse FocusControl, which allowed items to be part of a selection group. Unfortunately, in combination with our event-listener based system, there was undesirable behaviour. It was possible to click on an event and get a sticky popup to persist, but when another event was selected, the first popup would persist when it was no longer part of the selection group. It would disappear if you moused over the original event, but this was not always the case.

\subsubsection{Event roots}

The event 'root' was initially difficult to implement. In order for the root to only be visible on hover, the VisualItem had to be a special subclass known as a DecoratorItem. The problem was that generating multiple Decorators for a single Visualitem provided to be difficult.

The method that defined which Renderer was used for each Visualitem group, was not picking up the second Decorator. The solution was to borrow the Predicate chains concept from Prefuse and allow Decorators to add themselves to the chain.

Another minor problem was the positioning of the root. The line did not come from the centre of the event, but rather the left edge of the circle, causing the time reported to be wrong.

A problem not resolved, due to time constraints, was that on a dura- 
tion event, if the end of the event was outside of the view the root would not be visible and not give the user an indication of when the event ends. Introducing the date to the time label may have also been useful.

\subsubsection{Exception handling}

Getting started in Prefuse can be very difficult. Unless the whole pipeline is connected properly the result is just a blank Display. It was found that Prefuse did not throw exceptions when you omitted certain information, such as not having a Renderer for a group of Visualitems. It was very frustrating dissecting the Prefuse examples and creating your own visualisations from scratch.

Another problem was related to getting fields from VisualItems; if the method "canGetString" is called, for example, it would return a boolean value indicating whether the field can return a string, but it was still possible to call "getString" and be given a null. Therefore, occasional NullPointerExceptions would occur, where a String was expected but instead received null. It would have been desirable for "getString" to throw an exception if the value was null. 


\section{Chapter 5}

\section{Evaluation}

In this chapter a hypothesis is presented regarding the user evaluation of our tool's performance. This chapter will first cover a general overview of the experiment before covering the test participants, environment, and procedures. This is followed by the results and a discussion.

\subsection{Experimental overview}

The goal was to compare RescueTime against the whiteboard (see subsection 5.4.3), a traditional information management tool used by emergency workers. Twelve participants were asked to create a situational report from scenarios displayed on RescueTime and the whiteboard, as well as questions to grade their experience with each tool.

The School of Engineering and Computer Science (ECS) has a purpose built usability laboratory, which was used for the evaluations. The lab has video and audio recording facilities, which allow for both the computer and participants to be recorded at the same time. The Victoria University of Wellington (VUW) Emergency Operations Center (EOC) was not used, because it did not provide any recording facilities and it did not add anything that could not be simulated. 


\subsection{Hypothesis}

RescueTime will allow the participant to recall more details accurately immediately after use, than the whiteboard.

\subsection{Population}

The evaluation was performed with six members of the university's rescue team, and six non-rescue participants. The rescue team members train on a weekly basis, process reconnaissance information into structured reports, and four of our six rescue participants are even trained up to the Coordinated Incident Management Team (CIMS4) standard. Non-rescue participants provide insight into whether further development in the field of emergency management visualisations should focus on evaluating against rescue workers or just the general population.

The size of our testing population was limited by the number of rescue participants who were willing to be tested. In our case we were able to get six rescue participants, so matched that with six non-rescue participants. With such a small sample size, it is not possible to get statistically significant results.

In both the rescue and non-rescue groups there were four (of the six) who have attended some computer related courses. This background may cause participants to have higher expectations for any computer based tools.

The two members of the Incident Management Team (IMT), interviewed earlier, were not used as using only two participants would not be sufficient for any statistically significant feedback.

Participants are referred to later using P1 through to P12. 


\subsection{Experimental artifacts}

In order to test the hypothesis an environment was generated for evaluating both RescueTime and the whiteboard, using some test scenarios.

\subsubsection{Scenarios}

\section{Scenario One (S1)}

The first scenario was that of a region-wide power outage, which lasted just over an hour. The length was based off an actual event that occurred in Wellington. Full details of the scenario are available in section D.1

As expected in a power outage, elevators stopped with people in them, and automatic doors stopped operating. Some additional plausible events were added to add some drama to the situation; fume cupboards in a chemistry lab stopped operating causing a student to collapse, and a contractor, in dark tunnels under the university, tripped over and broke one of their legs.

The majority of incoming information, which was compressed into the first five minutes, was that of people being trapped in elevators, which was designed to overwhelm the participant.

The key pieces of information the participant was expected to identify and focus on were the two injured people. The chemistry lab victim was extracted, by Victoria Rescue, and then transported to hospital by Wellington Free Ambulance. The contractor was also extracted by Victoria Rescue, but taken to Student Health for treatment - as it was not a serious injury.

This scenario resolves itself when the power is restored and elevators return to normal function.

The expectation was that the participants would aggregate the people trapped in elevators or ignore them completely once they have scanned all the information and realised that all elevators are cleared later on. It was also expected there may be some confusion between the chemistry lab victim and contractor about which medical facility they end up at. 


\section{Scenario Two (S2)}

The second scenario is that of a devastating earthquake striking the Wellington region. This was a much longer scenario than the first, stretching over 24 hours, and non-concluding.

The local infrastructure was heavily damaged, with water and gas pipes severed, intermittent power supply, roads damaged, and both the airport and seaport at limited capacity. As the earthquake strike was near the middle of the day, at 1117, quite a few students were trapped in lecture theatres. As the situation progressed a more coordinated response developed with the formation of facilities, such as triage points, welfare camps, morgues, and rescue operation specific landmarks (EOC, Assembly Area (AA), Safe Forward Point (SFP), etc).

In this scenario it was less obvious what incoming information is important and what should be discarded mentally. Local infrastructure damage was useful knowledge, but does not directly effect rescue operations on the campus. Also due the nature of such an overwhelming disaster, there were unconfirmed reports of people trapped, which later get followed up by confirmed reports or resolution by the rescue operations.

The key pieces of information the participant was expected to identify and focus on were the students trapped in lectures theatres, and the location of key facilities.

The expectation was that the participants would have trouble absorbing all the various types of information and would not make connections between related pieces of information. It was also expected that there would be minor factual errors or key facts left out of their report.

For full details of the scenario see section D.2 


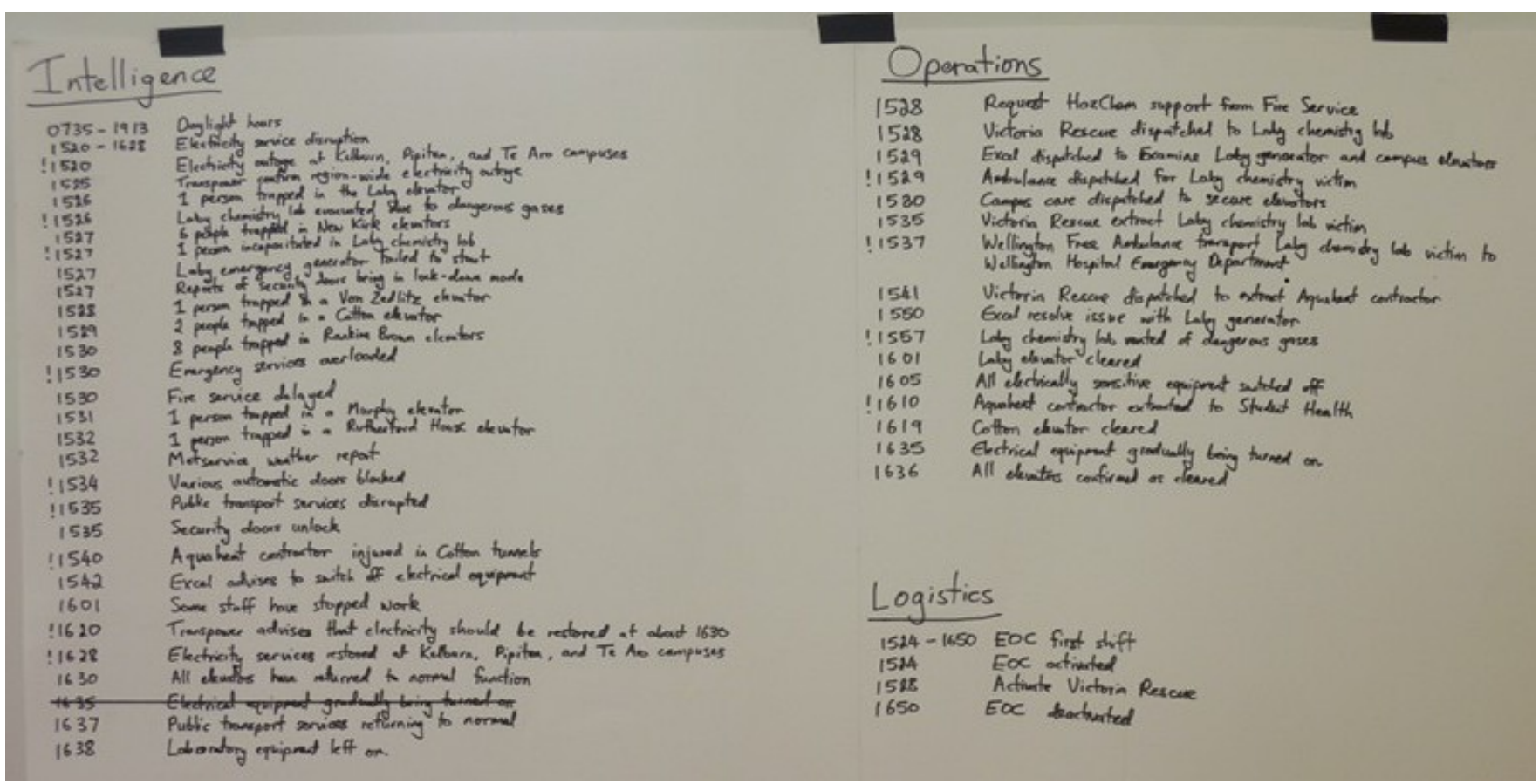



Figure 5.1: Scenario one as seen on the whiteboard 


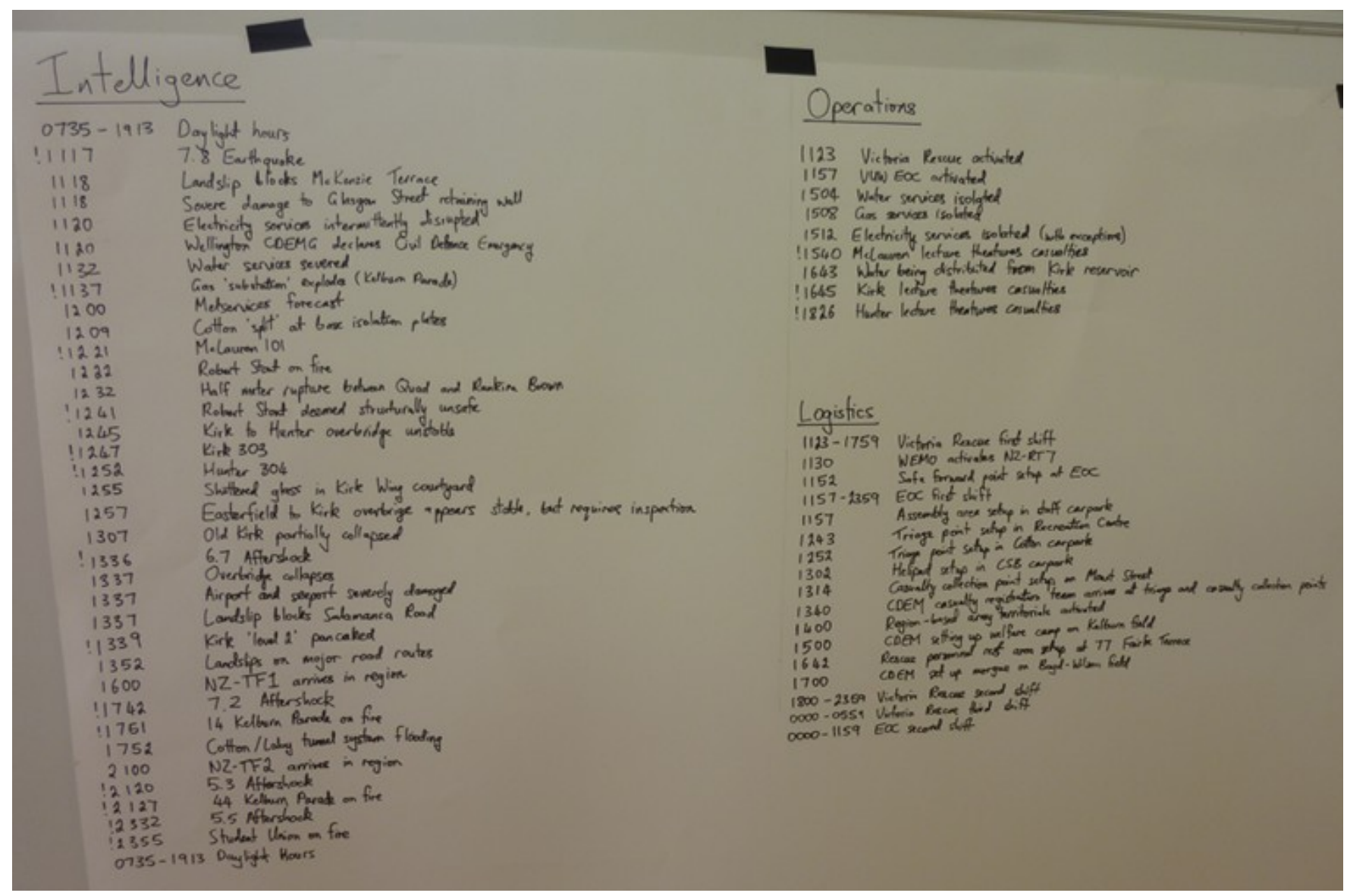

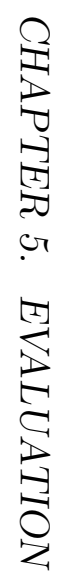




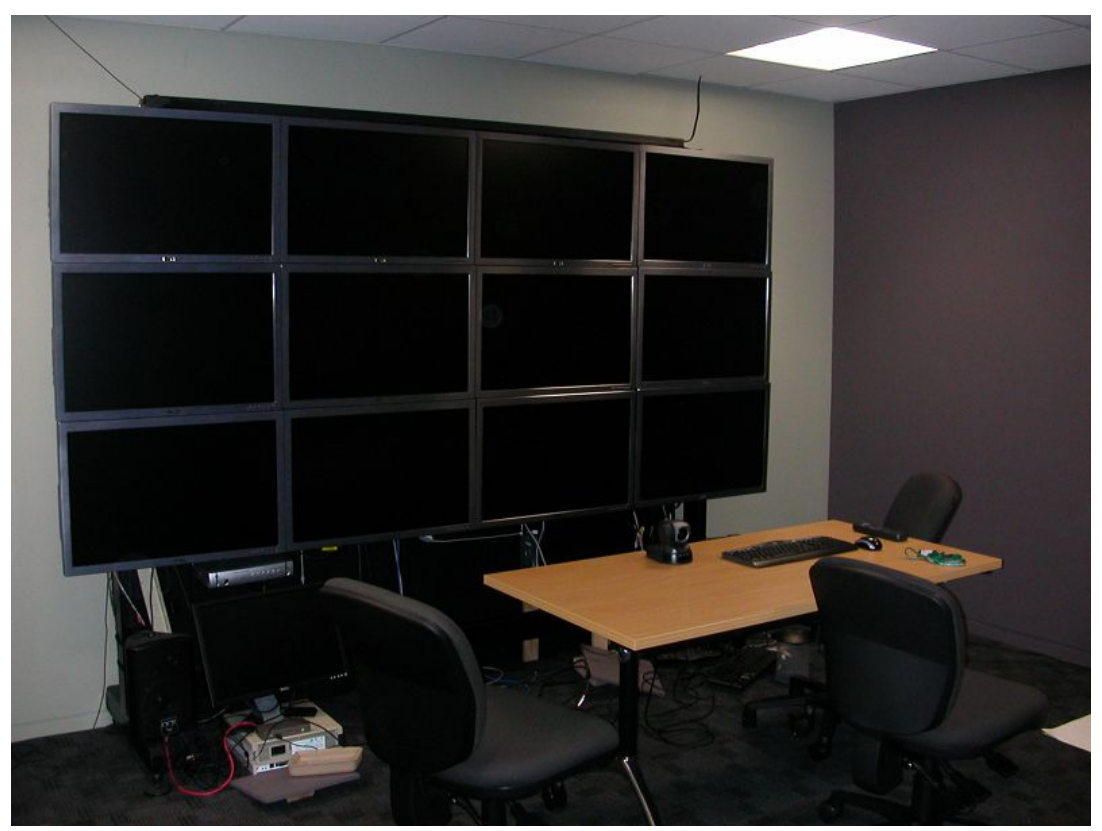

Figure 5.3: View of usability laboratory computer screens

\subsubsection{RescueTime}

RescueTime was presented on a single screen out of an array of 12 screens (3 high, 4 wide) - seen in Figure 5.3. A single screen was chosen instead of the whole array as introducing multiple screens may cause participants to react differently to RescueTime and the objective was not to test how participants would react to multiple screens. The machine hosting RescueTime was running Windows XP with Sun Java 6, and for the purposes of recording, the screen resolution was set to 1280 by 800 pixels.

\subsubsection{Whiteboard}

Two large sheets of paper were used to simulate a whiteboard. The large sheets seen in Figures 5.1 and 5.2 were attached to a portable whiteboard when the participant was to perform the whiteboard task.

The decision to use these sheets instead of the whiteboard itself was made for a few reasons. Firstly we wanted to make sure what was presented 


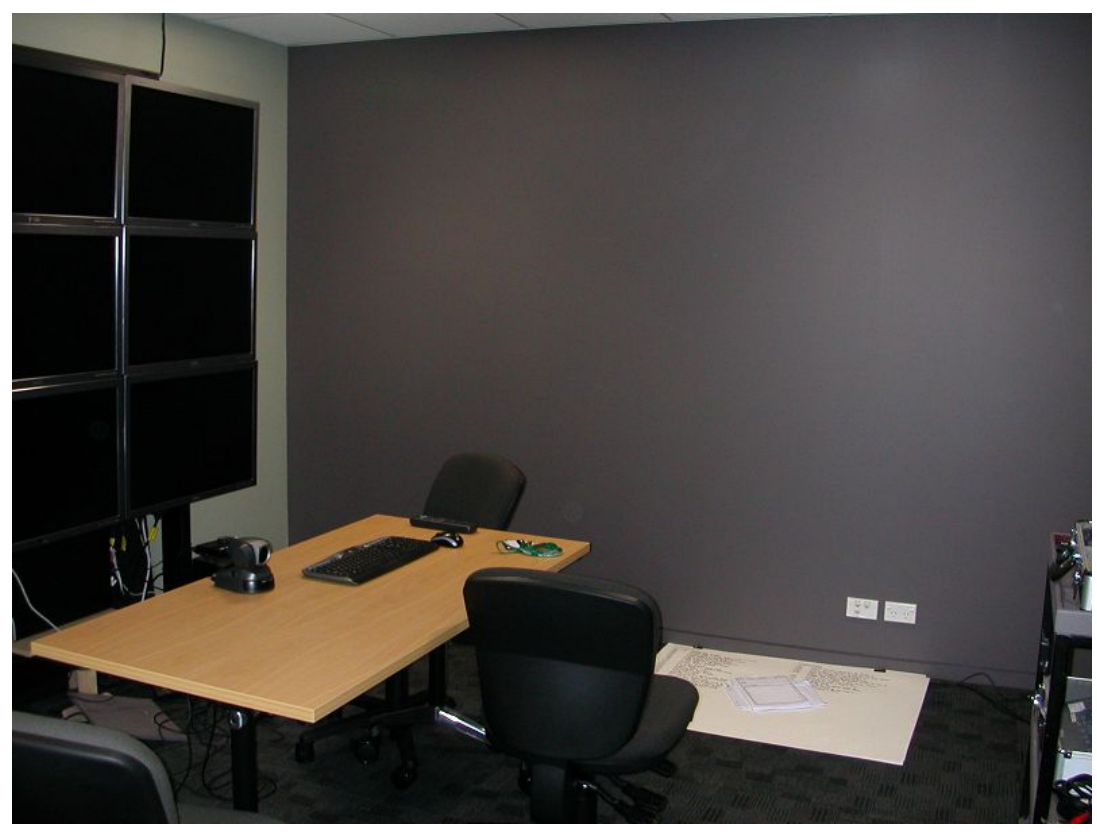

Figure 5.4: Usability laboratory view

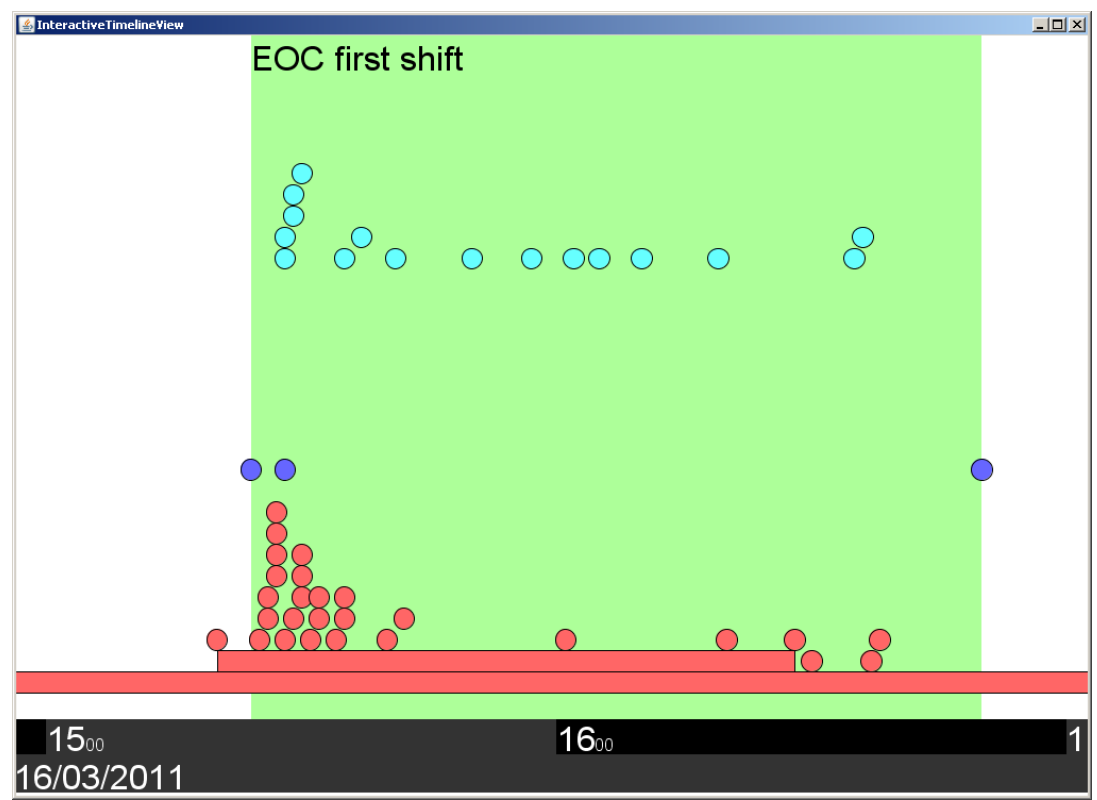

Figure 5.5: Scenario one as seen on RescueTime 


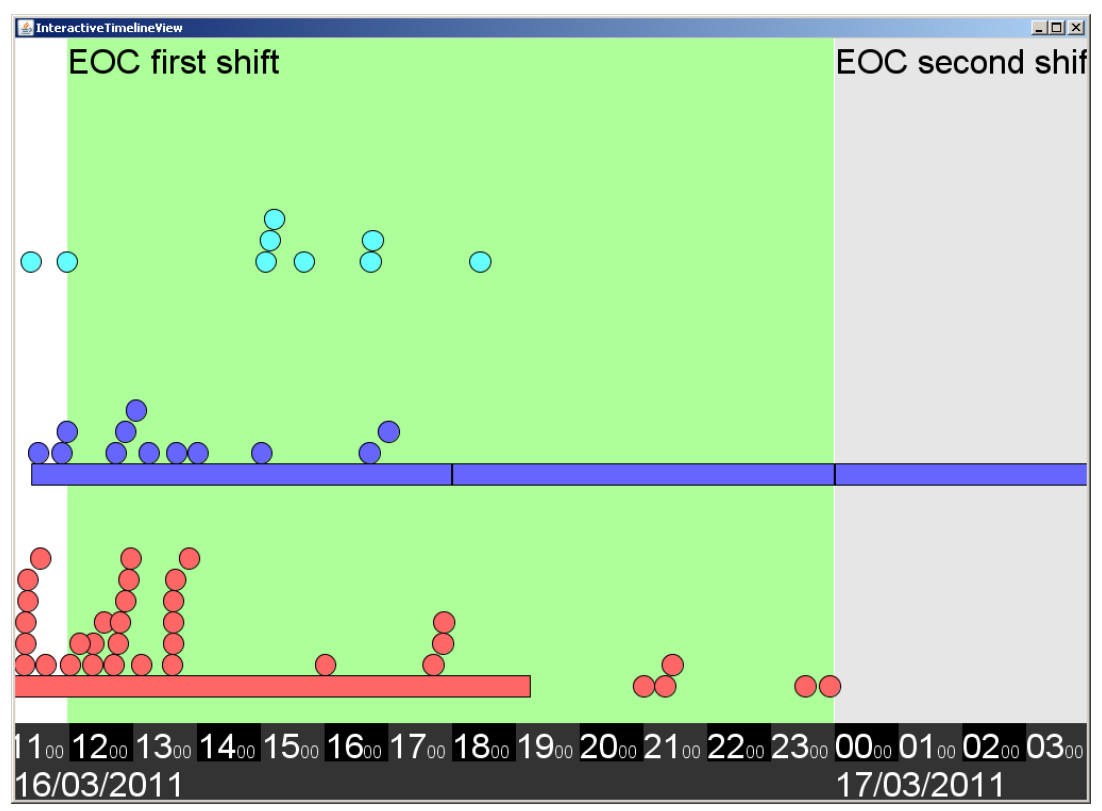

Figure 5.6: Scenario two as seen on RescueTime

between the participants was consistent, and not altered intentionally or accidentally (like rubbing something off). The portable whiteboard may also be used in the department between participants and would probably have its contents erased. Secondly it was necessary to be able to hide the scenario until the participant was ready and since the portable whiteboard available only has two sides, one of the scenarios would have been exposed to the participant from the start.

\subsection{Testing procedure}

Each participant was welcomed into the usability laboratory and sat them down at a table next to the evaluator. The evaluator then verbally introduced the participant to the purpose of the evaluation, and gave them an opportunity to ask questions (see section C.2 for the full transcript). Once the participant was comfortable, they were asked to sign human ethics forms as a written record that they agreed to be recorded for our study. 
At this point the video and audio recording equipment were started, and the participant was prepared for the first scenario and tool.

To help participants present a situation report, they were provided with a template sheet, in the ISPAARE format (see Glossary). If the participant was not familiar with the ISPAARE[8] situational report, they were introduced to each component of the situation report and provided examples of what sort of information would be placed in each component. The participant was provided with an ISPAARE template page (see Figure 5.7), and an acronyms sheet (see section C.9) for the scenarios they would be analysing.

For RescueTime, the participant was provided with a paper page with directions on how to use RescueTime (see section C.11). A sample data set was then loaded and displayed on RescueTime, giving the participant time to read through the page and ask any questions, while using RescueTime.

For the whiteboard, layout and symbols used for the data were introduced. The paper stack was also introduced, showing its relation to the whiteboard.

The participant was then given 10 minutes to analyse the scenario provided on the tool they had to use and take notes for a situation report.

After each round of scenario analysis the participant was asked some questions, seen in section 5.5.1, about the tool they used. The participant was then asked to give a verbal situational report of the scenario.

After both scenarios had been completed and situational reports had been given, the participant was asked some questions about which tool they preferred; RescueTime or the whiteboard. These questions can be seen in section 5.5.1 and section C.7

\subsubsection{Intended data collection}

\section{Recordings}

Conscious and unconscious responses were recorded from our participants during our evaluation. Conscious responses include responses to verbal questionnaires, and providing a verbal situation report. Unconscious responses 


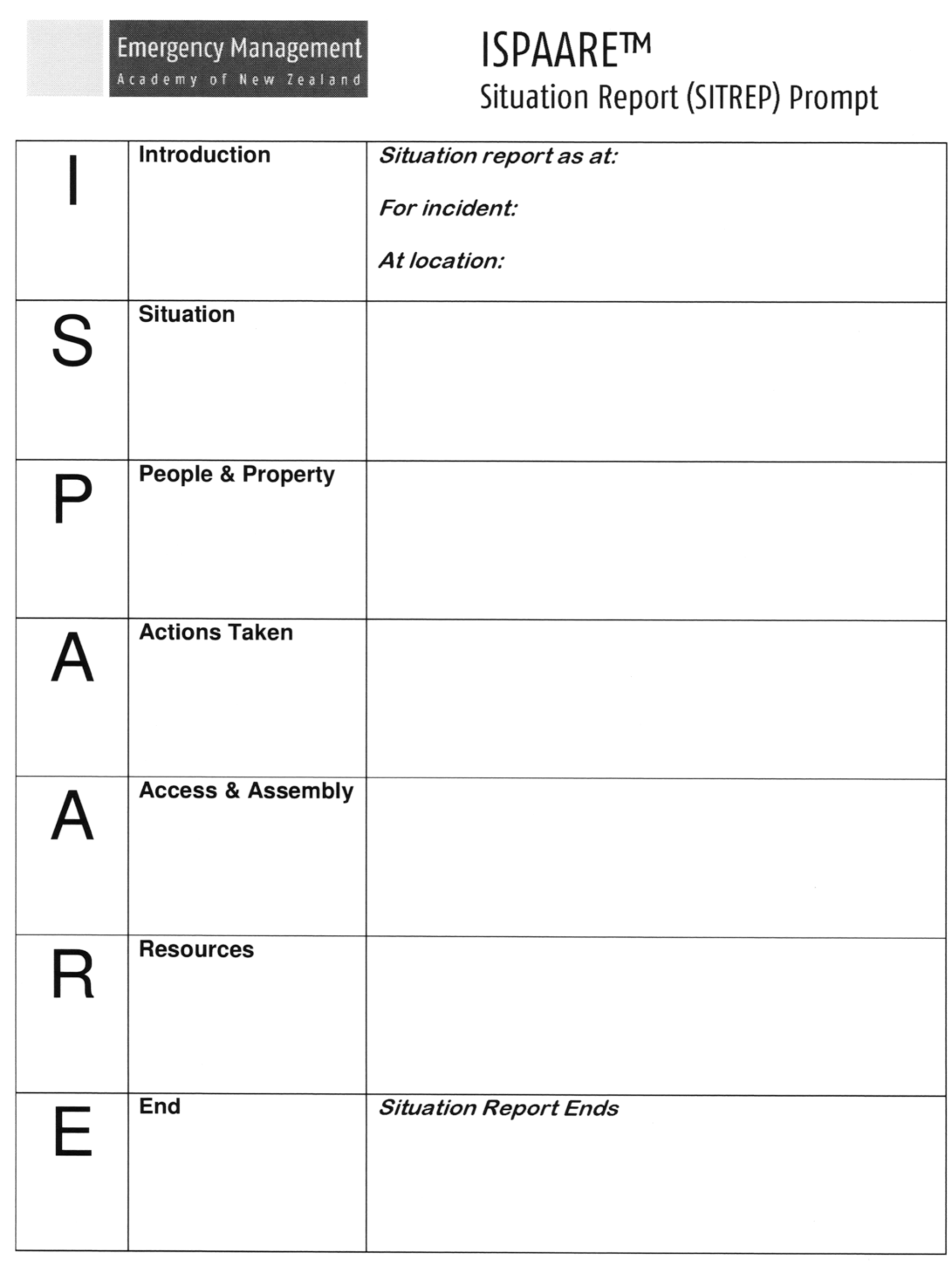

www.emanz.ac.nz

Figure 5.7: ISPAARE sheet[8]. To assist participants give a verbal situation report a template sheet was provided. Participants were given one per scenario and could write on it. 
include facial expressions throughout the evaluation and mouse movement when operating RescueTime.

Two preset recording configurations were used. The first preset, for when the participant was using RescueTime, displays RescueTime and a small window of the participant in the bottom right corner of the recording. The camera was set so that both the participant's hands and face were visible in the recording. The second preset, used for the whiteboard exercise, showed only the camera view, which displayed the whiteboard and participant. It would capture if the participant moved towards the whiteboard and their general head and face movements.

\section{Questions}

Questions were asked during various stages of the evaluation. Some were graded questions, from 1 (worst) to 5 (best), while others were open questions. Questions are referred to later using Q1 through to Q12.

The questions were as follows:

Q1 How confident are you in remembering most of the events (but not necessarily the details)? [1-5]

Q2 How confident are you in remembering the details of the events? [1-5]

Q3 How useful was the tool you used? [1-5]

Q4 What things did you like about the tool you used?

Q5 What things did you not like about the tool you used?

Q6 What information was the hardest to find in the tool?

Q7 What information was the easiest to find in the tool?

Q8 Where would you like to see improvement in the tool?

Q9 Which tool was easier to find information in? [1-5] 
Q10 Which tool provided the quickest overview? [1-5]

Q11 Which tool do you prefer overall? [1-5]

Q12 Which tool do you think you performed better with? [1-5]

\subsubsection{Controls}

Because more than one scenario was run per participant, it is easy to introduce bias. Controls were introduced in an attempt to eliminate this bias.

Possible bias was identified with the ordering of which tool was used first was identified - RescueTime or the whiteboard - and the order in which the scenarios were presented.

The concern with the tool order was that the second tool would appear to be easier because the participant had already performed the task required and had become more comfortable with the task. To mitigate this, the tool used first was changed between participant groups.

The scenario order concern was the similar to the tool concern. The scenarios were not identical and the difficulty of each scenario may colour the participants preferences for each tool. This again was mitigated by rotating the scenario used on each tool.

In total there were four participant groups required:

- Scenario One first, whiteboard first.

- Scenario One first, RescueTime first.

- Scenario Two first, whiteboard first.

- Scenario Two first, RescueTime first.

\subsection{Results}

The results from the evaluations are broken up into the following sections: Graded questions (subsection 5.6.1) goes through questions Q1 to Q3 and 
Q9 to Q12, where participants were asked to grade an aspect of the tool they used; Open questions (subsection 5.6.2) goes through questions Q4 to Q8, and any other comments provided by the participants; Situation reports (subsection 5.6.3) goes through the situation reports presented by the participants and how they were evaluated; and finally RescueTime observations (subsection 5.6.4) goes through the observed usage patterns of RescueTime.

\subsubsection{Graded questions}

Tables 5.1, and 5.2 shows the responses to questions about individual tools after the participants had used them. Table 5.3 shows the questions grouped by scenario rather than by tool. Table 5.4 shows the response to questions about which tool the participant prefers.

\section{Tool questions}

Tables 5.1, and 5.2 show the results of questions Q1 to Q3.

- Q1: Between both tools, the averages were fairly close to neutral, but on the confident side. Between scenarios, Q1 had similar results, with a 0.58 (see Table 5.3) difference in favour of $\mathrm{S} 1$ for the rescue average, and identical non-rescue average.

- Q2: On average participants were not confident they could remember the details of events, with the whiteboard technique coming out worse; participants made comments about their usage of the papers sheets in subsection 5.6.2, which may explain this. Between scenarios, Q2 once again had a 0.58 difference in favour of $\mathrm{S} 1$ for the rescue average, and a 0.25 difference in favour of $\mathrm{S} 1$ for the non-rescue average.

- Q3: Participants found that both tools were more useful than neutral. Between scenarios, Q3 had a 0.5 difference for the non-rescue average, in favour of $\mathrm{S} 2$ - the opposite direction to Q1 and Q2. 


\section{Comparison questions}

Table 5.4 shows the average between rescue and non-rescue participants as well as overall average. It is noticeable that there is considerable difference between the two groups:

- Q9: Rescue participants found neither tool easier to find information in, though one participant had a strong preference towards RescueTime, while non-rescue participants found RescueTime easier to find information in.

- Q10: Rescue participants found the whiteboard provided a better overview, while non-rescue participants were closer to neutral with a few strongly preferring RescueTime.

- Q11, Q12: Both participant groups preferred RescueTime overall and believed they performed better using it.

"The whiteboard was the easiest to find an immediate piece of information. A related piece of information was easier using the computer tool" $--\mathrm{P} 1$

66

"The quickest overview of the actual information - the written information - [pointing to whiteboard]; the quickest overview of seeing when events happened and how many events, and where they place on the timeline [RescueTime] gives you better."

- P4
}

\subsubsection{Open questions}

Participants were asked open questions about their experience with using RescueTime or the whiteboard. These were questions Q4 through Q8. 


\begin{tabular}{|c|c|c|c|}
\hline Participant & Q1: Overview & Q2: Details & Q3: Usefulness \\
\hline P1 & 4 & 3 & 4 \\
\hline P2 & 4 & 2 & 5 \\
\hline P3 & 2.5 & 2 & 3.5 \\
\hline $\mathrm{P} 4$ & 4 & 3.5 & 3.5 \\
\hline $\mathrm{P} 5$ & 3.5 & 2.5 & 4 \\
\hline $\mathrm{P} 6$ & 3 & 3 & 3 \\
\hline Rescue Mean & 3.5 & 2.67 & 3.83 \\
\hline P7 & 3 & 3 & 2 \\
\hline P8 & 4 & 2 & 4 \\
\hline P9 & 5 & 3 & 4 \\
\hline $\mathrm{P} 10$ & 3 & 4 & 4 \\
\hline $\mathrm{P} 11$ & 4 & 1 & 4 \\
\hline $\mathrm{P} 12$ & 3 & 3 & 4 \\
\hline Non-Rescue Mean & 3.67 & 2.67 & 3.67 \\
\hline Overall Mean & 3.58 & 2.67 & 3.75 \\
\hline & 2 & $\stackrel{4}{1}$ & \\
\hline
\end{tabular}

Table 5.1: Graded questions for RescueTime. Q1 and Q2 relate to ability to recall events and their detail, and Q3 rates usefulness of RescueTime. Participants were asked to grade their responses based on how they felt about the tool, whether a positive or negative experience. On average participants felt slightly more positive about the overview, and RescueTime's usefulness, but slightly negative about RescueTime's ability to show details. Notice there is no significant difference between the rescue and non-rescue means. 


\begin{tabular}{|c|c|c|c|}
\hline Participant & Q1: Overview & Q2: Details & Q3: Usefulness \\
\hline $\mathrm{P} 1$ & 4 & 2 & 4 \\
\hline $\mathrm{P} 2$ & 4 & 3 & 4 \\
\hline P3 & 4 & 1 & 4 \\
\hline $\mathrm{P} 4$ & 3 & 1 & 2 \\
\hline P5 & 2.5 & 1.5 & 2.5 \\
\hline $\mathrm{P} 6$ & 3 & 2 & 4 \\
\hline Rescue Mean & 3.42 & 1.75 & 3.42 \\
\hline $\mathrm{P} 7$ & 4 & 1 & 4 \\
\hline P8 & 5 & 2 & 3 \\
\hline $\mathrm{P} 9$ & 2 & 1 & 2 \\
\hline $\mathrm{P} 10$ & 4 & 2.5 & 4 \\
\hline P11 & 2 & 1 & 3 \\
\hline $\mathrm{P} 12$ & 3 & 2 & 2 \\
\hline Non-Rescue Mean & 3.33 & 1.58 & 3 \\
\hline Overall Mean & 3.38 & 1.67 & 3.21 \\
\hline
\end{tabular}

Table 5.2: Graded questions for whiteboard. Q1 and Q2 relate to ability to recall events and their detail, and Q3 rates usefulness of the whiteboard. On average participants felt more positive about the overview, and the whiteboard's usefulness, but felt quite negative about the whiteboard's ability to show details. Once again there is no significant difference between the rescue and non-rescue means. 


\begin{tabular}{|c|c|c|c|c|c|c|}
\hline \multirow[t]{2}{*}{ Participant } & \multicolumn{2}{|c|}{$\begin{array}{l}\text { Q1: } \\
\text { Overview }\end{array}$} & \multicolumn{2}{|c|}{$\begin{array}{l}\text { Q2: } \\
\text { Details }\end{array}$} & \multicolumn{2}{|c|}{$\begin{array}{l}\text { Q3: } \\
\text { Usefulness }\end{array}$} \\
\hline & S1 & $\mathrm{S} 2$ & $\mathrm{~S} 1$ & $\mathrm{~S} 2$ & S1 & $\mathrm{S} 2$ \\
\hline $\mathrm{P} 1$ & 4 & 4 & 2 & 3 & 4 & 4 \\
\hline $\mathrm{P} 2$ & 4 & 4 & 3 & 2 & 4 & 5 \\
\hline P3 & 4 & 2.5 & 1 & 2 & 4 & 3.5 \\
\hline $\mathrm{P} 4$ & 4 & 3 & 3.5 & 1 & 3.5 & 3.5 \\
\hline P5 & 3.5 & 2.5 & 2.5 & 1.5 & 4 & 4 \\
\hline P6 & 3 & 3 & 3 & 2 & 3 & 3 \\
\hline Rescue Mean & 3.75 & 3.17 & 2.5 & 1.92 & 3.75 & 3.83 \\
\hline P7 & 3 & 4 & 3 & 1 & 2 & 2 \\
\hline P8 & 4 & 5 & 2 & 2 & 4 & 4 \\
\hline P9 & 5 & 2 & 3 & 1 & 4 & 4 \\
\hline P10 & 4 & 3 & 2.5 & 4 & 4 & 4 \\
\hline P11 & 2 & 4 & 1 & 1 & 3 & 4 \\
\hline $\mathrm{P} 12$ & 3 & 3 & 2 & 3 & 2 & 4 \\
\hline Non-Rescue Mean & 3.5 & 3.5 & 2.25 & 2 & 3.17 & 3.67 \\
\hline Overall Mean & 3.63 & 3.32 & 2.38 & 1.96 & 3.48 & 3.76 \\
\hline
\end{tabular}

Table 5.3: Graded questions grouped by scenario. This shows the responses to graded questions as related to the scenario, as opposed to the tool they used. Q1 and Q2 scored more favourably for S1, and Q3 scored more favourably for S2. 

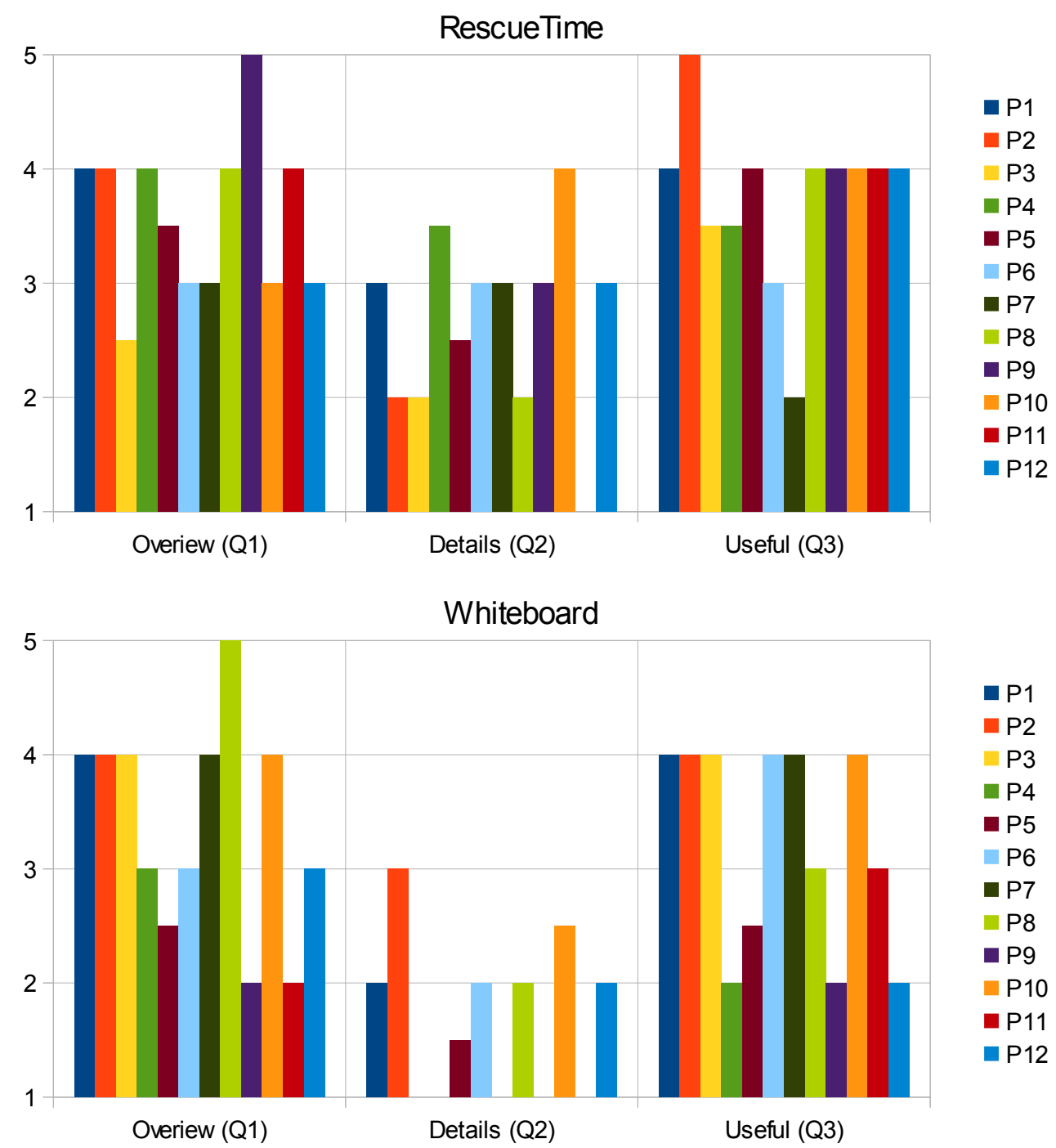

Figure 5.8: Graphs of graded tool questions. Graphs showing graded responses from participants for each tool (Tables 5.1 and 5.2). The range is from one to five, with no bar visible signifying a one. 

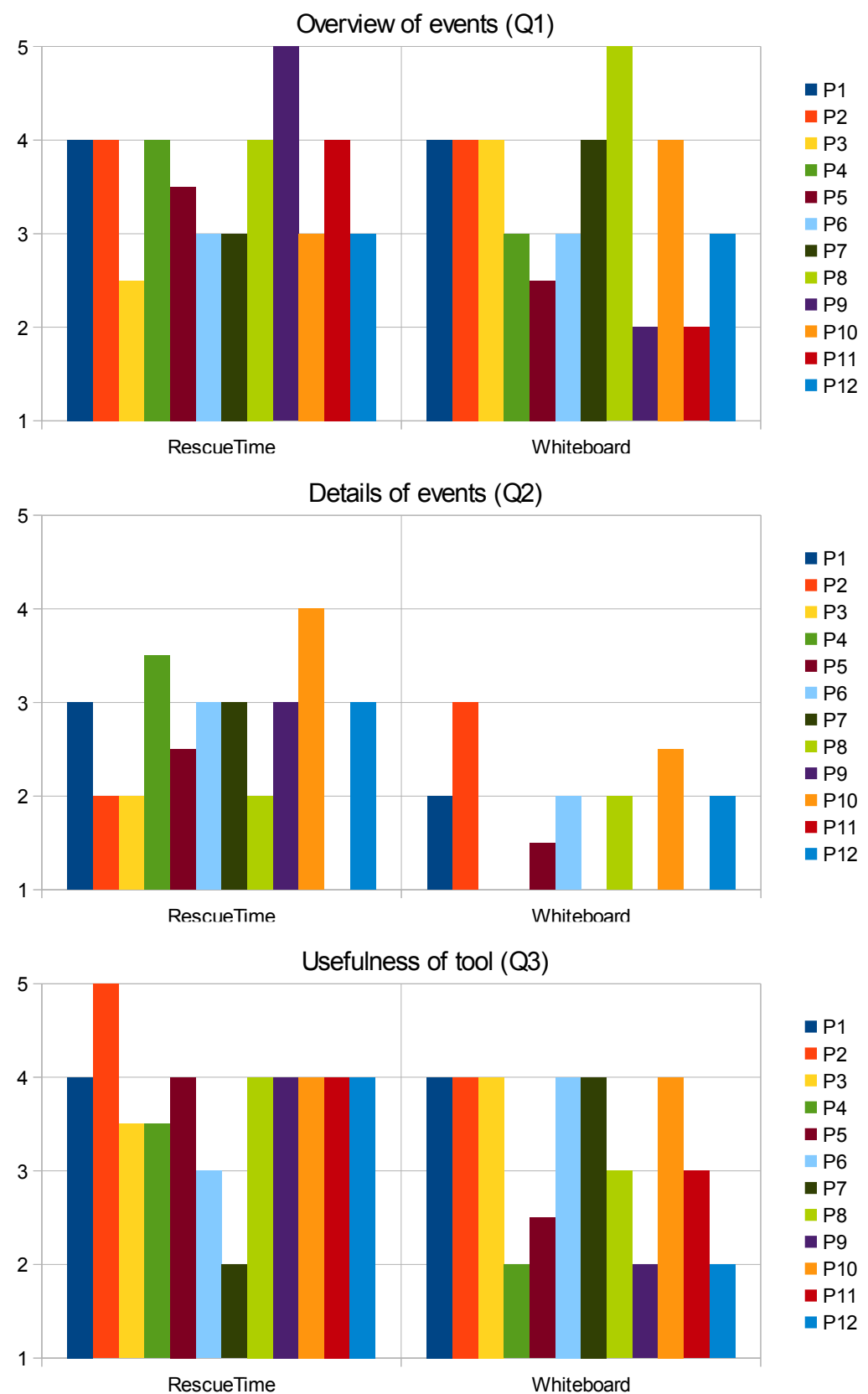

Figure 5.9: Side-by-side graphs of graded tool questions. Shows information from Figure 5.8 with each graph a question, showing differences between RescueTime and the whiteboard. 


\begin{tabular}{|c|c|c|c|c|}
\hline Participant & $\begin{array}{l}\text { Q9: } \\
\text { Easier } \\
\text { tool }\end{array}$ & $\begin{array}{l}\text { Q10: } \\
\text { Quickest } \\
\text { overview }\end{array}$ & $\begin{array}{l}\text { Q11: } \\
\text { Best } \\
\text { overall }\end{array}$ & $\begin{array}{l}\text { Q12: } \\
\text { Best per- } \\
\text { formance }\end{array}$ \\
\hline $\mathrm{P} 1$ & 2 & 2 & 3 & 4 \\
\hline P2 & 3 & 1 & 4 & 2 \\
\hline P3 & 2 & 3 & 2 & 2 \\
\hline $\mathrm{P} 4$ & 3 & 3 & 4 & 4 \\
\hline P5 & 5 & 2 & 4 & 4 \\
\hline P6 & 2 & 1 & 2 & 3.5 \\
\hline Rescue Mean & 2.83 & 2 & 3.17 & 3.25 \\
\hline P7 & 5 & 2 & 5 & 4 \\
\hline P8 & 4 & 1 & 4 & 2 \\
\hline P9 & 4 & 2 & 5 & 5 \\
\hline P10 & 2 & 4 & 1 & 4 \\
\hline P11 & 5 & 5 & 5 & 5 \\
\hline P12 & 5 & 5 & 5 & 2 \\
\hline Non-Rescue Mean & 4.17 & 3.17 & 4.17 & 3.67 \\
\hline Overall Mean & 3.5 & 2.58 & 3.67 & 3.46 \\
\hline
\end{tabular}

Table 5.4: Graded questions for comparing tools. Q7 asked which tool was easiest to find information in; Q8 asked which tool provided the quickest overview; Q9 asked which tool was the best overall; and Q10 asked which tool the participant thought they performed best in. Notice the fairly significant difference between rescue and non-rescue participants. Rescue participants tend to prefer the traditional whiteboard technique as an easier tool and quicker overview, whereas non-rescue participants tend to prefer RescueTime. Both groups are either neutral or tend towards preferring RescueTime as an overall tool, and believed their situational report performance were better. 

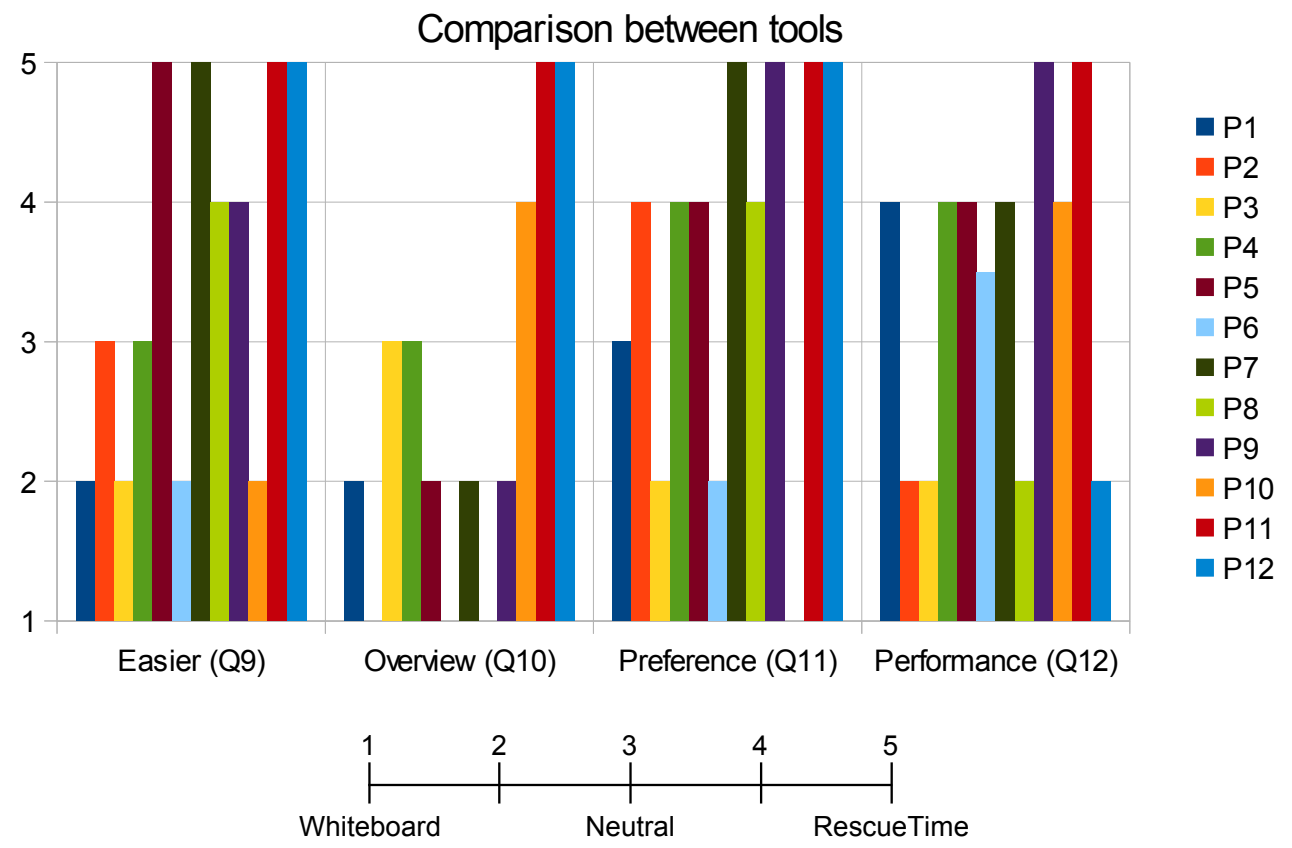

Figure 5.10: Graph of graded comparison questions. Graph showing Table 5.4 . 


\section{Likes and Dislikes}

There were too many likes and dislikes to list here, so the most common have been chosen, plus some interesting comments.

\section{Likes and Dislikes: Overview}

The most liked feature of both RescueTime or the whiteboard was having all the event titles visible on the whiteboard, which created an overview of the scenario. When comparing the overview to the drill-down style of RescueTime, one participant noted they did not like the fact that RescueTime was just a whole lot of dots until the mouse moved.

66

"Without any mousing over its a lot of dots"

-- P1 (RescueTime)

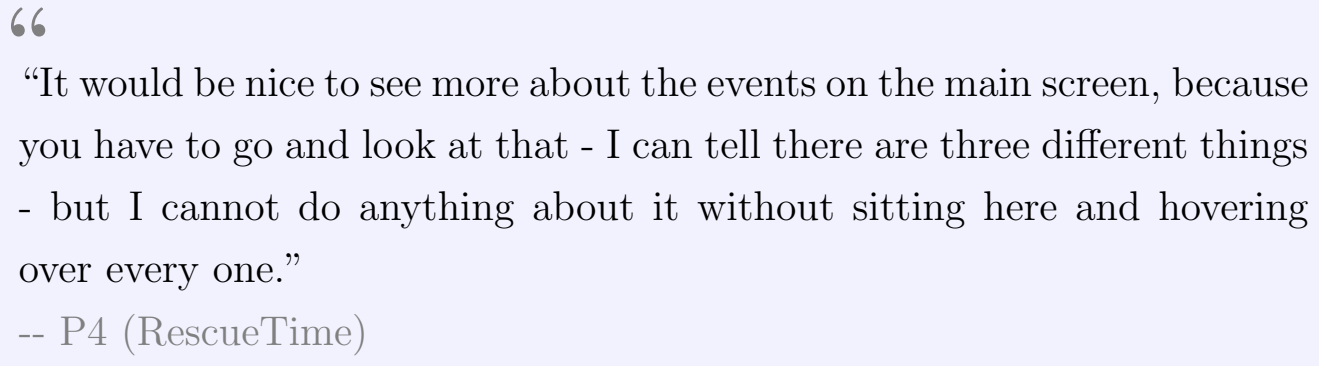

"It would be nice to see more about the events on the main screen, because you have to go and look at that - I can tell there are three different things

- but I cannot do anything about it without sitting here and hovering over every one."

-- P4 (RescueTime)

This is similar to the Elaborate[23] interactive technique introduced in subsection 2.3.1.

\section{Likes and Dislikes: Event grouping}

Grouping the events into the three major CIMS groups was a controversial feature. Some liked the grouping, mostly on RescueTime, and some did not like grouping, who wanted a single group. On the whiteboard the problem seemed to be amount of effort required to track where events between groups were relative to each other in time. 
66

"The separation of intelligence, operation, and logistics; you cant correlate them immediately to a certain time"

-- P1 (whiteboard)

\section{6}

"I am weighing up whether I like the logistics, operations, and intelligence in separate groups. I am thinking it is good because the different people, the ops manager, and logistics manager can see what they have been doing and how that relates to others."

-- P3 (RescueTime)

\section{Likes and Dislikes: Related}

Most participants liked the related events on RescueTime, while a few were confused about how the feature operated. This is despite being given an introduction to RescueTime (see section C.11).

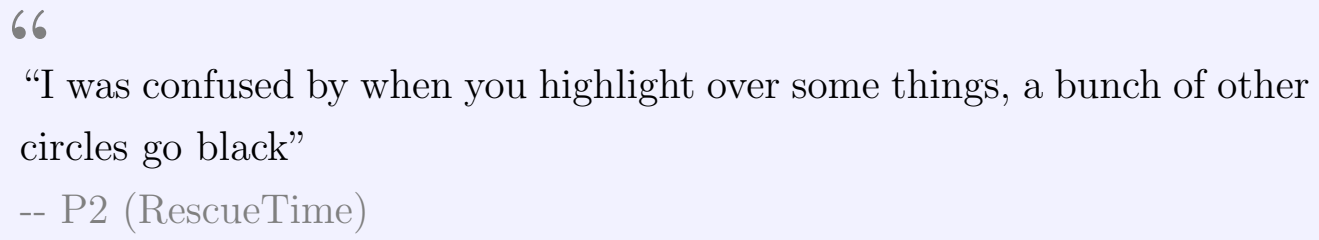

\section{Likes and Dislikes: Whiteboard paper stack}

The paper stack used with the whiteboard was almost universally disliked. It is believed to be because the paper stack was disjoint from the rest of the information and may have interrupted the mental flow of participants.

"I didn't look at the pieces of paper at all"

-- P1 (whiteboard) 
66

"The good thing with the whiteboard was it gave me an immediate overview of everything, so very easy to see stuff, but very hard to find information about stuff using the paper stack - that was quite frustrating" -- P8 (whiteboard)

\section{Likes and Dislikes: Event descriptions}

Only about half of the events contained descriptions. This was because either the title was considered sufficient information or additional information was not available - which would be the case in a real situation. Some participants noted this as a problem.

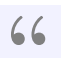

"With a couple of the dots the title was the description and there was very little written in [the box]. They were kind of confusing when you were going to read the box, which was the bulk, and went 'there is nothing there' and then you looked at the title and went 'aww it is there'."

-- P3 (RescueTime)

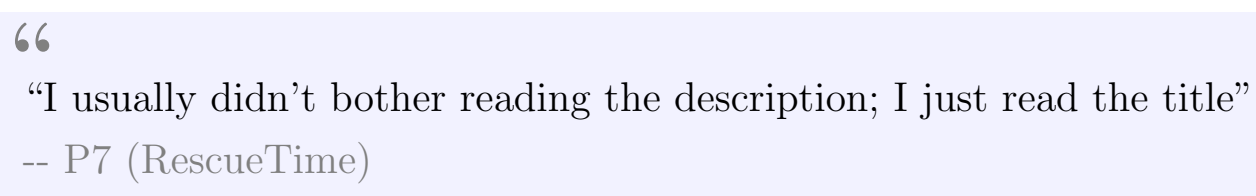

"I usually didn't bother reading the description; I just read the title" -- P7 (RescueTime)

\section{Likes and Dislikes: Event recall}

Quite a few of the participants noted they had trouble recalling events they had previously read. Particularly on RescueTime the participants knew the general area of dots where the event they wanted was, but could not directly locate the event. Instead they looked in the area where the thought the event was until they located it. 
66

"Recalling a previous event I know is on the system, especially in a big stack"

-- P1 (RescueTime)

66

"When I scanned through everything and it was time to find information, but when I wanted to go back, and go 'okay, now I need to try and match things up', then it was a bit of playing memory, on which dots were what job"

-- P3 (RescueTime)

66

"Once I had gone through and found things, to go find them again was really hard"

-- P4 (RescueTime)

\section{Likes and Dislikes: Event density}

Some participants liked the spacial density of events, which allowed them to identify periods of high activity.

66

"All the events look clumped together, you can't say lots happened at the start, but petered off, you can't see the magnitude of events at the start." [how whiteboard does not have time relative spacing]

-- P1 (whiteboard) 
66

"It is easy to see the span of the event, and how things occurred just by what things are stacked in what area"

-- P4 (RescueTime)

\section{Likes and Dislikes: Casualty differentiation}

An unexpected benefit from the method of generating the scenarios was that in the power cut scenario (S1) all the events that mentioned people trapped in elevators started with a number. Participants noticed this and used this as a differentiating feature to identify events related to people.

"I can immediately tally up the number of people trapped"

-- P1 (whiteboard)

\section{6}

"Because you had numbers in front of them, so my eyes were automatically skimming through to see the numbers"

-- P2 (whiteboard)

\section{6}

"Conveniently all the patients had numbers in front, so I could scan through and see the numbers. It was just something that differentiated, so you could have done that in a colour, you could have done that with a symbol, anything really"

-- P3 (whiteboard)

66

"It is very easy to scroll through and see the numbers"

-- P4 (RescueTime) 


\section{Information}

Participants were asked what pieces of information were easiest and hardest to find in the tool they used. The results can be seen in Table 5.5.

The title and time were almost unanimously seen as the easiest information to find, in both RescueTime and the whiteboard. The "People" result is titles, which began with a number, usually indicating a number of casualties in that event.

Description was seen as the single most difficult piece of information to find on the whiteboard. This is mostly because participants ignored the paper stack, as it was seen as providing little additional information.

Participants generally did not notice the priority field on RescueTime so chose it as the most difficult to locate. In the RescueTime instructions (see section C.11) it was deliberately decided not introduce where the priority was located. An event was a priority event if the title text was italic. The aim was to see if participants noticed italic text, as a sub experiment. It was clear from the results that italic is not a suitable for data differentiation.

\section{Improvements}

Some of the participants noted that they had trouble with recall on RescueTime and specifically suggested 'sticky popups'. They wanted to be able to click on an event dot, and have the information box be remain visible when they moused away from the event dot. There were some variations on the theme, but the only major difference was the inclusion of related events. A few wanted related events to have their information boxes pop up as well, so they did not need to navigate forward and backwards between related events. This had been attempted as an experimental feature, but did not make the final version (see subsection 4.4.5).

Another popular suggestion was to take the listing capabilities from the whiteboard and adapt them to RescueTime, in the form of an overview or task list. The user would then be able to generate an overview, then once 


\begin{tabular}{|l|l|l|l|l|}
\hline Participant & \multicolumn{2}{|c|}{ RescueTime } & \multicolumn{2}{c|}{ Whiteboard } \\
\hline & Easiest & Hardest & Easiest & Hardest \\
\hline P1 & Time & Recall & People & \\
\hline P2 & Group & Description & People & \\
\hline P3 & Title & Priority & People & \\
\hline P4 & Time & Related & Time & Priority \\
\hline P5 & Time & Priority & Title & Description \\
\hline P6 & Time & Title & Time & \\
\hline P7 & Title & Priority & Title & Description \\
\hline P8 & Title & Priority & Time & Description \\
\hline P9 & Title & Priority & Title & Description \\
\hline P10 & Description & Priority & Title & Priority \\
\hline P11 & Title & Priority & Title & Access/Assembly \\
\hline P12 & Related & Priority & Group & Description \\
\hline
\end{tabular}

Table 5.5: Information extraction open questions. Participant's opinions of which pieces of information was the easiest and hardest to extract from each tool. Most related to specific fields of data (time, title, description, priority, group and related events), but some relate to specific titles. The 'people' case is where events in S1 involving people started with a number and therefore were easy to locate. P11 mentions 'Access/Assembly', which is a specific field in the ISPAARE template sheet (see Figure 5.7). 
familiar with its contents, transition to the current timeline view. The list suggestions ranged from a single combined list (no grouping), to separate lists (like the whiteboard layout), to free-form tagging, which would generate category lists based on the tags.

A related suggestion was that of task lists. These lists would allow a user to have lists of resolved and unresolved events. For example in the power outage scenario (S1), all the elevators are cleared at the end of the scenario, so information about who were trapped in elevators is not necessarily as important as other people still injured or trapped.

Although most of the participants panned RescueTime to determine if there were any events out of view, it was suggested that some sort of indicator to show the number of events out of view would be useful. Halo[2] would be an appropriate technique to address this problem.

\subsubsection{Situation reports}

Table 5.6 shows which tool the participants believed they performed better in and the evaluation of their situational reports. Participants were rated, by the evaluator (author of this thesis), as either 'Bad', 'Poor', 'Average', 'Good', or 'Excellent', based on a participants presentation and key factors such as identifying all events involving casualties, actions taken, with a lesser emphasis on informational events, such as building damage. The author was chosen as the evaluator, as they knew the scenarios well, and would maintain the high-level of privacy required under the human ethics approval. Expanded tables of situation reports for each scenario are available in Appendix E.

On the whole most situational reports were good, with most - if not all casualties identified, and a majority of the general damage identified. Some were a little poor, where no casualties were reported.

The accuracy was also in general good; most participants stuck with the information presented and did not mix up events or create new information. There were a few who elaborated new information, which can be good or bad 
depending on your perspective. In S1 two participants added new pieces of information; one introduced the problem of students loosing work on computers, and the other introduced post-event analysis of where improvements to equipment or procedures are needed.

For the most part, participants appeared to perform better using RescueTime, with the exception of $\mathrm{P} 6$. The believed performance rating doesn't seem to have any particular connection to the actual performance. For example P2 and P3 believed they performed better with the whiteboard, but in fact performed better with RescueTime, and P6 believed they performed better with RescueTime, but performed better with the whiteboard.

For the participants, who had one report rated better than the other, there tends to be a trend towards the better being the first exercise (4 vs 1), RescueTime (4 vs 1), and S1 (4 vs 1). One would expect the second exercise to be better than the first, but this does not seem to be the case. The participants performance relative to their believed performance can be seen in Figure 5.11.

Participants more frequently perceived their performance as better using RescueTime, rather than the whiteboard. The results showed that their relative performance was generally equal or higher on RescueTime, which agrees with our hypothesis.

\subsubsection{RescueTime observations}

One matter of interest was to observe how participants navigated through a scenario in generating a situation report. In general participants appeared to have two search phases; exploration of data, and gathering for the report.

The main techniques observed were:

Chronological parallel group scan The participant would search events from left to right, by going up and down between groups as time progressed.

Chronological series group scan The participant would search a whole 


\begin{tabular}{|c|c|c|c|}
\hline Participant & $\begin{array}{l}\text { Believed } \\
\text { performance }\end{array}$ & RescueTime & Whiteboard \\
\hline $\mathrm{P} 1$ & 4 & Good (S2)(1st) & Good (S1) \\
\hline $\mathrm{P} 2$ & 2 & Good (S2)(1st) & Average (S1) \\
\hline $\mathrm{P} 3$ & 2 & Excellent (S2)(1st) & Good (S1) \\
\hline $\mathrm{P} 4$ & 4 & Average (S1) & Average (S2)(1st) \\
\hline $\mathrm{P} 5$ & 4 & Excellent (S1) & Excellent (S2)(1st) \\
\hline $\mathrm{P} 6$ & 3.5 & Poor (S1) & Average (S2)(1st) \\
\hline $\mathrm{P} 7$ & 4 & Average (S1)(1st) & Average (S2) \\
\hline P8 & 2 & Good (S1)(1st) & Good (S2) \\
\hline $\mathrm{P} 9$ & 5 & Excellent (S1)(1st) & Average (S2) \\
\hline $\mathrm{P} 10$ & 4 & Average (S2) & Bad (S1)(1st) \\
\hline $\mathrm{P} 11$ & 5 & Poor (S2) & Poor (S1)(1st) \\
\hline P12 & 2 & Average (S2) & Average (S1)(1st) \\
\hline
\end{tabular}

Table 5.6: Evaluation of situation reports. This shows which tool the participant believed they performed better with and the evaluation of their situational reports for S1 and S2. The situation reports are graded either 'Bad', 'Poor', 'Average', 'Good', or 'Excellent'. The evaluation is based off factors such as identifying all events involving casualties, actions taken, with a lesser emphasis on informational events, such as building damage. The table also notes which scenario was used for the tool, and whether it was the first scenario done by the participant. 


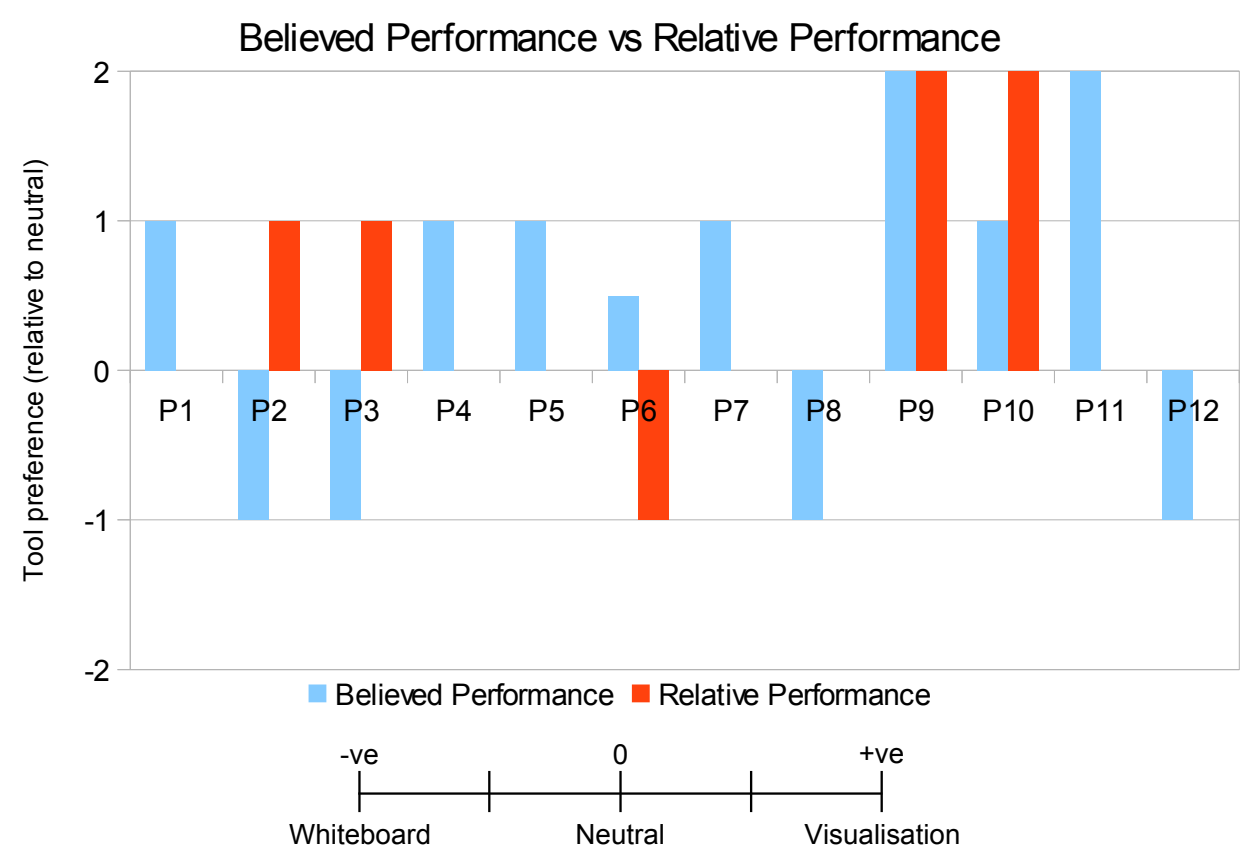

Figure 5.11: Participant believed performance vs relative performance graph. This shows the participant's believed performance from Table 5.6 relative to neutral and compares it against their relative tool performance. The relative tool performance is where the participant performed better in one tool over the other. Where there is no bar the participant was evaluated to perform equally in each tool. 
group from left to right, before moving on to the next group, usually from bottom to top.

Follow related events The participants would follow related events while performing one of the former scan techniques.

Table 5.7 shows the techniques used by the participants. A dash (-) in the exploration search pattern column means the participant did not do any exploration before gathering information for the situation report. Where two scan techniques are presented, that is where the participant changed techniques, with the first being their primary technique and the second being occasionally observed.

There are a few patterns in the result, where the participants fell mainly into three groups:

- Used series based scanning throughout (6/12)

- Used parallel based scanning throughout $(3 / 12)$

- Used parallel for exploration and series for information gathering $(2 / 12)$

One participant did not follow the above patterns, but instead strongly followed related events when exploring, but used series based scanning for information gathering.

The majority (8/12) of participants followed a related event link at some point during their usage, but not many used the feature heavily.

The majority (9/12) also panned RescueTime to check if there were any events outside of the view presented to them for their scenario.

\subsection{Experimental issues}

\subsubsection{Screen colour management}

Colour management between the development computer and evaluation computer was a minor issue. The green on the development computer was bright 


\begin{tabular}{|c|l|l|l|l|}
\hline Participant & $\begin{array}{l}\text { Exploration } \\
\text { search pattern }\end{array}$ & $\begin{array}{l}\text { Gathering } \\
\text { search pattern }\end{array}$ & Pan & Related \\
\hline P1 & Parallel & Series & Y & Y \\
\hline P2 & Series & Series & N & Y \\
\hline P3 & Parallel & Series & N & N \\
\hline P4 & - & Series & Y & N \\
\hline P5 & Related & Series & Y & Y \\
\hline P6 & Parallel/Related & Parallel/Related & Y & Y \\
\hline \hline P7 & Parallel/Series & Parallel & Y & Y \\
\hline P8 & Parallel & Parallel/Series & Y & Y \\
\hline P9 & Series & Series/Related & Y & Y \\
\hline P10 & Series & Series & N & N \\
\hline P11 & Series & Series & Y & Y \\
\hline P12 & - & Series & Y & N \\
\hline
\end{tabular}

Table 5.7: RescueTime information search techniques. This table shows the search patterns used by participants to locate information in RescueTime. Parallel is where the participant searched across the event groups while searching from left to right (progressing forward in time). Series is where the participant searched within an event group before returning to the start and searching the next group. It was also noted whether participants panned the view or followed related events. Note that participants showed a mix of parallel and series searching, but where one was clearly used more it is marked as that. Where both are present, the participant use both equally. Some participants did not explore the scenario before gathering information for their situation report. These are noted with a dash (-). 
and contrasted against the black text, whereas the green on the evaluation computer appeared darker and made it a little harder to read the text. By the time this was noticed it was too late to change the screen settings without effecting the results.

\subsubsection{Inconsistent questioning}

During the progression through the participants it became clear that although the questions were fixed, some explanation was required depending on the participant. This led to prompting, for example, the types of information available in each tool. The problem is that it is possible to introduce bias or suggestions based on the order of information fields provided. An attempt was made to minimise this by changing the order across the participants, but some bias may remain.

\subsubsection{Uncontrolled bias}

Some bias could not be easily eliminated. The evaluator personally knew all the participants, through either the search and rescue team or computer science department at Victoria University. This was partially compounded by the population restrictions from the human ethics approval.

Another possible bias was that the evaluator was present while the participant was performing analysis of the scenario with whatever tool was being used at the time. This may have introduced pressure for the participant to perform better with RescueTime. 


\section{Chapter 6}

\section{Conclusion}

This thesis contributes the development of a timeline based visualisation design for use by emergency managers during a disaster; a proof-of-concept prototype of the design using the Prefuse information visualisation library; and an evaluation of the implementation against both rescue and non-rescue participants.

In analysis, we interviewed emergency managers, and performed a literature search. The result of the interviews was that shift handovers were of concern. Requirements for a visualisation design was then developed based off the interviews and knowledge of the emergency managers.

In design, an information visualisation was designed, with the aim to assist volunteer emergency managers perform shift handovers. The design was based off a traditional timeline, updated to include shift and interactive features. We also presented some alternative designs, and a design for presenting information on a whiteboard (for the purposes of evaluating our tool).

In implementation, the design was implemented using Java and the Prefuse visualisation library. We provided an overview of Prefuse, and described how it was used to implement each feature designed in the previous chapter. We also discussed some of the challenges, limitations and problems encountered during our implementation period. Some of these challenges were; time 
calculations; CPU cost; and popup boxes.

In evaluation, the complete tool, called RescueTime, was evaluated by search and rescue volunteers and university students and alumni. Participants were asked to extract information from two scenarios, one displayed on RescueTime, and one displayed on a whiteboard, and then present a situation report after ten minutes. Participants were then given some questions. Some questions were to grade aspects of their experience with each tool, from one to five. Additionally open questions were asked, where participants could comment about what they liked or disliked about a tool. After both tools had been used, we asked participants to directly compare the tools, with both open and graded questions.

Results, from the evaluation, showed that participants performed just as well on RescueTime as using the whiteboard. They also showed that participants preferred and thought they performed better using RescueTime. Participants had similar likes and dislikes about each tool, as well as similar desires to 'move' a feature from one tool to another. The likes were; the whiteboard overview; related events; spatial event density; and casualty differentiation by number. The dislikes were; the whiteboard paper stack; event descriptions; and event recall. Finally, we inspected how participants used RescueTime to gather information, and identified a few techniques used.

\subsection{Future work}

RescueTime could be extended to include features identified in our interviews and from the results of our evaluations. We also suggest the ability of data entry, which was not requested, but would be needed for realtime usage.

The features to be extended are:

Data entry The ability to add and update data in the visualisation model.

Overview list Create a separate view, which just lists the titles of events, and allows users to transition between the view developed for Rescue- 
Time, and the whiteboard design used in the evaluations.

Pending list Similar to the overview list, a list of events with pending actions that require attention from the user.

Overdue alarms Some sort of alert system to alert users to the fact an action has not been performed or that an upcoming event requires urgent attention.

Another area that should be reinspected was the user evaluations. As stated in the evaluation discussion, the sample size used was fairly small and therefore cannot be used for statistical analysis. Any future evaluations should use a larger sample set. It would also be beneficial if evaluations could be performed during shift handovers.

Further in the future the ability to operate multiple instances of the visualisation, with some sort of networking should also be considered. 


\section{Appendix A}

\section{Glossaries}

\section{Acronyms}

ECS School of Engineering and Computer Science. 44, 61, 134, 136, 142, 144

HEC Human Ethics Committee. 6, 9, 135, 143

MSc Master of Science. 1, 134, 135, 142, 143

NZQA New Zealand Qualifications Authority. 3, 4

UN United Nations. 4

VUW Victoria University of Wellington. 7, 9, 14, 20, 25, 27, 61, 134, 135, 142

W3C World Wide Web Consortium. 41 


\section{Rescue concepts}

AA Assembly Area. An area where rescue personnel assemble went arriving from an offsite location. 64, 108

CCP Casualty Collection Point. An area where injured casualties are picked up from for advanced medical treatment, usually by an ambulance. 108

CDEMG Civil Defence and Emergency Management Group. Regional organisation responsible for organising emergency management before, during, and after an emergency. 108

CIMS Coordinated Incident Management System. New Zealand system for coordinating emergency services attending an emergency. 3, 4

CIMS4 Coordinated Incident Management Team. Emergency Managers who coordinate the response to an emergency. 3, 9, 14, 18, 62, 134

EOC Emergency Operations Center. An area where the CIMS4 team operate. $19,61,64,108$

IMT Incident Management Team. Synonym for CIMS4 team. 7-10, 13-15, $18-20,25,27,38,62,107,135,136$

Incident Controller The person responsible for coordinating and directing rescue efforts for an incident. 3, 9, 10, 14

INSARAG International Search And Rescue Advisory Group. A UN body for defining international search and rescue standards. 4, 17

Intelligence Manager The person who gathers situation information and investigates future possibilities. 3, 9

ISPAARE Introduction, Situation, People/Property, Actions Taken, Access \& Assembly, Resources needed, Ends. An acronym for providing a situation report. 70, 105, 107-109 
Logistics Manager The person responsible for acquiring and handling assets as required. 3

MCDEM Ministry of Civil Defence and Emergency Management. New Zealand agency responsible for emergency management reduction of hazards, readiness of rescue resources, response, and recovery emergency management phases. 108

Operations Manager The person responsible directing personnel to complete tasks. 3

SA Staging Area. Area where rescue personnel can cache and organise their equipment before beginning work. 108

SPF Safe Forward Point. An area which is deemed the last safe location before entering an operations zone. At this point protective equipment must be checked and worn. 64, 108

USAR Urban Search and Rescue. Search and Rescue in an urban context, where buildings and modern infrastructure may be damaged. 4

WEMO Wellington Emergency Management Office. Wellington cities local EOC. 108

\section{Technical concepts}

.net Microsoft .net. A general purpose programming language for creating applications. 43

API Application Programming Interface. A part of a program or library that is designed to be used by other programmers to extend functionality. 44 
AWT Abstract Windowing Toolkit. A Java GUI API. 48

BSD Licence Berkeley Software Distribution Licence. A software licence that allows developers to modify source code developed by another person, without re-releasing their modifications to the public. 44

CSV Comma Separated Values. A plain text data format, where each line in a file is an entry, and each field is separated by a comma (,). 46

Flash Adobe Flash. A graphics platform used primarily on the Internet, for developing interactive graphics. 20, 44

GraphML An XML data format for defining graph structures (nodes and edges). 46

GUI Graphical User Interface. An interface between an application and the user. It commonly creates 'windows' and buttons, which can be interacted with by either keyboard or mouse input. 48, 55, 58

HSB Hue, Saturation, and Brightness. A scheme for defining colours. Hue is a colour value from 0-360 degrees (red-orange-yellow-green-blue-violetred), saturation is the percentage of colour used, and brightness defines how bright the resulting colour is. 28

Java A general purpose programming language for creating applications. $43,44,48,55,57,67$

MVC A structural design pattern for describing how various components of a system interact. 46,57

OO A method of programming that treats collections of data as objects categorised by classes. Objects have properties and can be manipulated through calls to methods. 57 
OS Operating System. A piece of software, which mediates data flow between hardware and applications. 15

Prefuse A Java visualisation library able to create interactive visualisations. 44

SQL Structured Query Language. A language for querying a database for data. 46

Swing A Java GUI API. 48

TreeML An XML data format for defining tree structures. 46 


\section{Appendix B}

\section{Bibliography}

[1] Andrienko, N., And Andrienko, G. Intelligent visualisation and information presentation for civil crisis management. Transactions in GIS 11, 6 (2007), 889.

[2] Baudisch, P., And Rosenholtz, R. Halo: a technique for visualizing off-screen objects. In Proceedings of the SIGCHI conference on Human factors in computing systems (New York, NY, USA, 2003), CHI '03, ACM, pp. 481-488.

[3] British Broadcasting Corporation and AllofUs. British history in depth: British history timeline. Internet (http://www.bbc.co.uk/history/british/launch_tl_british.shtml). Last accessed 2011-05-30.

[4] Chen, C. Information Visualization: Beyond The Horizon, second ed. Springer-Verlag London, 2006.

[5] Collins, C. Docuburst: Radial space-filling visualisation of document content. Technical Report KMDI-TR-2007-1, Knowledge Media Design Institute, University of Toronto, 2007.

[6] Dymon, U. An analysis of emergency map symbology. International Journal of Emergency Management 1, 3 (2003), 227-237. 
[7] Emergency Management Academy of New Zealand (EMANZ). Targeted Incident Planning System (TIPS). Internet (http://www.emanz.ac.nz/pdf/resources/TIPS2_Information_Sheet.pdf). Last accessed 2011-05-30.

[8] Emergency Management Academy of New Zealand (EMANZ). EM222 Applied CIMS, 2007.

[9] Heer, J., Card, S. K., and Landay, J. A. prefuse: a toolkit for interactive information visualization. In Proceedings of the SIGCHI conference on Human factors in computing systems (New York, NY, USA, 2005), CHI '05, ACM, pp. 421-430.

[10] International Search and Rescue Advisory Group. Insarag overview. Internet (http://www.unocha.org/what-we-do/coordinationtools/insarag/overview). Last accessed 2011-06-05.

[11] Liu, L., Hoelscher, U., and Gruchmann, T. Symbol comprehension in different countries: Experience gained from medical device area. In Workshops-Proceedings der 5. fachbergreifenden Konferenz Mensch und Computer. Wien: Oesterreichische Computer Gesellschaft (2005), pp. 81-87.

[12] Morton, J. Color voodoo \#1: A guide to color symbolism. Internet (http://www.dsbn.edu.on.ca/schools/anmss/training module/DRC/Colour Theory/color Symbolism.pdf), 1997. Last accessed 2011-0530 .

[13] New Zealand Fire Service. Usar awareness: Student manual, 2002.

[14] New Zealand Qualifications Authority (NZQA). Demonstrate knowledge of, and provide support at, urban search and rescue operations (unit standard 18516). Internet (http://www.nzqa.govt.nz/nqfdocs/units/pdf/18516.pdf). Last accessed 2011-06-05. 
[15] New Zealand Qualifications Authority (NZQA). Demonstrate knowledge of the coordinated incident management system (cims) (unit standard 17279). Internet (http://www.nzqa.govt.nz/nqfdocs/units/pdf/17279.pdf). Last accessed 2011-06-05.

[16] New Zealand Qualifications Authority (NZQA). Describe the roles and functions of a cims incident management team (imt) at an incident (unit standard 22445). Internet (http://www.nzqa.govt.nz/nqfdocs/units/pdf/22445.pdf). Last accessed 2011-06-05.

[17] New Zealand Qualifications Authority (NZQA). Rescue casualties using rescue techniques (unit standard 10618). Internet (http://www.nzqa.govt.nz/nqfdocs/units/pdf/10618.pdf). Last accessed 2011-06-05.

[18] Patterson, E., Roth, E., Woods, D., Chow, R., And Gomes, J. Handoff strategies in settings with high consequences for failure: lessons for health care operations. International Journal for Quality in Health Care 16, 2 (2004), 125-132.

[19] Prefuse package diagram. Internet (http://prefuse.org/doc/manual/introduction/structure/package_guide_full.gif). Last accessed 2011-0321.

[20] Prefuse pipeline model diagram. Internet (http://prefuse.org/doc/manual/introduction/structure/reference_model.gif). Last accessed 2011-01-07.

[21] Tang, C., And Carpendale, S. An observational study on information flow during nurses' shift change. In Proceedings of the SIGCHI conference on Human factors in computing systems (2007), ACM, pp. 219-228. 
[22] Web Accessibility Consortium. Contrast analyser. Internet (http://www.paciellogroup.com/resources/contrast-analyser.html), 12 2008. Last accessed 2011-05-30.

[23] Yi, J., AH Kang, Y., Stasko, J., And JaCko, J. Toward a deeper understanding of the role of interaction in information visualization. Visualization and Computer Graphics, IEEE Transactions on 13, 6 (2007), 1224-1231. 


\section{Appendix C}

\section{Evaluation protocol}

\section{C.1 Room setup}

- Blinds down

- Desk for computer facing Optiportal screens

- Whiteboard facing away from door

\section{C.2 Greeting participant}

Hi [participant], thank you for taking the time to do this usability evaluation for me. Before we start I need to give you a description of what we are doing today, and have you fill out some paper work; which basically says you understand what we are interested in and that you consent to us collecting information.

For my Masters of Science in Computer Science I am investigating how Interactive Information Visualisations can assist emergency workers. Just to give a little background, Information Visualisations are like scatter plot or pie graphs - they help humans better understand raw numbers and data by representing them visually. 
In the past if you wanted to change an Information Visualisation you had to redraw it yourself, but with the advent of computers, you can redraw the visualisation to focus on a particular part of the data almost instantly.

For this evaluation I have created a timeline-based visualisation and two scenarios, so that I can simulate a shift-changeover between emergency managers. One scenario will have the information on the computer and the other on the whiteboard. What I want you to do is use each tool and try and learn as much as you can about the scenario in no more than 10 minutes. Afterwards I will get you to do a debrief and answer some questions about the scenario and the tool you used.

To help me identify the problems in my visualisation tool, I will be recording both audio and video; video recording will record both the computer screen and your facial expressions and just the whiteboard when it is used.

Do you have any questions? Could I get you to read and fill out those consent forms?

\section{C.3 Thanking participant}

Thank you again [participant] for taking the time to do my usability evaluation. 


\section{C.4 First round of questions}

Participant ID:

- How confident are you in remembering most of the events (but not necessarily the details)? [1-5]

- How confident are you in remembering the details of the events? [1-5]

- How useful was the [tool] you used? [1-5]

- What things did you like about the [tool] you used?

- What things did you not like about the [tool] you used?

- What information was the hardest to find in the [tool]?

- What information was the easiest to find in the [tool]?

- Where would you like to see improvement in the [tool]?

\section{C.5 Scenario specific questions}

Introduction, Situation, People/Property, Actions Taken, Access \& Assembly, Resources needed, Ends (ISPAARE) 


\section{C.6 Second round of questions}

- How confident are you in remembering most of the events (but not necessarily the details)? [1-5]

- How confident are you in remembering the details of the events? [1-5]

- Do you think you could recall many details without referencing the [tool]? [1-5]

- How useful was the [tool] you used? [1-5]

- What things did you like about the [tool] you used?

- What things did you not like about the [tool] you used?

- What information was the hardest to find in the [tool]?

- What information was the easiest to find in the [tool]?

- Where would you like to see improvement in the [tool]?

\section{C.7 Comparison of tools}

- Which tool was easier to find information in? [1-5]

- Which tool provided the quickest overview? [1-5]

- Which tool do you prefer overall? [1-5]

- Which tool do you think you performed better with? [1-5] 


\section{C.8 Instructions}

You are a member of an Incident Management Team (IMT) who is about to do a handover to another shift. All the information you have is either on the whiteboard and paper or on an information visualisation. The purpose of doing a handover is to identify how much information you can extract from the tool you have used.

I want you to spend 10 minutes looking at your data source and memorising the most important parts. Then I will get you to do a handover using the ISPAARE format (see acronyms sheet). 


\section{C.9 Acronyms}

- Assembly Area (AA)

- Casualty Collection Point (CCP)

- Civil Defence and Emergency Management Group (CDEMG)

- Emergency Operations Center (EOC)

- Introduction, Situation, People/Property, Actions Taken, Access \& Assembly, Resources needed, Ends (ISPAARE)

- Ministry of Civil Defence and Emergency Management (MCDEM)

- Staging Area (SA)

- Safe Forward Point (SFP)

- Wellington Emergency Management Office (WEMO) 


\section{C.10 Checklist}

1. Acronyms sheet

2. Consent sheet

3. ISPAARE sheet

4. Information sheet

5. Instructions sheet

6. Introduction sheet

7. Question sheet

8. Tape record sheet 


\section{C.11 Introduction to the visualisation}

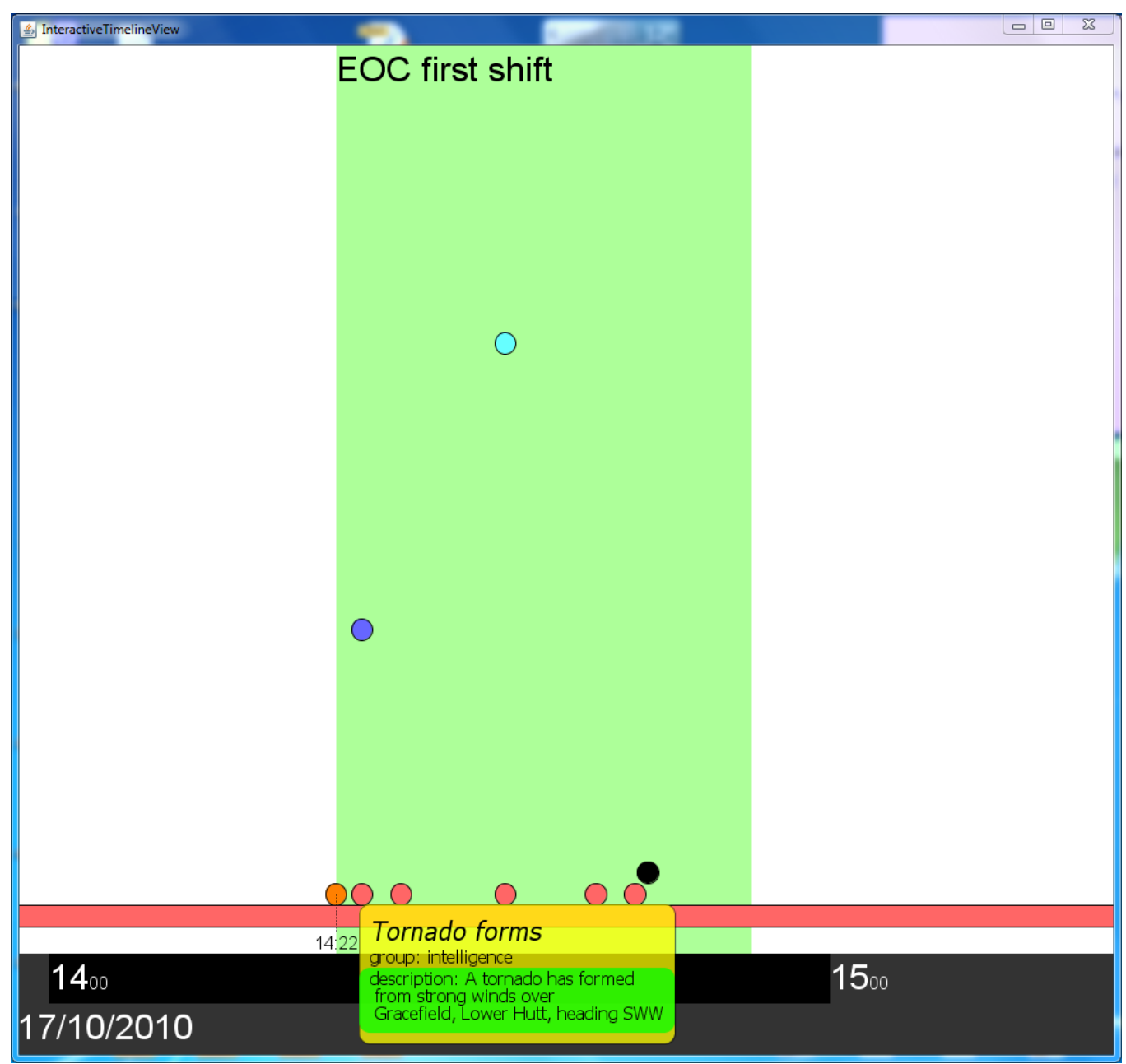

The visualisation you are about to use is interactive and responds to mouse movement. It is organised in a linear time fashion on the $\mathrm{x}$ axis, with the time progression going from left to right; that is the left is towards the past and the right is towards the future.

The y axis is used for grouping common data elements together, so that all data elements in the same group - such as 'intelligence' - are kept in a similar $y$ axis location. Some elements stack on top of each other; this is because they would overlap each other and we are avoiding that by stacking them. 
When you hover over a data element you get a pop up box telling you the title of event, the group it is part of, and a description about the event. The time of the event is represented by a line going down from the data element to the timeline below. Additionally the colours of some data elements may change; the currently selected data element changes to orange, and related data elements change to black.

You can move the visualisation to the left or right by holding down the left mouse button and dragging it to the left or right.

Have a play with the visualisation until you are comfortable. 


\section{Appendix D}

\section{Evaluation data}

\section{D.1 Scenario One: Electricity service disrup- tion}

\begin{tabular}{|c|c|c|}
\hline Time & Group & Title \\
\hline $1520-1530$ & era & Information gathering \\
\hline $1531-1640$ & era & Response \\
\hline 0735-1913 & intelligence & $\begin{array}{l}\text { Daylight hours - } \\
\text { Daylight hours for the 1st April } 2010 \text { from } \\
\text { the MetService }\end{array}$ \\
\hline $1520-1628$ & intelligence & $\begin{array}{l}\text { Electricity service disruption - } \\
\text { Region-wide electricity service outage. }\end{array}$ \\
\hline $1524-1650$ & operations & EOC first shift \\
\hline 1522 & intelligence & $\begin{array}{l}\text { Electricity outage at Kelburn, Pipitea, and } \\
\text { Te Aro campuses - } \\
\text { Kelburn, Pipitea, and Te Aro campuses lost } \\
\text { electricity services at } 1522 \text {. Karori campus } \\
\text { was unaffected. }\end{array}$ \\
\hline 1524 & operations & EOC activated \\
\hline
\end{tabular}




\begin{tabular}{|c|c|c|}
\hline Time & Group & Title \\
\hline 1525 & intelligence & $\begin{array}{l}\text { Transpower confirm region-wide electricity } \\
\text { outage - } \\
\text { Transpower have confirmed an unexpected } \\
\text { region-wide electricity outage, with a fault } \\
\text { that appears to originate from the Wilton } \\
\text { substation }\end{array}$ \\
\hline 1526 & intelligence & 1 person trapped in the Laby elevator \\
\hline 1526 & intelligence & $\begin{array}{l}\text { Laby chemistry lab evacuated due to danger- } \\
\text { ous gases - } \\
\text { Fume cupboards in the Laby Chemistry lab } \\
\text { stopped operating at the time power outage. } \\
\text { The lab was evacuated but not confirmed as } \\
\text { cleared. }\end{array}$ \\
\hline 1527 & intelligence & 6 people trapped in New Kirk elevators \\
\hline 1527 & intelligence & $\begin{array}{l}1 \text { person incapacitated in Laby chemistry lab } \\
\text { - } \\
\text { The Laby Chemistry lab technician has con- } \\
\text { firmed one student did not evacuate and has } \\
\text { been incapacitated by the fumes. }\end{array}$ \\
\hline 1527 & intelligence & $\begin{array}{l}\text { Laby emergency generator failed to start - } \\
\text { The Laby emergency generator failing to } \\
\text { start seems to be the cause for the Laby } \\
\text { Chemistry lab's fume cupboard stopping. }\end{array}$ \\
\hline 1527 & intelligence & $\begin{array}{l}\text { Reports of security doors being in lock-down } \\
\text { mode - } \\
\text { Campus care have been getting reports that } \\
\text { some magnetic security doors are locked and } \\
\text { will not open via the push buttons. }\end{array}$ \\
\hline
\end{tabular}




\begin{tabular}{|c|c|c|}
\hline Time & Group & Title \\
\hline 1528 & operations & $\begin{array}{l}\text { Request HazChem support from Fire Service } \\
\text { The EOC has made a call to the Fire Service } \\
\text { (via 111) for HazChem support for the Laby } \\
\text { Chemistry lab contamination. }\end{array}$ \\
\hline 1528 & logistics & Activate Victoria Rescue \\
\hline 1528 & operations & $\begin{array}{l}\text { Victoria Rescue dispatched to Laby chem- } \\
\text { istry lab - } \\
\text { Victoria Rescue have been dispatched to the } \\
\text { Laby Chemistry lab to extract the incapac- } \\
\text { itated casualty for advanced medical treat- } \\
\text { ment. }\end{array}$ \\
\hline 1528 & intelligence & 1 person trapped in a Von Zedlitz elevator \\
\hline 1529 & intelligence & 2 people trapped in a Cotton elevator \\
\hline 1529 & operations & $\begin{array}{l}\text { Excel dispatched to examine Laby generator } \\
\text { and campus elevators - } \\
\text { Excel have been dispatched to manually ex- } \\
\text { tract people trapped in elevators across the } \\
\text { campus, as well as determine why the Laby } \\
\text { emergency generator did not start. }\end{array}$ \\
\hline 1529 & operations & $\begin{array}{l}\text { Ambulance dispatched for Laby chemistry } \\
\text { victim - } \\
\text { The EOC has advised Wellington Free Am- } \\
\text { bulance of the Laby Chemistry lab victim }\end{array}$ \\
\hline 1530 & intelligence & 8 people trapped in Rankine Brown elevator \\
\hline 1530 & intelligence & $\begin{array}{l}\text { Emergency services overloaded - } \\
\text { Large volumes of calls to emergency services } \\
\text { has reduced their response times, and lim- } \\
\text { ited them to high-priority emergencies (life- } \\
\text { or-death). }\end{array}$ \\
\hline
\end{tabular}




\begin{tabular}{|c|c|c|}
\hline Time & Group & Title \\
\hline 1530 & intelligence & $\begin{array}{l}\text { Fire Service delayed - } \\
\text { Traffic chaos in Wellington has delayed the } \\
\text { Fire Service from attending the Laby Chem- } \\
\text { istry lab HazMat situation. }\end{array}$ \\
\hline 1530 & operations & $\begin{array}{l}\text { Campus care dispatched to secure elevators } \\
- \\
\text { Campus care have been dispatched to locate } \\
\text { the floor position of each elevator on cam- } \\
\text { pus and ensure constant contact with those } \\
\text { trapped inside. }\end{array}$ \\
\hline 1531 & intelligence & 1 person trapped in a Murphy elevator \\
\hline 1532 & intelligence & $\begin{array}{l}1 \text { person trapped in a Rutherford House ele- } \\
\text { vator }\end{array}$ \\
\hline 1532 & intelligence & $\begin{array}{l}\text { Metservice weather report - } \\
\text { Metservice report "Fine spells. Warm } \\
\text { northerlies increasing.", valid until } 2000 \\
\text { tonight }\end{array}$ \\
\hline 1534 & intelligence & $\begin{array}{l}\text { Various automatic doors blocked - } \\
\text { Electronic automatic sliding doors blocked } \\
\text { due to power outage. All doors have alter- } \\
\text { native routes. }\end{array}$ \\
\hline 1535 & intelligence & $\begin{array}{l}\text { Public transport services disrupted - } \\
\text { Public transport heavily affected by electri- } \\
\text { cal outage; traffic signals out; trolley buses } \\
\text { stopped; trains stopped. }\end{array}$ \\
\hline 1535 & intelligence & $\begin{array}{l}\text { Security doors unlock - } \\
\text { Non-critical magnetic security doors have } \\
\text { now opened automatically. Critical magnetic } \\
\text { security doors now push-button exit only. }\end{array}$ \\
\hline
\end{tabular}




\begin{tabular}{|c|c|c|}
\hline Time & Group & Title \\
\hline 1535 & operations & $\begin{array}{l}\text { Victoria Rescue extract Laby chemistry lab } \\
\text { victim - } \\
\text { Victoria Rescue HazMat and medics extract } \\
\text { Laby Chemistry lab casualty and prepare for } \\
\text { transport by Wellington Free Ambulance }\end{array}$ \\
\hline 1537 & operations & $\begin{array}{l}\text { Wellington Free Ambulance transport Laby } \\
\text { chemistry lab victim to Wellington Hospital } \\
\text { Emergency Department }\end{array}$ \\
\hline 1540 & intelligence & $\begin{array}{l}\text { Aquaheat contractor injured in Cotton tun- } \\
\text { nels - } \\
\text { An Aquaheat contractor tripped in the dark } \\
\text { Cotton tunnels after the electrical service } \\
\text { outage and suffered a broken leg. }\end{array}$ \\
\hline 1541 & operations & $\begin{array}{l}\text { Victoria Rescue dispatched to extract Aqua- } \\
\text { heat contractor }\end{array}$ \\
\hline 1542 & intelligence & $\begin{array}{l}\text { Excel advises to switch off electrical equip- } \\
\text { ment - } \\
\text { Excel has advised the university to switch off } \\
\text { any electrically sensitive equipment, due to } \\
\text { the likely surge when electricity services are } \\
\text { restored. }\end{array}$ \\
\hline 1550 & operations & $\begin{array}{l}\text { Excel start Laby generator - } \\
\text { Excel report the Laby generator's auto-start } \\
\text { mechanism was faulty. The generator has } \\
\text { been manually started. }\end{array}$ \\
\hline 1557 & operations & $\begin{array}{l}\text { Laby chemistry lab vented of dangerous gases } \\
\text { - } \\
\text { The air extraction systems in the Laby } \\
\text { Chemistry lab, now with power, have vented } \\
\text { the lab of dangerous gases. }\end{array}$ \\
\hline
\end{tabular}




\begin{tabular}{|c|c|c|}
\hline Time & Group & Title \\
\hline 1601 & intelligence & $\begin{array}{l}\text { Some staff have stopped work - } \\
\text { With the proximity to the end of the working } \\
\text { day and no indication of when electricity will } \\
\text { be restored have started to head home. }\end{array}$ \\
\hline 1602 & operations & Laby elevator cleared \\
\hline 1605 & operations & $\begin{array}{l}\text { All electrically sensitive equipment switched } \\
\text { off - } \\
\text { Building wardens report all electrically sen- } \\
\text { sitive equipment has been switched off }\end{array}$ \\
\hline 1610 & operations & $\begin{array}{l}\text { Aquaheat contractor extracted to Student } \\
\text { Health - } \\
\text { Victoria Rescue have extracted the Aquaheat } \\
\text { contractor to Student Health for treatment } \\
\text { for a broken leg. }\end{array}$ \\
\hline 1619 & operations & Cotton elevator cleared \\
\hline 1620 & intelligence & $\begin{array}{l}\text { Transpower advises that electricity should } \\
\text { restored at about } 1630\end{array}$ \\
\hline 1628 & intelligence & $\begin{array}{l}\text { Electricity services restored at Kelburn, Pip- } \\
\text { itea, and Te Aro campuses }\end{array}$ \\
\hline 1630 & intelligence & $\begin{array}{l}\text { All elevators have returned to normal func- } \\
\text { tion - } \\
\text { All elevators have 'rebooted' and returned to } \\
\text { their home floor. }\end{array}$ \\
\hline 1635 & operations & $\begin{array}{l}\text { Electrical equipment gradually being turned } \\
\text { on }\end{array}$ \\
\hline 1636 & operations & $\begin{array}{l}\text { All elevators confirmed as cleared - } \\
\text { Campus care have confirmed all elevators } \\
\text { have been cleared and people trapped are } \\
\text { fine. }\end{array}$ \\
\hline 1637 & intelligence & Public transport services returning to normal \\
\hline
\end{tabular}




\begin{tabular}{|r|l|l|}
\hline Time & Group & Title \\
\hline 1638 & intelligence & $\begin{array}{l}\text { Laboratory equipment left on - } \\
\text { Some chemistry lab equipment left on at } \\
\text { the time of the electricity outage was not } \\
\text { switched off. A lab technician noticed them } \\
\text { on and has turned the equipment off. }\end{array}$ \\
\hline 1650 & operations & EOC deactivated \\
\hline
\end{tabular}

Table D.1: Scenario One: Electricity Service Disruption

\section{D.2 Scenario Two: Earthquake}

\begin{tabular}{|r|l|l|}
\hline Time & Group & Title \\
\hline $1200-1459$ & era & Reconnaissance \\
\hline $1500-1529$ & era & Elimination of utilities \\
\hline $1530-$ & era & Primary surface search \\
\hline $1134-1759$ & logistics & Victoria Rescue first shift \\
\hline $1157-2359$ & logistics & VUW EOC first shift \\
\hline $1800-2359$ & logistics & Victoria Rescue second shift \\
\hline $0000-0559$ & logistics & Victoria Rescue third shift \\
\hline $0000-$ & logistics & VUW EOC second shift \\
\hline $0735-1913$ & intelligence & $\begin{array}{l}\text { Daylight hours - } \\
\text { Daylight hours for the } 1 \text { st April 2010 from } \\
\text { the MetService }\end{array}$ \\
\hline 1117 & intelligence & $\begin{array}{l}7.8 \text { Earthquake - } \\
\text { Richter 7.8, depth 30km, 2km off south coast }\end{array}$ \\
\hline 1123 & operations & Victoria Rescue activated \\
\hline 1336 & intelligence & $\begin{array}{l}\text { 6.7 Aftershock - } \\
\text { Richter 6.7, depth 20km, Karori Reservoir } \\
\text { Catchment Area }\end{array}$ \\
\hline 1337 & intelligence & Overbridge collapses \\
\hline &
\end{tabular}




\begin{tabular}{|c|c|c|}
\hline Time & Group & Title \\
\hline 1742 & intelligence & $\begin{array}{l}7.2 \text { Aftershock - } \\
\text { Richter } 7.2 \text {, depth } 25 \mathrm{~km} \text {, Kaiwharawhara }\end{array}$ \\
\hline 2120 & intelligence & $\begin{array}{l}5.3 \text { Aftershock - } \\
\text { Richter 5.3, depth } 15 \mathrm{~km} \text {, Hutt Road }\end{array}$ \\
\hline 2332 & intelligence & $\begin{array}{l}5.5 \text { Aftershock - } \\
\text { Richter } 5.5 \text {, depth } 20 \mathrm{~km} \text {, Taita Gorge }\end{array}$ \\
\hline 1118 & intelligence & $\begin{array}{l}\text { Landslip blocks McKenzie Terrace - } \\
\text { A landslip has completely blocked the } \\
\text { McKenzie Terrace road. This means there } \\
\text { is no vehicle access to Waiteata Road and } \\
\text { Boyd-Wilson park. }\end{array}$ \\
\hline 1118 & intelligence & $\begin{array}{l}\text { Severe damaged to Glasgow Street retaining } \\
\text { wall - } \\
\text { The retaining wall holding up Glasgow Street } \\
\text { above the Marae has taken severe damage. } \\
\text { Victoria University has been advised that } \\
\text { Glasgow Street has been reduced to one lane } \\
\text { for light vehicles and pedestrians only. Heavy } \\
\text { vehicles will need to use Kelburn Parade and } \\
\text { St Michaels Crescent for access to Kelburn } \\
\text { village. }\end{array}$ \\
\hline 1222 & intelligence & $\begin{array}{l}\text { Robert Stout on fire - } \\
\text { The windows on the second floor have blown } \\
\text { out and flames are pouring out. The building } \\
\text { was previously evacuated. }\end{array}$ \\
\hline 1337 & intelligence & $\begin{array}{l}\text { Airport and seaport severely damaged - } \\
\text { The aftershock has caused further damage to } \\
\text { both the airport and seaport, both of which } \\
\text { have closed operations to assess their viabil- } \\
\text { ity for emergency usage. }\end{array}$ \\
\hline
\end{tabular}




\begin{tabular}{|c|c|c|}
\hline Time & Group & Title \\
\hline 1337 & intelligence & $\begin{array}{l}\text { Landslip blocks Salamanca Road - } \\
\text { The cliff on Salamanca Road across from the } \\
\text { netball court has collapsed over the road. No } \\
\text { vehicles may pass, but can be easily cleared } \\
\text { (30-40 worker hours). }\end{array}$ \\
\hline 1352 & intelligence & $\begin{array}{l}\text { Landslips on major road routes - } \\
\text { The aftershock has caused already unstable } \\
\text { rocks to fall on major arterial routes (SH1, } \\
\text { SH2, SH58, Rimutaka incline) reducing their } \\
\text { throughput. }\end{array}$ \\
\hline 1751 & intelligence & $\begin{array}{l}14 \text { Kelburn Parade on fire - } \\
\text { The Victoria Careers Development and Em- } \\
\text { ployment building on Kelburn parade has } \\
\text { caught fire. }\end{array}$ \\
\hline 1752 & intelligence & $\begin{array}{l}\text { Cotton/Laby tunnel system flooding - } \\
\text { Some burst piping in the Cotton/Laby tun- } \\
\text { nel system is slowly flooding the tunnels. } \\
\text { The flooding should not rise above the an- } \\
\text { kle due to no water being supplied by the } \\
\text { regional services. }\end{array}$ \\
\hline 2127 & intelligence & $\begin{array}{l}44 \text { Kelburn Parade on fire - } \\
\text { The Media Studies building is on fire. }\end{array}$ \\
\hline 2355 & intelligence & $\begin{array}{l}\text { Student union on fire- } \\
\text { A fire broke out in the coffee shop on the top } \\
\text { level of the Student Union building. With no } \\
\text { one to control the fire and the fire sprinklers } \\
\text { without water, it has spread out of control. }\end{array}$ \\
\hline 1157 & operations & VUW EOC activated \\
\hline 1145 & logistics & Assembly area setup in staff carpark \\
\hline 1152 & logistics & Safe forward point setup at EOC \\
\hline
\end{tabular}




\begin{tabular}{|c|c|c|}
\hline Time & Group & Title \\
\hline 1243 & logistics & Triage point setup in Recreation Centre \\
\hline 1252 & logistics & Triage point setup in Cotton carpark \\
\hline 1302 & logistics & Helipad setup in CSB carpark \\
\hline 1314 & logistics & $\begin{array}{l}\text { Casualty collection point setup on Mount } \\
\text { Street }\end{array}$ \\
\hline 1642 & logistics & $\begin{array}{l}\text { Rescue personnel rest area setup at } 77 \text { Fairlie } \\
\text { Terrace }\end{array}$ \\
\hline 1120 & intelligence & Electricity services intermittently disrupted \\
\hline 1132 & intelligence & Water services severed \\
\hline 1137 & intelligence & $\begin{array}{l}\text { Gas 'substation' explodes (Kelburn Parade) } \\
- \\
\text { "65" Kelburn Parade's gas substation was } \\
\text { severely damaged in the earthquake. Com- } \\
\text { bined with pressure changes within the gas } \\
\text { network has caused this substation to ex- } \\
\text { plode. The nearby bush has caught fire and } \\
\text { there is a continuous flame shooting up from } \\
\text { where the substation was. }\end{array}$ \\
\hline 1504 & operations & $\begin{array}{l}\text { Water services isolated - } \\
\text { Victoria Rescue have isolated all water ser- } \\
\text { vices to Kelburn campus }\end{array}$ \\
\hline 1508 & operations & $\begin{array}{l}\text { Gas services isolated - } \\
\text { Victoria Rescue have isolated all gas services } \\
\text { to Kelburn campus }\end{array}$ \\
\hline 1512 & operations & $\begin{array}{l}\text { Electricity services isolated (with exceptions) } \\
\text { Victoria Rescue have isolated electricity ser- } \\
\text { vices to Kelburn campus, except for some } \\
\text { charging stations which will use what is avail- } \\
\text { able from the national grid. }\end{array}$ \\
\hline
\end{tabular}




\begin{tabular}{|c|c|c|}
\hline Time & Group & Title \\
\hline 1643 & operations & $\begin{array}{l}\text { Water being distributed from Kirk reservoir } \\
\text { Victoria Rescue have setup and Campus } \\
\text { Care are operating the water distribution } \\
\text { system from the Kirk water reservoir }\end{array}$ \\
\hline 1209 & intelligence & Cotton 'split' at base isolation plates \\
\hline 1232 & intelligence & $\begin{array}{l}\text { Half meter rupture between Quad and Rank- } \\
\text { ine Brown }\end{array}$ \\
\hline 1241 & intelligence & Robert Stout deemed structurally unsafe \\
\hline 1245 & intelligence & Kirk to Hunter over bridge unstable \\
\hline 1255 & intelligence & Shattered glass in Kirk Wing courtyard \\
\hline 1257 & intelligence & $\begin{array}{l}\text { Easterfield to Kirk over bridge appears sta- } \\
\text { ble, but requires inspection }\end{array}$ \\
\hline 1307 & intelligence & Old Kirk partially collapsed \\
\hline 1339 & intelligence & Kirk 'level 2' pancaked \\
\hline 1540 & operations & $\begin{array}{l}\text { McLauren lecture theatres casualties - } \\
\text { Victoria Rescue has made access to } \\
\text { MCLT101, MCLT102(cleared), and } \\
\text { MCLT103(cleared). MCLT101 had } 32 \\
\text { uninjured people, } 8 \text { with broken bones, } \\
\text { and } 2 \text { with major injuries. All have been } \\
\text { transported to the Cotton car park triage } \\
\text { point. }\end{array}$ \\
\hline 1645 & operations & $\begin{array}{l}\text { Kirk lecture theatres casualties - } \\
10 \text { people were trapped in KKLT303. } 9 \text { were } \\
\text { uninjured, but } 1 \text { was starting to have dia- } \\
\text { betic issues. All have been transported to } \\
\text { the Recreation Centre triage point. }\end{array}$ \\
\hline
\end{tabular}




\begin{tabular}{|c|c|c|}
\hline Time & Group & Title \\
\hline 1826 & operations & $\begin{array}{l}\text { Hunter lecture theatres casualties - } \\
6 \text { people were trapped in HULT???. All in- } \\
\text { juries were minor. All have been transported } \\
\text { to the Recreation Centre triage point. }\end{array}$ \\
\hline 1221 & intelligence & $\begin{array}{l}\text { McLauren } 101- \\
42 \text { people are trapped in MCLT101. The in- } \\
\text { juries reported are mostly minor }\end{array}$ \\
\hline 1247 & intelligence & $\begin{array}{l}\text { Kirk } 303 ?- \\
10 \text { people are trapped in KKLT303. The in- } \\
\text { juries reported are all minor. }\end{array}$ \\
\hline 1252 & intelligence & $\begin{array}{l}\text { Hunter - } \\
\text { An unknown number of people are trapped } \\
\text { in HULT???. No further information is avail- } \\
\text { able. }\end{array}$ \\
\hline 1120 & intelligence & $\begin{array}{l}\text { Wellington CDEMG declares Civil Defence } \\
\text { Emergency }\end{array}$ \\
\hline 1130 & logistics & WEMO activates NZ-RT7 \\
\hline 1200 & intelligence & $\begin{array}{l}\text { Metservice forecast - } \\
\text { Fine with light northerlies dying down } \\
\text { overnight. }\end{array}$ \\
\hline 1340 & logistics & $\begin{array}{l}\text { CDEM casualty registration team arrives at } \\
\text { triage and casualty collection points. }\end{array}$ \\
\hline 1400 & logistics & $\begin{array}{l}\text { Region-based army territorials activated - } \\
\text { Region-based army territorials activated, } \\
\text { which may be utilised via requests to } \\
\text { WEMO. }\end{array}$ \\
\hline
\end{tabular}




\begin{tabular}{|r|l|l|}
\hline Time & Group & Title \\
\hline 1500 & logistics & $\begin{array}{l}\text { CDEM setting up a welfare camp on Kelburn } \\
\text { field - } \\
\text { A Civil Defence welfare camp has been setup } \\
\text { on Kelburn field. Any uninjured people } \\
\text { should be directed there. }\end{array}$ \\
\hline 1600 & intelligence & $\begin{array}{l}\text { NZ-TF1 arrives in region - } \\
\text { USAR NZ-TF1 has arrived in the region. A } \\
\text { representative has made contact with Victo- } \\
\text { ria University. }\end{array}$ \\
\hline 1700 & logistics & CDEM set up morgue on Boyd-Wilson field \\
\hline 2100 & intelligence & $\begin{array}{l}\text { NZ-TF2 arrives in region - } \\
\text { USAR NZ-TF2 has arrived in the region. A } \\
\text { representative has made contact with Victo- } \\
\text { ria University. }\end{array}$ \\
\hline
\end{tabular}

Table D.2: Scenario Two: Earthquake 
Appendix E

\section{Evaluation results}




\begin{tabular}{|c|c|c|c|c|c|c|c|c|c|c|}
\hline \multirow[t]{2}{*}{ Participant } & \multicolumn{2}{|c|}{$\begin{array}{l}\text { Q1: } \\
\text { Overview }\end{array}$} & \multicolumn{2}{|c|}{$\begin{array}{l}\text { Q2: } \\
\text { Details }\end{array}$} & \multicolumn{2}{|c|}{$\begin{array}{l}\text { Q3: } \\
\text { Useful- } \\
\text { ness }\end{array}$} & \multirow[t]{2}{*}{$\begin{array}{l}\text { Q9: } \\
\text { Easier } \\
\text { tool }\end{array}$} & \multirow[t]{2}{*}{$\begin{array}{l}\text { Q10: } \\
\text { Quickest } \\
\text { overview }\end{array}$} & \multirow[t]{2}{*}{$\begin{array}{l}\text { Q11: } \\
\text { Best } \\
\text { overall }\end{array}$} & \multirow[t]{2}{*}{$\begin{array}{l}\text { Q12: } \\
\text { Best per- } \\
\text { formance }\end{array}$} \\
\hline & $\mathrm{V}$ & $\mathrm{W}$ & $\mathrm{V}$ & $\mathrm{W}$ & $\mathrm{V}$ & $\mathrm{W}$ & & & & \\
\hline $\mathrm{P} 1$ & 4 & 4 & 3 & 2 & 4 & 4 & 2 & 2 & 3 & 4 \\
\hline $\mathrm{P} 2$ & 4 & 4 & 2 & 3 & 5 & 4 & 3 & 1 & 4 & 2 \\
\hline P3 & 2.5 & 4 & 2 & 1 & 3.5 & 4 & 2 & 3 & 2 & 2 \\
\hline $\mathrm{P} 4$ & 4 & 3 & 3.5 & 1 & 3.5 & 2 & 3 & 3 & 4 & 4 \\
\hline $\mathrm{P} 5$ & 3.5 & 2.5 & 2.5 & 1.5 & 4 & 2.5 & 5 & 2 & 4 & 4 \\
\hline $\mathrm{P} 6$ & 3 & 3 & 3 & 2 & 3 & 4 & 2 & 1 & 2 & 3.5 \\
\hline Rescue Mean & 3.5 & 3.42 & 2.67 & 1.75 & 3.83 & 3.42 & 2.83 & 2 & 3.17 & 3.25 \\
\hline $\mathrm{P} 7$ & 3 & 4 & 3 & 1 & 2 & 4 & 5 & 2 & 5 & 4 \\
\hline P8 & 4 & 5 & 2 & 2 & 4 & 3 & 4 & 1 & 4 & 2 \\
\hline P9 & 5 & 2 & 3 & 1 & 4 & 2 & 4 & 2 & 5 & 5 \\
\hline P10 & 3 & 4 & 4 & 2.5 & 4 & 4 & 2 & 4 & 1 & 4 \\
\hline P11 & 4 & 2 & 1 & 1 & 4 & 3 & 5 & 5 & 5 & 5 \\
\hline $\mathrm{P} 12$ & 3 & 3 & 3 & 2 & 4 & 2 & 5 & 5 & 5 & 2 \\
\hline Non-Rescue Mean & 3.67 & 3.33 & 2.67 & 1.58 & 3.67 & 3 & 4.17 & 3.17 & 4.17 & 3.67 \\
\hline \multirow[t]{2}{*}{ Overall Mean } & 3.58 & 3.38 & 2.67 & 1.67 & 3.75 & 3.21 & 3.5 & 2.58 & 3.67 & 3.46 \\
\hline & Wor & & $\mathrm{Net}$ & & & est & & & & 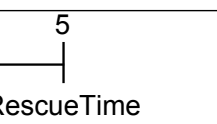 \\
\hline
\end{tabular}

Table E.1: Graded questions complete table 


\begin{tabular}{|c|c|c|c|c|c|c|}
\hline \multirow[t]{2}{*}{ Participant } & \multicolumn{2}{|c|}{$\begin{array}{l}\text { Q1: } \\
\text { Overview }\end{array}$} & \multicolumn{2}{|c|}{$\begin{array}{l}\text { Q2: } \\
\text { Details }\end{array}$} & \multicolumn{2}{|c|}{$\begin{array}{l}\text { Q3: } \\
\text { Useful- } \\
\text { ness }\end{array}$} \\
\hline & S1 & S2 & S1 & S2 & S1 & S2 \\
\hline $\mathrm{P} 1$ & 4 & 4 & 2 & 3 & 4 & 4 \\
\hline $\mathrm{P} 2$ & 4 & 4 & 3 & 2 & 4 & 5 \\
\hline P3 & 4 & 2.5 & 1 & 2 & 4 & 3.5 \\
\hline $\mathrm{P} 4$ & 4 & 3 & 3.5 & 1 & 3.5 & 3.5 \\
\hline P5 & 3.5 & 2.5 & 2.5 & 1.5 & 4 & 4 \\
\hline $\mathrm{P} 6$ & 3 & 3 & 3 & 2 & 3 & 3 \\
\hline Rescue Mean & 3.75 & 3.17 & 2.5 & 1.92 & 3.75 & 3.83 \\
\hline $\mathrm{P} 7$ & 3 & 4 & 3 & 1 & 2 & 2 \\
\hline P8 & 4 & 5 & 2 & 2 & 4 & 4 \\
\hline P9 & 5 & 2 & 3 & 1 & 4 & 4 \\
\hline P10 & 4 & 3 & 2.5 & 4 & 4 & 4 \\
\hline $\mathrm{P} 11$ & 2 & 4 & 1 & 1 & 3 & 4 \\
\hline $\mathrm{P} 12$ & 3 & 3 & 2 & 3 & 2 & 4 \\
\hline Non-Rescue Mean & 3.5 & 3.5 & 2.25 & 2 & 3.17 & 3.67 \\
\hline \multirow[t]{2}{*}{ Overall Mean } & 3.63 & 3.32 & 2.38 & 1.96 & 3.48 & 3.76 \\
\hline & Worst & & & & & est \\
\hline
\end{tabular}

Table E.2: Graded questions grouped by scenario 


\begin{tabular}{|l|l|l|l|l|l|l|}
\hline Participant & Rating & \multicolumn{2}{|c|}{ Casualties } & Elevators & Generator & Lab gasses \\
\hline & & Laby lab & Aquaheat & & & \\
\hline P1 & Good & X & T & R & N & N \\
\hline P2 & Average & T & X & N & N & - \\
\hline P3 & Good & T & T & R & N & N \\
\hline P4 & Average & L & L & R & N & N \\
\hline P5 & Excellent & T & T & R & N & R \\
\hline P6 & Poor & - & - & R & R & R \\
\hline \hline P7 & Average & - & T & N & N & N \\
\hline P8 & Good & X & T & R & - & R \\
\hline P9 & Excellent & T & T & R & R & - \\
\hline P10 & Bad & T & - & - & - & - \\
\hline P11 & Poor & X & - & N & - & - \\
\hline P12 & Average & L & T & R & - & N \\
\hline
\end{tabular}

Table E.3: Situation report gradings for scenario one (S1): Participants, their gradings, and what information they gathered. The grade is based both off their presentation, from the recordings, and the information gathered. For casualties, L means located, X means extracted, and T means transported. Some participants may mention all of the states, but only the last is noted. For other items, N means an event was noted as occurring, and $\mathrm{R}$ means the event was resolved. A dash means the item was not mentioned. 


\begin{tabular}{|c|c|c|c|c|c|c|c|c|}
\hline \multirow[t]{2}{*}{ Participant } & \multirow[t]{2}{*}{ Rating } & \multicolumn{3}{|c|}{ Casualties } & \multirow[t]{2}{*}{ Facilities $(/ 7)$} & \multirow[t]{2}{*}{ Services $(/ 3)$} & \multirow[t]{2}{*}{ Fire $(/ 4)$} & \multirow[t]{2}{*}{ Damaged $(/ 5)$} \\
\hline & & MC101 & KK303 & HU304 & & & & \\
\hline $\mathrm{P} 1$ & Good & - & - & - & 6 & $3 \mathrm{R}$ & 1 & 3 \\
\hline $\mathrm{P} 2$ & Good & - & $\mathrm{N}$ & $\mathrm{N}$ & - & $3 \mathrm{~N}$ & 1 & 2 \\
\hline P3 & Excellent & $\mathrm{N}$ & $\mathrm{N}$ & $\mathrm{N}$ & 4 & $3 \mathrm{R}$ & 2 & 2 \\
\hline $\mathrm{P} 4$ & Average & $\mathrm{N}$ & $\mathrm{N}$ & - & - & - & - & 3 \\
\hline $\mathrm{P} 5$ & Excellent & - & $\mathrm{X}$ & $\mathrm{X}$ & 2 & $3 \mathrm{~N}$ & 2 & 3 \\
\hline $\mathrm{P} 6$ & Average & $\mathrm{X}$ & - & - & 2 & - & 2 & 1 \\
\hline P7 & Average & $\overline{\mathrm{N}}$ & $\overline{\mathrm{N}}$ & $\overline{\mathrm{N}}$ & 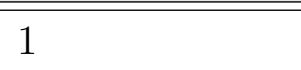 & $2 \mathrm{~N}$ & - & $\overline{1} 1$ \\
\hline $\mathrm{P} 8$ & Good & $\mathrm{X}$ & $\mathrm{X}$ & $\mathrm{X}$ & - & $3 \mathrm{R}$ & 2 & - \\
\hline P9 & Average & - & - & - & 6 & - & 3 & 4 \\
\hline P10 & Average & $\mathrm{N}$ & $\mathrm{N}$ & $\mathrm{N}$ & 2 & $2 \mathrm{~N}$ & 1 & 2 \\
\hline P11 & Poor & - & - & - & 5 & $3 \mathrm{R}$ & - & 2 \\
\hline $\mathrm{P} 12$ & Average & - & $\mathrm{X}$ & $\mathrm{X}$ & 3 & $2 \mathrm{R}$ & - & 2 \\
\hline
\end{tabular}

Table E.4: Situation report gradings for scenario two (S2): Participants, their gradings, and what information they gathered. The grade is based both off their presentation, from the recordings, and the information gathered. For casualties, L means located, X means extracted, and T means transported. Some participants may mention all of the states, but only the last is noted. For other items, $\mathrm{N}$ means an event was noted as occurring, and $\mathrm{R}$ means the event was resolved. A dash means the item was not mentioned. 
Appendix F

Human Ethics Committee

forms - 1st round 


\title{
Victoria University of Wellington
}

\section{Interview of Emergency Managers to evaluate work flows and information management}

\author{
Research Interviewee Information Sheet
}

- Researcher: Neil Ramsay (neil.ramsay@ecs.vuw.ac.nz) (+64 21047 7528), School of Engineering and Computer Science (ECS)

- Supervisor: Stuart Marshall (stuart.marshall@ecs.vuw.ac.nz) (+64 4 463 6730), ECS

I am a Master of Science (MSc) in Computer Science student from Victoria University of Wellington (VUW) investigating how Emergency Managers manage information. As part of the research I need to interview Emergency Managers with experience in running exercises where they have had to manage tasks and incoming situational data. I am focusing on workflows and data management techniques used, not the performance of the participant. I am specifically focusing on the Coordinated Incident Management Team (CIMS4) roles: Incident Controller; Logistics Manager; Operations Manager; and Planning/Intelligence Manager.

The data collected on data management and workflows will contribute to the design and development of a computer system, which is aimed to assist a CIMS4 team manage the vast amounts of data they collect while performing their roles. I am particularly interested in how to visually track task workflows and the situation overview. Also of interest is how to assist in a 'hand over' between managers at the end of a shift. 
The interview schedule, attached, is expected to take roughly 30 to 45 minutes.

Approval to interview the Incident Management Team (IMT) has been obtained from the VUW Fire and Emergency Coordinator, Roy Bridge and Human Ethics Committee (HEC) (in anticipation that it is granted). The research cannot be done anonymously as we need to contact specific individuals for these roles. Confidentiality of data collected also cannot be maintained as the participant may be identifiable by role they perform. There is absolutely no obligation to participate in this research.

All data collected in the interviews will be kept in a secured location: paper notes and any other physical items will be stored in a locker; and digital data will be stored in an encrypted archive (one on the School of Engineering and Computer Science systems, and a backup stored on my home computer system). The data collected will be destroyed one year after the conclusion of research. The participant may request access to data provided and request factual or contextual corrections, up until the 16th of June 2010. Participants may also withdraw data provided, up until the 16th of June 2010. Participants may request an electronic copy of the thesis upon acceptance; this is when all corrections have been made and the university accepts the thesis for a MSc. 


\section{Victoria University of Wellington}

\section{Interview of Emergency Managers to evaluate work flows and information management

\author{
Research Interviewee Consent Sheet
}

- Researcher: Neil Ramsay (neil.ramsay@ecs.vuw.ac.nz), School of Engineering and Computer Science (ECS)

- Supervisor: Stuart Marshall (stuart.marshall@ecs.vuw.ac.nz), ECS

I consent to being interviewed by Neil Ramsay in regards to my role in Victoria University's Incident Management Team (IMT). I have been given the Interviewee Information sheet and Interviewee Question sheet and understand the purpose of the research being performed. I have been given the opportunity to ask questions and have had them answered to my satisfaction. The researcher understands that my IMT role is an ancillary to my day-to-day role.

I understand that, up until the 16th of June 2010, I may:

- provide factual or contextual corrections

- withdraw data I have provided

I also understand that any information I provide may be identified by my IMT role, and therefore is not confidential, because my IMT role may be public information. Statements made, that are used for justification of software development choices, will not be attributed to any individual member of the IMT 
Name of participant:

Signature:

Email:

I would like to receive an electronic copy of the final thesis report: Yes / No 


\section{Victoria University of Wellington}

\section{Interview of Emergency Managers to evaluate work}

\section{flows and information management}

\section{Research Interviewee Question Sheet}

- Task

- What is your role in the IMT?

- What does this entail?

- What problems do you usually encounter?

- Data

- What pieces of information do you handle?

- How do you categorise your data?

- Do you grade the quality of your data source?

- How do you prioritise your tasks?

- Can corrections be done or is data permanent (with appended corrections)?

- What standard forms do you use?

- Data sharing

- What information do you share with other roles (including what you need from other roles)?

- Do you need to track who is responsible for a task? 
- Do you need access restrictions to your data?

- How do you brief those that replace you?

- Visual representation

- What information is difficult to keep track of?

- What information would be useful if searchable?

- What 'perspectives' are of interest to your role?

- What reports/summaries do you create?

- What usual drawings do you use? 
1E WHAR WANA VICTORIA

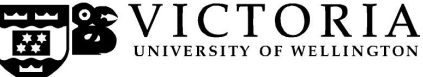

MEMORANDUM

$\begin{array}{ll}\text { Phone } & 0-4-4635676 \\ \text { Fax } & 0-4-4635209\end{array}$

Email Allison.kirkman@vuw.ac.nz

\begin{tabular}{l|l}
\hline TO & Neil Ramsay \\
\hline COPY TO & Stuart Marshall \\
\hline FROM & Dr Allison Kirkman, Convener, Human Ethics Committee \\
\hline \multicolumn{2}{|c}{} \\
\hline DATE & November 202009 \\
\hline PAGES & 1 \\
\hline SUBJECT & $\begin{array}{l}\text { Ethics Approval: No 16998 - Task-Orientated Workflow System } \\
\text { for Emergency Managers }\end{array}$ \\
\hline
\end{tabular}

Thank you for your application for ethical approval, which has now been considered by the Standing Committee of the Human Ethics Committee.

Your application has been approved from the above date and this approval continues until 31 August 2010. If your data collection is not completed by this date you should apply to the Human Ethics Committee for an extension to this approval.

Best wishes with the research.

Allison Kirkman

Convener 
Appendix G

Human Ethics Committee

forms - 2nd round 


\title{
Victoria University of Wellington
}

\section{Emergency Response Team Evaluation of Information Visualisation}

\author{
Research Interviewee Information Sheet
}

- Researcher: Neil Ramsay (neil.ramsay@ecs.vuw.ac.nz) (+64 21047 7528), School of Engineering and Computer Science (ECS)

- Supervisor: Stuart Marshall (stuart.marshall@ecs.vuw.ac.nz) (+64 4 463 6730), ECS

- Usability Lab manager: Roger Cliffe (roger.cliffe@ecs.vuw.ac.nz) (+64 $44635653)$, ECS

I am a Master of Science (MSc) in Computer Science student from Victoria University of Wellington (VUW) investigating how Emergency Managers manage information. As part of the research I need Emergency Response Team members to use an information visualisation tool to identify it's strengths and weaknesses. We intend our visualisation tool to be used by different team members followed by questions related to the information shown in the visualisation, and an evaluation of how confident they feel about their scenario knowledge. We will also get the participants to perform the same tasks, but using a whiteboard to track data. We expect both tasks combined will take approximately an hour. I am focusing on workflows and data management techniques used, not the performance of the participant.

We will be recording the output of the computer screen, the participant's face, and audio to allow us to determine how the visualisation tool is being used, where it has problems, and where things are not intuitive. 
The evaluation feedback will contribute towards the thesis report of the computer based information visualisation, which is aimed to assist a CIMS4 team manage the vast amounts of data they collect while performing their roles.

Approval to interview the Victoria Rescue Team has been obtained from the Victoria Rescue Team Leader, Roger Cliffe and Human Ethics Committee (HEC). The research cannot be done anonymously as we need to contact specific individuals for these roles. There is absolutely no obligation to participate in this research.

All data collected in the interviews will be kept in a secured location: paper notes and any other physical items will be stored in a locker; and digital data will be stored in an encrypted archive (one on the School of Engineering and Computer Science systems, and a backup stored on my home computer system). The data collected will be destroyed one year after the conclusion of research. The participant may request access to data provided and request factual or contextual corrections, up until the 19th of November 2010. Participants may also withdraw data provided, up until the 19th of November 2010. Participants may request an electronic copy of the thesis upon acceptance; this is when all corrections have been made and the university accepts the thesis for a MSc. 


\section{Victoria University of Wellington}

\section{Emergency Response Team Evaluation of Information Visualisation}

\section{Research Interviewee Consent Sheet}

- Researcher: Neil Ramsay (neil.ramsay@ecs.vuw.ac.nz), ECS

- Supervisor: Stuart Marshall (stuart.marshall@ecs.vuw.ac.nz) (+64 4 463 6730), ECS

- Usability Lab manager: Roger Cliffe (roger.cliffe@ecs.vuw.ac.nz) (+64 4463 5653), ECS

I consent to being recorded and asked questions by the Researcher in regards to the scenarios and tools used to manage the situational data. I have been given the Interviewee Information sheet and understand the purpose of the research being performed. I understand that this is not anonymous as the Researcher knows all the participants, but that any information gathered is confidential. I have been given the opportunity to ask questions and have had them answered to my satisfaction.

I understand that, up until the 19th of November 2010, I may:

- provide factual or contextual corrections

- withdraw data I have provided

Name of participant:

Signature:

Email:

I would like to receive an electronic copy of the final thesis report: Yes / No 


\title{
Victoria University of Wellington
}

\section{Interview of Emergency Managers to evaluate work flows and information management}

\author{
Research Interviewee Expected Questions Sheet
}

The questions are broken up into the following sections:

- Questions about the scenario

- When events occurred (earthquakes, activation of teams, start/end of shifts, casualties located, etc)

- Accuracy of event data (earthquake Richter scale, number of casualties located, etc.)

- Questions about the participants confidence in their situational awareness

- Questions about the participants evaluation of the tool used

- Comparisons between the two approaches (visualisation vs. white board)

After the participant has had 10 minutes to familiarise themselves with the scenario, we will ask them the following questions:

- How confident are you in remembering most of the events (but not necessarily the details)? $[1-5]^{1}$

- How confident are you in remembering the details of the events? [1-5]

\footnotetext{
${ }^{1} 1$ - best, 5 - worst
} 
- Do you think you could recall many details without referencing the $[\text { tool }]^{2} ?[1-5]$

- Do you think you could recall more details while referencing the [tool]? $[1-5]$

- How useful did you find the tool you used? [1-5]

- What information was the hardest to find in the [tool]?

- What information was the easiest to find in the [tool]?

- What information was the [tool] lacking?

We would then ask them the questions about the particular scenario. There will be four different scenarios and the questions will be related to information displayed to the participants.

After the questions about the scenario we would ask the following:

- How well did you think you did in answering the scenario questions? $[1-5]$

- Did the questions change how you felt about the [tool]? (If yes, in what way? More useful, less useful)

- How confident are you in remembering most of the events (but not necessarily the details)? [1-5]

- How confident are you in remembering the details of the events? [1-5]

- Do you think you could recall many details without referencing the [tool]? [1-5]

- What information was the tool lacking?

\footnotetext{
${ }^{2}$ visualisation or white-board will be used where appropriate
} 
- What information was the hardest to find in the [tool]?

- What information was the easiest to find in the [tool]?

- What information was the [tool] lacking?

After the participant has had the opportunity to use both the whiteboard and the visualisation tool we would ask the following questions:

- Which tool was easier to find information in? [scale $]^{3}$

- Which tool provided the quickest overview? [scale]

- Which tool do you prefer overall? [scale]

- Which tool do you think you performed better with? [scale]

\footnotetext{
${ }^{3} 1-5$ scale where 1 is one tool, and 5 is the other tool
} 
1.

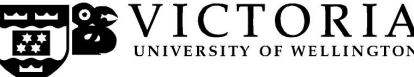

MEMORANDUM

$\begin{array}{ll}\text { Phone } & 0-4-4635676 \\ \text { Fax } & 0-4-4635209\end{array}$

Email Allison.kirkman@vuw.ac.nz

\begin{tabular}{l|l}
\hline TO & Neil Ramsay \\
\hline COPY TO & Stuart Marshall \\
\hline FROM & Dr Allison Kirkman, Convener, Human Ethics Committee \\
\hline \multicolumn{2}{|l}{} \\
\hline DATE & 17 June 2010 \\
\hline PAGES & 1 \\
\hline SUBJECT & $\begin{array}{l}\text { Ethics Approval: No 17740 Task-Orientated Workflow system } \\
\text { for emergency managers }\end{array}$ \\
\hline
\end{tabular}

Thank you for your applications for ethical approval, which have now been considered by the Standing Committee of the Human Ethics Committee.

Your applications have been approved from the above date and this approval continues until 31 August 2010. If your data collection is not completed by this date you should apply to the Human Ethics Committee for an extension to this approval.

Best wishes with the research.

Allison Kirkman

Convener 